\title{
SEDIMENT OXYGEN DEMAN IN THE CENTRAL BASIN OF LAKE ERIE
}

\author{
by
}

DEREK SMITH

Submitted in partial fulfillment of the requirements for the degree of Master of Science

Thesis Advisor: Gerald Matisoff

Department of Geological Sciences

CASE WESTERN RESERVE UNIVERSITY

January 2008 


\section{CASE WESTERN RESERVE UNIVERSITY \\ SCHOOL OF GRADUATE STUDIES}

We hereby approve the dissertation of

\section{Derek Smith}

candidate for the Ph.D. degree *.

\begin{tabular}{l} 
(signed) $\frac{\text { Gerald Matisoff }}{\text { (chair of the committee) }}$ \\
Joseph Koonce \\
\hline
\end{tabular}

\section{Peter McCall}

(date) $8 / 28 / 07$

*We also certify that written approval has been obtained for any proprietary material contained therein. 


\section{$\underline{\text { Table of Contents }}$}

$\underline{\text { Section }}$ pages

List of Figures and Tables.............................................. 2 - 3

Abstract.......................................................... 4 - 5

Introduction................................................................ 17

Methods.......................................................... 18 - 24

Results........................................................... 25 - 31

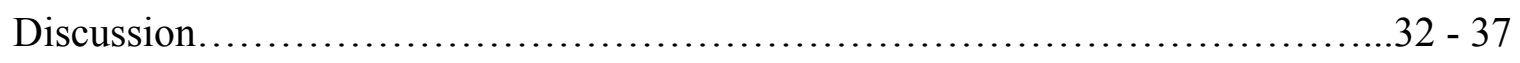

Conclusions............................................................. 38

Tables and Figures................................................ $40-73$

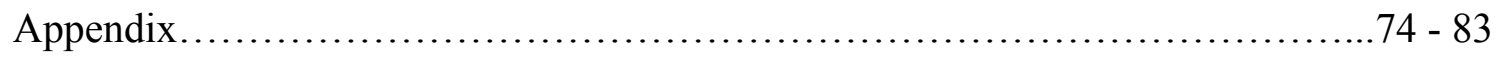

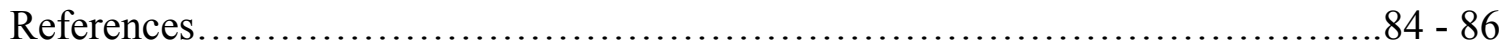




\section{List of Tables}

Page No.

Table 1: Redox Reactions Leading to the Degradation of Organic Matter 43

Table 2: Rate Expressions for SOD

Table 3: BRNS Model Inputs

Table 4: SSRs comparison among treatment, depth and, $\mathrm{C}_{\mathrm{o}}$

Table 5: SODs determined from SSRs

63

Table 6: SOD Comparison

73 


\section{List of Figures}

Page No.

Figure 1: Temperature vs. Hypolimnion Thickness in Lake Erie 40

Figure 2: Dissolved Oxygen Depletion Rate for the Central Basin 41

Figure 3: Total Phosphorous in Lake Erie $\quad 42$

Figure 4: Ekman Box Corer 45

Figure 5: Oxygen and Nitrate Profiling Platform 46

Figure 6: $\mathrm{pH}$ and Sulfide Profiling Platform 47

Figure 7: Plug Flow-Through Reactor 48

Figure 8: Dissolved Oxygen Microprofile for ER-43M 50

Figure 9: $\left[\mathrm{NO}_{3}{ }^{-}\right]$Microprofile for ER-43M 51

Figure 10: $\left[\mathrm{S}^{-2}\right]$ Microprofile for ER-43M 52

Figure 11: Lower [ $\left.\mathrm{S}^{-2}\right]$ Microprofile Values for ER-43M 53

Figure 12: $\mathrm{pH}$ Microprofile for ER-43M 54

Figure 13: $\left[\mathrm{Fe}^{+2}\right],\left[\mathrm{NH}_{4}^{+}\right],\left[\mathrm{SO}_{4}^{-2}\right]$, and $\left[\mathrm{NO}_{3}{ }^{-}\right]$in Pore Waters 55

Figure 14: Total Carbonate Alkalinity in Pore Waters 56

Figure 15: Activity of Cs-137 and Pb-210 vs Depth 57

Figure 16: Total Solid-Phase Fe and Mn 58

Figure 17: Microbially-Available Solid-Phase Fe and Mn 59

Figure 18: Whole Core Incubation Experiment 60

Figure 19: Representative Monitoring of Nutrients and Products in Flow-Through 61

Figure 20: Untreated Steady State Reduction Rates vs. $C_{o} \quad 64$

Figure 21: Azide Treated Steady State Reduction Rates vs. $C_{0} \quad 65$

Figure 22: Untreated Steady State Reduction Rates vs. $\mathrm{C}_{\mathrm{oEA}} \quad 66$

Figure 23: Azide Treated Steady State Reduction Rates vs. $\mathrm{C}_{\mathrm{oEA}}$

Figure 24: Sensitivity Analysis of BRNS Based on SOD 68

Figure 25: Sensitivity Analysis of BRNS Based on Organic Matter 69

Figure 26: BRNS Model Results $\quad 70$ 


\section{Sediment Oxygen Demand in the Central Basin of Lake Erie}

Abstract

By

\section{DEREK SMITH}

Four separate procedures were used to estimate the sediment oxygen demand (SOD) in the central basin of Lake Erie. First, core incubations involved sealing sediment cores at $12^{\circ} \mathrm{C}$ to ensure no interaction between the overlying water and the atmosphere and monitoring continuously to define the linear disappearance of oxygen. Second, vertical profiles of the dissolved oxygen concentrations obtained by microelectrodes were modeled to obtain the flux of oxygen into the sediments. Third, sediment plugs were placed inside flow-through reactors and the influent and effluent concentrations were monitored. Steady-state reaction rates were calculated from the data. Fourth, an extensive data set for the central basin of Lake Erie was collected for input into the diagenetic BRNS model, and the SOD was calculated assuming all primary redox reactions, but no secondary reactions. All procedures produce reasonably precise estimates of SOD, but show a rise from the work performed over the previous 35 years. Whole core incubations yield an average SOD of $7.40 \times 10^{-12} \mathrm{moles} / \mathrm{cm}^{2} / \mathrm{sec}$. In comparison, the $\mathrm{O}_{2}$ diffusion model results in an average SOD for the central basin of $8.29 \times 10^{-12} \mathrm{moles} / \mathrm{cm}^{2} / \mathrm{sec}$. The BRNS model predicts an SOD of $7.87 \times 10^{-12}$ moles $/ \mathrm{cm}^{2} / \mathrm{sec}$ over the top $10 \mathrm{~cm}$ of sediment, and appears to be calibrated reasonably 
well to the conditions of the central basin of Lake Erie. The untreated group of the flowthrough experiments had an average SOD of $4.04 \times 10^{-12} \mathrm{moles} / \mathrm{cm}^{2} / \mathrm{sec}$. These findings suggest that the SOD of the central basin has decreased, presumably, in response to the decrease in chemical loadings of Lake Erie; nevertheless the dead zone is as extensive today as it was more than thirty years ago. 


\section{Introduction}

Water column hypoxia (depleted of oxygen), leads to and can be indicative of many environmental problems. Aquatic organisms, including fish and benthic dwelling organisms suffocate and die due to the lack of oxygen; fish may be able to move to other more suitable locations of the lake, but many species are less mobile and too intolerant of such conditions. In Lake Erie, the topography and bathymetry, and the loading of anthropogenic nutrients adds to the complexity of the problem. Most of the loading of phosphorus which can lead to eutrophic conditions, an abundance of nutrients present in the water stimulating algal growth, comes from the dumping of sewage into Lake Erie and from agricultural runoff (DePinto et al. 1986). Phosphorus is the limiting nutrient for primary production in many fresh water environments (Kalff 2002), i.e., the amount of phosphorous in the water limits the amount of primary production, so the addition of phosphorous from anthropogenic sources can lead to extensive algal growth.

During the summer months, solar heating of the surface of the lake results in a thermal stratification in which the surface water, which exchanges oxygen with the atmosphere, is warm and less dense than the cooler bottom waters. The bottom waters are cut off from a continuous supply of oxygen from the atmosphere. Primary production occurs mostly in the warm sunlit upper waters. The phytoplankton and other, organic rich materials are transported or sink to the bottom waters where they are decomposed by bacteria and fungi. During this respiration process oxygen is consumed. Since the bottom waters are not readily supplied with oxygen from the atmosphere, due to the stratification of the lake, this respiration causes the dissolved oxygen that is left to be further depleted. This leads to hypoxic or even anoxic (devoid of oxygen) conditions and 
occurs predominantly in the central basin of Lake Erie, because of the thin bottom layer of water. Eventually during autumn, the top layer of water cools, becomes rich in oxygen, and is mixed into the deeper bottom waters. An isocline develops allowing mixing of the entire water column.

In Lake Erie, the western basin is much shallower than the rest of the lake, allowing the prevailing winds to constantly stir the waters, which allows for mixing of the bottom waters and constantly replenishes oxygen from the atmosphere. The central basin is broad and shallow, so only a small thin band of the bottom waters develop which can readily undergo oxygen depletion whereas the eastern basin is much deeper and the hypolimnion is more oxygenated, so while its oxygen concentration does decrease during stratification it does not reach hypoxic conditions.

The severity, duration, and variability of the rate of oxygen depletion is highly dependent upon the climate over the lake during the spring months. The average wind speed and direction, coupled with the average air temperature will determine the thickness and temperature of the bottom waters. A cool spring with violent winds will cause more mixing to occur, which leads to a thin warmer bottom layer. A warm spring with calm winds allows a deeper, cooler, and thicker hypolimnion to form. More oxygen is maintained further into the summer months if there is a deeper and colder hypolimnion; however, a warm and thin hypolimnion leads to hypoxia.

Environmental Protection Agency (EPA) measurements from 1993-2004 of the levels of the dissolved oxygen in the central basin of Lake Erie show that on average there was more than $6 \mathrm{mg} / \mathrm{L}$ of dissolved oxygen at the onset of June, but by late August this has been reduced to almost nothing (GLNPO 2007). Depending upon the water 
temperature and equilibrium with the air, the amount of dissolved oxygen can vary from $14 \mathrm{mg} / \mathrm{L}$ in the cold winter waters to $8 \mathrm{mg} / \mathrm{L}$ in the warm summer waters (GLNPO 2007). Few organisms are extremely tolerant of low oxygen conditions; any concentration of dissolved oxygen greater than $6 \mathrm{mg} / \mathrm{L}$ is viewed as suitable and a concentration below 2 $\mathrm{mg} / \mathrm{L}$ of dissolved oxygen is viewed as the onset of necrosis (GLNPO 2007).

To reduce variability and allow appropriate comparisons to be made, data involving the rate of oxygen depletion is approximated by assuming a constant temperature of $10^{\circ} \mathrm{C}$ and a constant depth of $4.6 \mathrm{~m}$ in the hypolimnion of the Central basin, (Figure 1). These assumptions enable calculation of oxygen depletion rates of $\mathrm{mg} / \mathrm{L} / \mathrm{month}$. This does not provide exact values of the hypolimnetic-oxygen demand, but does allow annual comparisons to be made. From 1969-1989 there was a steady decline in the oxygen depletion rate in the central basin of Lake Erie; however, since 1990 there has been an increase in the rate of depletion of oxygen (Figure 2). This trend is inevitably linked to the phosphorus loading of the central basin and the overall concentration of phosphorous in the water column (Figure 3). The total phosphorus in the water column of the central basin has been slowly rising since 1990. This increase in phosphorus would enhance primary production and produce organic matter that would further deplete the hypolimnion's oxygen.

Industrialization and European settlement have severely altered the Great Lakes. Prior to settlement and industrialization, small amounts of nitrogen and phosphorous would be naturally provided by the atmosphere and the runoff from heavily forested lands. The urban centers of the lakes drastically changed all of that, in a large part through municipal discharge and agricultural runoff in the form of phosphate fertilizers 
and the lakes started showing distress signals. The biological production of the lakes was accelerated by the pumping of untreated waste, the runoff of synthetic fertilizers and phosphate detergents discharged into the lakes. Lake Erie is the smallest, by volume, of the Great Lakes and is most reactive to inputs. In the 1950s it was the first to show signs of lake-wide eutrophication with massive algal blooms and the creation of a dead zone, where dissolved oxygen levels of the hypolimnion become too low to support life. Significant reductions in phosphorus loading were imposed for Lake Erie in the 1970s in the Great Lakes Water Quality Agreement (GLQWA) with a target load that would lead to a phosphorous concentration in the water of $10 \mu \mathrm{g} / \mathrm{L}$ (DePinto 1986). The decreased loading has come about as a direct result of the closing of high pollution producing plants, improvements in sewer treatment facilities, changes in agricultural practices, and the elimination of phosphates from detergents. Even though the direct external phosphorus loading has been maintained near the target load, the lake is seeing an increase in total phosphorus concentration. The cause for this is not known.

The Great Lakes Water Quality Agreement between the United States and Canada has been in place for over thirty years, but Lake Erie's zones of hypoxia and anoxia are as far reaching today as they were when the agreement was passed (Rockwell et al. 2005). The small amount of dissolved oxygen that is available for uptake in the bottom waters does not get consumed by fish or higher taxonomic benthic organisms; instead it will be consumed in the reactions leading to the decomposition of organic matter. Much of that consumption occurs in the surface layer of the bottom sediment. However, the sediment oxygen demand (SOD) is still one of the most poorly understood and constrained parameters of the system. 
Exact values on the impact that the SOD exerts on water column oxygen demand do not necessarily agree, nevertheless the SOD is understood to be a key component in the problem. Charlton claims that the sediment-water interface accounts for approximately half of the overall rate of oxygen depletion (1980). More recent work evaluating ecosystem metabolism using oxygen isotopes, reports that at Station ER-43M in the central basin of Lake Erie, $93.3 \%$ of the overall respiration rate of the water column is directly attributable to the respiration of the sediment (Ostrom 2007).

The flux of oxygen from the water column into the sediments is defined as the SOD. This parameter takes into account and is representative of the oxidation of reduced solids and upwardly diffusing reduced solutes and gases, as well as benthic respiration (Matisoff and Neeson 2007). Downward diffusion, microbial respiration, counterdiffusing reductant reactions, reduced solid reactions, and the upward movement of gas bubbles under supersaturated conditions can all account for the depletion of oxygen from pore waters (Rabouille and Gaillard 1991, Bouldin 1968, Boudreau 1996).

Many of the reactions that lead to the degradation of organic matter are facilitated by microorganisms. Microbes often serve as catalysts in the transfer of electrons in a series of chemical reactions. In the case of aquatic sediment systems, microbes generally follow a sequence of reactions that reflects the thermodynamic potential available during the decomposition of organic matter. Here the most reduced species, organic matter, serves as an electron donor, providing an energetic driving force (Stumm and Morgan 1981). The oxidation of organic matter causes the $\mathrm{C}$ in organic matter to undergo a fourfold change in the oxidation state from ' 0 ' to a ' +4 ' in bicarbonate $\left(\right.$ or $\left.\mathrm{CO}_{2}\right)$. Organic matter is oxidized while the electron acceptors are sequentially reduced. Oxygen is most 
readily reduced, going from a ' 0 ' oxidation state in $\mathrm{O}_{2}$ to a ' -2 ' in $\mathrm{H}_{2} \mathrm{O}$. Nitrogen is the second most thermodynamically favored species to be reduced which causes a reduction from a ' +5 ' oxidation state in $\mathrm{NO}_{3}{ }^{-}$to ' 0 ' in the elemental $\mathrm{N}_{2}$. Manganese will accept electrons causing a reduction from a ' +4 ' in the oxide solid to ' -2 ' in the dissolved phases. Iron is reduced from ' +3 ' in the solid hydroxide form to ' -2 ' in the dissolved phase; and $\mathrm{S}$ is reduced from ' +6 ' in $\mathrm{SO}_{4}{ }^{-2}$ to ' -2 ' in $\mathrm{H}_{2} \mathrm{~S}$.

The transfer of electrons to the chemical species with the most unoccupied valence shell, typically those species containing oxygen, provides a progression of reactions, (Table 1), that microbes are able to capitalize upon. Through these reactions, microbes are able to obtain the energy that they require to sustain proper life functioning processes. From a purely theoretical thermodynamic approach, these reactions should be sequential with the most energetically favorable reactions being driven to completion until the next sequential reaction begins, by the microbes that are mediating these processes. While this thermodynamic trend is followed in the natural world, there are multiple zones of overlap with multiple reactions occurring.

A common approach to solving the problem of obtaining an SOD is the implementation of an in situ chamber placed on the bottom of the lake. A cross sectional triangular chamber with a width of $0.3 \mathrm{~m}$ and height of $0.2 \mathrm{~m}$ and rectangular bottom with dimensions of $0.3 \mathrm{~m}$ and $0.6 \mathrm{~m}$ placed on the bottom by a diver has been used (Lucas and Thomas 1972, Davis et al. 1981, Snodgrass and Fay 1987). Water circulates with a velocity of $5 \mathrm{~cm} / \mathrm{s}$ inside the chamber, which provides well mixed conditions, and requires 1-2 hours for an SOD measurement to be made. A similar design was used by Snodgrass (1987), however this was a $0.6 \mathrm{~m}$ diameter hemisphere domed chamber. This 
device was put in place by lines from a boat on the surface of the lake, achieved well mixed conditions by a stirring oxygen probe, and took 12 hours to 4 days for an SOD measurement. Similar chambers are still being used in experiments in such locations as the European Union for the Coastal Observatory Benthic Observatory (COBO). While these chambers do have the advantage of providing an in situ SOD, they have the main disadvantages of being costly to construct and to place on the bottom of the body of water, and the designs are not able to distinguish individual reaction rates.

An analogous method is to measure SOD by incubating a sediment core. A sediment core, with a sufficient volume of overlying water, can be collected in an altered biological oxygen demand (BOD) bottle, returned to the laboratory where the core is placed in a constant temperature bath and an oxygen probe is inserted (Matisoff and Neeson 2005 and Christensen et al. 1990). The system is sealed from the atmosphere and the sediment is allowed to consume nearly all of the available dissolved oxygen in the overlying water. The rate of disappearance of dissolved oxygen can be used to calculate the SOD if the surface area and total water volume are known. This approach is much more cost effective, can be performed in a laboratory, but still does not allow individual reactions to be examined.

Another common approach to ascertain the SOD is to obtain an oxygen profile of the sediment using oxygen electrodes. This down core profiling permits calculation of the SOD, assuming a Fickian flux of oxygen into the sediment (Matisoff and Neeson 2005):

$$
S O D \equiv F l u x=-\left.\varphi D_{S} \frac{\partial\left[O_{2}\right]}{\partial z}\right|_{z=0}
$$


here SOD is defined as a flux that is dependent upon $(\varphi)$ the sediment porosity, $\left(D_{s}\right)$ the dispersion coefficient of oxygen, and the oxygen concentration gradient at the sedimentwater interface $(z=0)$. This model assumes that the flux of oxygen into the sediment is the sole cause of the consumption of oxygen and that it can be described simply as a Fickian flux. In addition it is difficult to accurately determine the concentration gradient at the sediment-water interface.

Theoretical modeling has been employed over the years as a predictive tool and means of obtaining and examining the SOD and its many components. Some of the earliest models and work that was done on the organic matter and nutrient diagenesis in the sediments described the system in terms of a steady-state diffusion and advection reaction model. The G-model had oxidation of organic matter, followed by a proportionate release of nutrients (Berner 1974). This type of model can be considered as uncoupled single electron acceptor models and has been significantly expanded upon. Improvements and advances to this very basic model structure include time dependence, multiple types of organic matter, bioturbation and pore water irrigation, a strong dependency on concentrations of oxidant species, decay kinetics, seasonality and temperature dependency, and the release of reduced species (Matisoff and Neeson 2005). Such additions do improve sophistication, but still lack oxygen-nutrient coupling.

Some models are able to ascertain the percentage of hypolimnetic oxygen depletion that is accounted for by the SOD. These models generally either determine the SOD directly or take a statistical approach that examines the vertical components of the water column depletion as well as the SOD (Snodgrass 1987). In the case of the model for SOD created by Snodgrass and Walker, the components of SOD are broken down into 
chemical and biological components, with the microbial limitation being defined by Monod kinetics (Snodgrass 1987). In this model the chemical component is assumed to be rate limited, at any given temperature, by the diffusion of oxygen across the aerobic layer.

DiToro et al. (1987) developed a model that incorporated the downward flux of algae and organic matter into the sediments, where burial and degradation reactions occur. In this model, particulate forms of nitrogen and carbon decay into reduced soluble species. The SOD is then proportional to the reduced soluble carbon species being fully oxidized at the sediment water interface. DiToro (2001) later developed the nutrient and oxygen sediment flux model, predominantly using concentration and mass balance equations. This is essentially a four box mass balance model. The four boxes are: the overlying water column, an aerobic layer of sediment, an anaerobic layer of sediment, and burial below the anaerobic layer. Each nutrient: ammonia, nitrate, phosphorous, silica, oxygen, sulfide and methane, is treated and transported individually with the same four box approach to obtain individual reaction rates and concentrations. The model applies oxygen equivalents, i.e. the chemical oxygen demand, to determine an SOD for the sediment. These earlier approaches to modeling do not incorporate all of the various redox reactions that are leading to the degradation of organic matter, nor do they allow simultaneous or coupled reactions to occur.

In actuality the sediment oxygen demand is a summation of chemical reactions and reactions that follow Michaelis-Menten kinetics, due to the involvement of microbes. They are occurring simultaneously, and are not sequential as previous assumed, with each reaction dependent upon the previous reaction (Van Cappellen and Wang 1996), as 
indicated by the equations in Table 2. Each one of the rate expressions is in the form of Michaelis-Menten kinetics. The reactions begin with oxic degradation and the initial concentration of oxygen in the sediments; the subsequent rate expression is that of denitrification, followed by the remaining thermodynamically favored reactions. The rate of denitrification is not only in the Michaelis-Menten form for denitrification, dependent upon the original concentration of nitrate, but also the rate of oxic degradation and the initial concentration of oxygen with the kinetic parameters represented with $\mathrm{K}^{\prime}{ }_{\mathrm{O} 2}$. A similar pattern holds for all the primary redox reactions reproduced in Table 2. This system of equations is much more representative of the processes that are taking place in natural systems that generate the SOD.

While there are multiple possible approaches to obtaining the SOD, very few techniques allow one to distinguish individual reaction parameters. In this work we employ multiple techniques that allow the SOD to be determined as well as individual reaction components leading to an overall SOD.

Major advancements in biogeochemical modeling of the sediment have taken place since the earliest models. They couple the decomposition of organic matter with aerobic respiration, denitrification, manganese and iron (hydr)oxides, sulfate reduction and methane fermentation while taking into account bioturbation and irrigation of benthic fauna, as well as reoxidized mobile substances (Van Cappellen and Wang 1995, Wang and Van Cappellen 1996). These newer models focus on sulfate reduction, as they are predominantly of marine origin, and the decomposition of organic matter. The Biogeochemical Reaction Network Simulator (BRNS) (@ P. Regnier, C. Meile, D. Aguilera, P. Jourabchi) allows for simultaneous reactions, incorporates the many redox 
reactions that are occurring, and allows one to distinguish individual reaction rates (Van Cappellen and Wang 1995, Wang and Van Cappellen 1996). A summation of the various reactions rates, as represented by $\mathrm{R}_{\mathrm{ox}}$ in Table 2, allows an SOD to be determined. The BRNS is one of the most sophisticated and advanced diagenetic models, allowing one to examine individual reactions and reaction rates, while still allowing an overall SOD to be ascertained from these rates.

One of the difficulties in using biogeochemical models like BRNS to calculate the SOD is that the rates of the individual reactions are not generally known. Recent advances have been made in the utilization of plug flow-through reactors to obtain the reaction rate parameters (Pallud and Van Cappellen 2006 and Roychoudhury, Viollier, and Van Cappellen 1998). A sediment plug of varying length based on experimental design is placed in a fluidized bed reactor which has an inlet that allows solution to flow into the reactor and an outlet for fluid which has reacted with the sediment. An inert tracer, $\mathrm{Br}^{-}$, is used to determine the breakthrough and to monitor dispersion. The concentrations of ions in the influent solution are fixed and the effluent solution is monitored for the $\mathrm{Br}^{-}$tracer and for the ions of interest. The reactor is allowed to reach steady state; the difference between the concentrations of the ions of interest in the influent and effluent solutions at steady state allows reaction rates to be determined. These studies have focused on the marine or estuarine environments, with very little work and applications in fresh water locations. Consequently, sulfate reduction kinetic parameters are the main scope of these previous studies and oxygen reduction has not been studied 
This work incorporates four of the techniques described above to obtain and compare an SOD for the central basin of Lake Erie: 1) whole core incubation experiments, 2) the BRNS model, 3) monitoring pore water diffusion of $\mathrm{O}_{2}$ (Matisoff and Neeson 2005), and 4) plug flow-through experiments. A comprehensive data set from sediment cores collected in the central basin was generated on board the EPA R/V Lake Guardian during the summer of 2006. The 2005 work of Matisoff and Neeson was not repeated; instead the results are presented as a comparative measure. Microprofiles, sediment porewater and solid profiles were used to calibrate and constrain the BRNS model. This work also presents a novel approach of using plug flow-through reactors to obtain oxygen kinetic data. 


\section{Methods}

Sediment samples were taken on board the US EPA R/V Lake Guardian on June 26, 2006 and August 10, 2006 from station ER-43M (41.78848 N and 081.94488 W, and 41.78833 $\mathrm{N}$ and $081.94500 \mathrm{~W}$, respectively) in the central basin of Lake Erie. A $30 \mathrm{~cm} \mathrm{x}$ $30 \mathrm{~cm}$ x $30 \mathrm{~cm}$ Ekman box core was used for grab sampling; once on board the box core was sub-cored (Figure 4). In June four separate box cores were collected: the first two were used to obtain 24 sediment cores for the plug flow-through reactors, the third for whole core incubations and micro-profiling, and the fourth for sediment solids, pore water, and general analysis. In August four more box cores were collected. Once again, the first two were used to collect 24 cores for the plug flow-through reactors. The other two were used to collect $226.75 \mathrm{~cm}$ outer diameter cores for multiple purposes including general and pore water analysis, and sediment solids. Each sub-core was collected so that overlying water covered the top of the core, and the bottom was capped before removal from the box core. Once removed from the box core the top was capped as well. All samples were either used immediately or stored in refrigeration at ambient temperature conditions of the bottom of Lake Erie until use. For use in micro-profiling, a core tube ranging in length from $10-15 \mathrm{~cm}$ with an outer diameter of $6.75 \mathrm{~cm}$ was used. For plug flow through reactors, a core tube of $10 \mathrm{~cm}$ length with an outer diameter of $5.7 \mathrm{~cm}$ was used. A Benthos gravity corer with a $1 \mathrm{~m}$ section of $6.75 \mathrm{~cm}$ outer diameter core tube was used for pore water and sediment solid analysis. During the June cruise two gravity cores were collected, while only one was taken in August. On each cruise a minimum of 3 gallons of bottom waters were collected for use in the plug flow-through experiments. 
Microprofiles: Oxygen and nitrate profiles were collected on board ship using a Microelectrodes, Inc. MI-730 oxygen electrode and a Lazar Research Laboratories, Inc. ISM-146NO3 nitrate electrode, and a Microelectrodes, Inc. MI-401 micro-reference (modified with a $20 \mathrm{~cm}$ barrel). A platform for the mounting of the electrodes was constructed (Figure 5). The platform insured that the same depth was profiled by each probe, with a maximum penetration depth of $3 \mathrm{~cm}$, limited by the shaft length of the nitrate and oxygen electrodes. This platform was mounted on a Velmex precision screw slide that enabled measurements to be taken at $0.05 \mathrm{~cm}$ intervals.

Due to longer shaft lengths, allowing deeper penetrable depths of up to $10 \mathrm{~cm}$, another profiling platform was constructed to accommodate a Microelectrodes Inc. MI411 combination $\mathrm{pH}$ electrode, and a Lazar Research Laboratories, Inc. ISM-146S,C micro-combination ion sulfide electrode (Figure 6). The profiling platform insured that the same depth was profiled by each probe, to within measurable limits. The Velmex precision screw slide allowed intervals of $0.1 \mathrm{~cm}$ for the first centimeter of sediment, followed by $0.2 \mathrm{~cm}$ resolution for the next two centimeters. Below $3 \mathrm{~cm}$, intervals of 0.5 $\mathrm{cm}$ were used for the remaining $7 \mathrm{~cm}$ of the core.

Two sets of profiles, each in triplicates, were performed while the cores were submerged in constant temperature water baths. Readings were taken starting at the sediment water interface and continued through successive depths. A WTW StirOxG probe was used to minimize the development of a benthic boundary layer by gently mixing the overlying water column at a velocity below what is required for sediment resuspension. At each depth interval the probes were allowed to record for $30 \mathrm{sec}$ before moving to the next depth, as indicated by literature accompanying the various electrodes. 
All electrodes were calibrated prior to use. The MI-730 oxygen electrode was calibrated using a $21 \%$ dissolved oxygen solution accomplished by bubbling atmospheric air through de-ionized water for at least $30 \mathrm{~min}$, and a Flinn Scientific Inc. 0\% dissolved oxygen solution containing $2 \mathrm{M}$ sodium sulfite $\left(\mathrm{Na}_{2} \mathrm{SO}_{3}\right)$. All other electrodes were calibrated using a five point logarithmic calibration technique, in accordance with the accompanying documentation of the individual electrode, using ion specific solutions, dependent upon electrode, ranging from $10.0 \mu \mathrm{M}$ to $1.0 \mathrm{M}$.

Whole Core Incubations: Two cores were collected for incubation in BOD bottles with removable bottoms for coring purposes. The sediment height, total volume of water overlying the sediment, and surface area of the sediment were all recorded. A third BOD bottle was filled only with Lake Erie bottom water to account for probe and water column consumption. Each bottle was wrapped in aluminum foil to ensure no light penetration. Vernier dissolved oxygen probes were placed in each of the bottles at approximately the same depth, ensuring that there was plenty of space between the sediment and the bottom of the probe. Prior to insertion the Vernier dissolved oxygen probes had been calibrated with a Flinn Scientific Inc. 0\% dissolved oxygen calibration solution containing $2 \mathrm{M}$ sodium sulfite $\left(\mathrm{Na}_{2} \mathrm{SO}_{3}\right)$ and an air saturation calibration was performed by placing the probe in a sealed container containing a quarter of an inch of water that was not in contact with the tip of the probe. The space between the shaft of the probe and the opening of the BOD bottle was sealed with plumbers' putty, to ensure no exchange between the water and the atmosphere. All three bottles were then placed in a constant temperature water bath at $12^{\circ} \mathrm{C}$, the temperature of the bottom waters. Measurements began immediately after sealing the electrode and were taken continuously at $1 \mathrm{~min}$ 
intervals using a Vernier LoggerPro connected to a Dell Inspiron 3800 until nearly all of the oxygen in the water had been consumed by the sediment.

Pore Water Analysis: A core collected by a Benthos gravity corer was sectioned over the top $40 \mathrm{~cm}$ in a nitrogen filled glove box. In the top $10 \mathrm{~cm}, 2 \mathrm{~cm}$ depth intervals were used, from $10-22 \mathrm{~cm}, 4 \mathrm{~cm}$ depth intervals were used, and from $22-40 \mathrm{~cm}, 6 \mathrm{~cm}$ depth intervals were used. The sediment depth intervals were transferred into squeeze barrels containing a nylon mesh screen and $0.22 \mu \mathrm{m}$ Osmonic filter paper, covered with a 12.7 $\mathrm{cm}$ by $12.7 \mathrm{~cm}$ piece of dental dam and then squeezed inside a nitrogen gas filled glove box to extract the porewater. Microelectrodes were used to take nitrate, $\mathrm{pH}$, and sulfide concentrations on about $2 \mathrm{~mL}$ of the sample. Colorimetric analyses were performed for reduced iron (ferrozine technique), ammonium (phenol method), and total carbonate alkalinity (titration) (Clesceri, et al. 1998) (See Appendix). An ion chromatograph was used to obtain sulfate concentations.

Sediment Solids: A core over $1 \mathrm{~m}$ in length was sectioned in a nitrogen filled glove box for sediment solids analyses. The top $10 \mathrm{~cm}$ were sectioned at $1 \mathrm{~cm}$ depth intervals, from $10-58 \mathrm{~cm}, 2 \mathrm{~cm}$ depth intervals were used, and from depths of $58-103 \mathrm{~cm}$ a $5 \mathrm{~cm}$ depth interval was used. Each soil sample was dried at $110^{\circ} \mathrm{C}$ for $18-24$ hours, dependent upon sample. The total sample mass was weighed, and then ground with a pestle and mortar until the soil was thoroughly mixed. Falcon Petri dishes $(100 x 15 \mathrm{~mm})$ were filled with a homogenous sample from each depth interval. Not all of the soil from each depth interval was able to fit into the Petri dishes (particularly those at depth); excess soil was stored in $60 \mathrm{cc}$ Falcon tubes. The Petri dishes were sealed with methylene chloride, and once thoroughly dried, were wrapped with electrical tape to ensure no gaseous Ra-222 
would escape. Samples were analyzed for Pb-210 (46.52kV), Cs-137 (609.32kV), and Bi-214 (661.62kV) on a Canberra LEGe or EG\&G Ortec HPGe detector for 23 hours.

A separate core was sectioned in $1 \mathrm{~cm}$ intervals for the first $6 \mathrm{~cm}$, then $2 \mathrm{~cm}$ intervals were used until $10 \mathrm{~cm}$ depth was reached. An acid extractable digestion of sediment was used to obtain metal concentrations (3030 D and $3030 \mathrm{~F}$ in Clesceri, et al 1998). The samples were then run on a Perkin Elmer Auto Analyst 200 for iron and manganese. Not all of the iron and manganese is available for uptake by the microbes. For example, the component of the metals held in the clay material of the sediment would not be available as a reactive component. A common approach to solving this problem is to subtract the background concentrations of Fe and $\mathrm{Mn}$ at depth from the total Fe and Mn recorded elsewhere in the core (Van Cappellen and Wang 1996). This correction results in the concentration of the reactive component for the (hydr)oxides, defined here as the microbially available Fe and Mn.

Plug Flow Through: Each plug flow-through reactor is composed of two acrylic caps with an inlet/outlet hole in the center that has been fitted with a barb fitting (Figure 7). From the hole at the center, radial grooves extend outward allowing a more even flow and distribution of liquid to permeate through the sediment plug. This decreases the build up of a diffusion boundary layer between the sediment and the inflowing solutions (Pallud and Van Cappellen 2006). Sitting on top of the radial grooves are two $47 \mathrm{~mm}$ filter membranes, one being a glass fiber membrane filter and the other an Osmonic 0.22 $\mu \mathrm{m}$ nylon filter. In between the two end caps there is a $1 \mathrm{~cm}$ high wall with a $48 \mathrm{~mm}$ inner diameter ring. This ring presses against a silicone gasket to provide a leak-proof seal. The reactor is held together and is tightened by four stainless steel bolts. When 
tightened the silicone gaskets ensure the immobility of the filter media, impermeability of exchanges with gases and liquids, and in situ conditions for the sediment plug (Roychudbury et al 1998 and Pallud and Van Cappllen 2006). The $1 \mathrm{~cm}$ sediment plug holder has the same inner diameter of the core tube that was used to collect the sediment samples, allowing precise placement of a sediment core section into the reactor inside of a nitrogen filled glove bag. The top $5 \mathrm{~cm}$ of sediment core was sampled and each $1 \mathrm{~cm}$ sediment plug was placed inside a reactor. All of the reactors were then placed in a constant temperature water bath at $22.4+/-2.5^{\circ} \mathrm{C}$.

Lake Erie bottom water spiked with $100 \mu \mathrm{M}$ bromide, used as an inert tracer, was pumped through each $1 \mathrm{~cm}$ sediment plug at a constant flow rate of $3.0 \mathrm{~mL} / \mathrm{hr}$ by a peristaltic pump. Prior to the pumping of spiked Lake Erie bottom water, half of the samples were treated with sodium azide $\left(\mathrm{NaN}_{3}\right)$, a known biocide (Brock 1994 and Roychudbury et al 1998). The influent solution was fixed at varying dissolved oxygen concentrations of approximately $40,90,130,150$, and $175 \mu \mathrm{M}$ for the untreated group and $40,115,120,140$, and $175 \mu \mathrm{M}$ for the azide treatment. This influent solution was monitored for oxygen, bromide (using an Orion Research bromide specific ion electrode model 94-35A), nitrate, $\mathrm{pH}$ and sulfide concentration. Nitrate, $\mathrm{pH}$, and sulfide concentrations were monitored with electrodes as described above. The effluent solution, that is the solution coming out of the reactor chambers, was monitored for the same parameters. The experiment ran until steady state was reached; steady state being defined as when the effluent and influent concentrations of bromide were equal.

The data was processed to first obtain steady state rates for oxygen consumption. This can be done by applying the formula (Pallud and Van Cappellen 2006) 


$$
S S R=\frac{\left(C_{o u t}-C_{0}\right) Q}{V}
$$

where SSR refers to steady state reduction rate, $\mathrm{C}_{\mathrm{out}}$ is the effluent concentration of dissolved oxygen, $\mathrm{C}_{\mathrm{o}}$ is the influent concentration of dissolved oxygen, $\mathrm{Q}$ is the volumetric flow rate, and $\mathrm{V}$ is the internal volume of the reactor $\left(15.5 \mathrm{~cm}^{3}\right)$.

Modeling: The BRNS model using the primary redox reactions was employed to provide a theoretical approach to obtaining the sediment oxygen demand. Our field data were used as input parameters for the pore water concentrations and the sediment solids concentrations with the exceptions of: the $\mathrm{CH}_{2} \mathrm{O}$ sediment solid profile was taken from Matisoff, Fisher, and Lick (1977), the $\mathrm{CH}_{4}$ profile was taken from Adams, Matisoff and Snodgrass (1986), and the $\mathrm{HPO}_{4}^{-2}$ pore water profile was taken from Hansen 2003 (unpublished materials). The corresponding depth dependent pore water, sediment solid, and microprofile concentrations were used as the input values into the model, fixed as the upper and lower bounds, as well as initial value in the sediment (Table 3). The values for the temperature dependency $(\alpha)$ and molecular diffusion coefficients $\left(D_{0}\right)$ of all species examined were taken from VanCappellen and Wang (1995). Rate parameters for the consumption of oxygen determined by the Hanes Plot method were incorporated into the BRNS. The depth dependent primary redox reaction rates predicted by the BRNS were then combined to obtain an overall $\mathrm{SOD}\left(\mathrm{R}_{\mathrm{ox}}\right.$ in Table 2$)$. 


\section{Results}

Microprofiles: Triplicate profiles of the dissolved oxygen were in good agreement, showing a similar trend in each case. The profiles were collected beginning half a centimeter above the sediment-water interface, this portion of the profile indicates the development of a slight benthic boundary layer due to the apparent vertical profile of the bottom waters accompanied by a linear decline of oxygen into the sediment (Figure 8). All three oxygen profiles show a similar gradient in the decrease of dissolved oxygen, with the complete disappearance of oxygen by $0.7 \mathrm{~cm}$.

The three nitrate $\left(\mathrm{NO}_{3}{ }^{-}\right)$profiles show similar down core trends. In two of the profiles there is a linear decline from $0.5 \mathrm{~cm}$ above the sediment-water interface until the sediment-water interface (Figure 9). In each of the three profiles the concentration at the sediment surface is a minimum. Over the next $0.25-1 \mathrm{~cm}$, dependent upon profile and core, there is a gradual increase in the nitrate concentration that results in a concentration maximum within the top $2-2.5 \mathrm{~cm}$ of the sediment. Below this maximum, concentrations decrease.

The replicate sulfide $\left(\mathrm{S}^{-2}\right)$ profiles in sediment core ER-43M are not in as good agreement. One of the profiles seems exhibits elevated concentrations the entire length of the core compared to the other two profiles (Figure 10). This profile shows a very large spike in the concentration centered at $1 \mathrm{~cm}$, where as the other two profiles only show a small spike at $1 \mathrm{~cm}$ (Figure 11). The development of a benthic boundary layer does not seem to be present in any of the profiles. In each profile the concentration of sulfide increases downcore below the sediment surface. 
The $\mathrm{pH}$ profiles exhibit numerous maxima and minima. In the upper $3 \mathrm{~cm}$ of the triplicate $\mathrm{pH}$ profiles there does not seem to be a consistent trend (Figure 12). However below $3 \mathrm{~cm}$, the spikes in the profiles seem to show a similar cyclical downcore trend in maxima and minima. However, the general trend is a decrease in $\mathrm{pH}$ from about 7.4 near the surface to about 7.2 at a depth of $10 \mathrm{~cm}$.

Porewater: Concentration profiles were ascertained in porewaters for $\left[\mathrm{Fe}^{+2}\right],\left[\mathrm{NH}_{4}{ }^{+}\right]$, $\left[\mathrm{SO}_{4}^{-2}\right],\left[\mathrm{NO}_{3}^{-}\right]$and alkalinity. A core over $45 \mathrm{~cm}$ in length was used for porewater analysis, allowing deeper trends in the data to be seen (Figure 13). The nitrate concentrations are roughly constant at about $4 \mu \mathrm{M}$ over the entire $40 \mathrm{~cm}$ profile. These nitrate concentrations are substantially lower than those in Figure 9. Sulfate concentrations are the highest near the sediment-water interface and decrease sharply to a depth of $5 \mathrm{~cm}$ with the minimum concentration near $4 \mu \mathrm{M}$. Over the remaining $35 \mathrm{~cm}$ of the core the sulfate concentrations are approximately $40 \mu \mathrm{M}$. The soluble ferrous iron concentrations are between $60-90 \mu \mathrm{M}$, with the lower concentrations near the sediment surface and the remainder of the data about $80 \mu \mathrm{M}$. The ammonium concentrations increase with depth. They are lowest at the surface, at approximately $100 \mu \mathrm{M}$, while they are highest, at approximately $700 \mu \mathrm{M}$ at the bottom of the profile. The alkalinity profile for June, 2006 lies within the measurements for alkalinity obtained during the summer months of 2002 (Figure 14). The alkalinity concentrations tend to increase with depth. There is a small amount of variability in the data with a maximum at a depth of $5 \mathrm{~cm}$ and a minimum at about $10 \mathrm{~cm}$.

Sediment Solids: A $1 \mathrm{~m}$ core was counted for $\mathrm{Pb}-210$ and Cs-137 (Figure 15). The spike in the cesium activity profile reveals that the maximum occurs at the depth interval 
of $7-8 \mathrm{~cm}$. The Cs-137 that is observed in North America is largely the result of nuclear bomb testing during the late 50 s to early 70 s. The fallout of Cs- 137 was substantial during this time, and has since become negligible. The maximum in Cs-137 activity corresponds to the 1963. The median depth of the peak, and the 43 year difference between 1963 and 2006 results in a burial velocity of $0.174 \mathrm{~cm} / \mathrm{yr}$. The sedimentation rate was also determined using the $\mathrm{Pb}-210$ activity and the Constant Initial Concentration (CIC) model, which does not account for porosity changes a function of depth (see Appendix for data and equation). This method produces a burial velocity of $0.205 \mathrm{~cm} / \mathrm{yr}$, which is only slightly higher than the velocity determined from the Cs-137 data.

Iron and manganese concentrations in the sediment solids were determined over the top $10 \mathrm{~cm}$ (Figure 16). The total manganese profile concentrations are between 40 $100 \mathrm{mg} / \mathrm{kg}$ with the higher concentrations near the surface of the sediment and concentrations of about $50 \mathrm{mg} / \mathrm{kg}$ below. The total iron increases from the surface where the concentration is approximately $2500 \mathrm{mg} / \mathrm{kg}$ to a depth of $4 \mathrm{~cm}$, where the concentration is $3750 \mathrm{mg} / \mathrm{kg}$. The iron profile has two minima, one at the surface and one at $7 \mathrm{~cm}$. Below the maximum at $4 \mathrm{~cm}$ the concentration decreases to about $2500-$ $3000 \mathrm{mg} / \mathrm{kg}$ at a depth of $7-9 \mathrm{~cm}$.

Only a portion of the concentration of iron and manganese reported above is available for uptake by microbes. The microbially-available portion of iron and manganese was estimated by subtracting the concentration of iron $(\sim 2300 \mathrm{mg} / \mathrm{kg})$ or manganese $(\sim 50 \mathrm{mg} / \mathrm{kg})$ at depth from each of the concentrations. These data are shown in Figure 17. Because a constant concentration was subtracted the same overall trends 
present in the total solid profiles are maintained; the only real change occurs in the substantially lower microbially-available concentrations.

Whole Core Incubations: Oxygen concentrations in the water were monitored continuously in the whole core incubations. The concentrations remained approximately constant in the control core (water only) and decreased nearly linearly in the cores with water and a sediment core (Figure 18). By fitting a linear curve through the data, a rate for the disappearance of oxygen can be calculated (Figure 18). In order to ascertain the SOD, probe and water column consumption was determined separately; shown here as the control, in which oxygen concentrations of approximately $7.0 \mathrm{mg} / \mathrm{L}$ decreased slightly. The linear fits for sediment consumption, (DO 1 and DO4), are nearly parallel, indicative of similar rates of consumption: 0.1218 and $0.1007 \mathrm{mg} / \mathrm{L} / \mathrm{hr}$, after correction of probe and water column consumption determined in the control. By further correcting for the sediment surface area, and the total volume of overlying water an SOD for each core is obtained: DO 1 and DO 4 have SODs of $8.47 \times 10^{-12}$ and $6.32 \times 10^{-12}$ moles $/ \mathrm{cm}^{2} / \mathrm{sec}$, respectively.

Plug Flow-Through Reactors: The simultaneous monitoring of influent $\left(\mathrm{C}_{\mathrm{o}}\right)$ and effluent (C) concentrations of dissolved oxygen, nitrate, bromide, sulfide, and $\mathrm{pH}$ had consistent trends. Only in the case of oxygen was there a higher ratio of $\mathrm{C} / \mathrm{C}_{\mathrm{o}}$ at the onset of the experiment, this subsequently decreased with time (Figure 19). Bromide behaved the same way each time with a starting $\mathrm{C} / \mathrm{C}_{\mathrm{o}}$ of 0 or nearly 0 , eventually approaching 1 , indicative of breakthrough and the system reaching steady state. The starting and ending values of $\mathrm{C} / \mathrm{C}_{\mathrm{o}}$ for nitrate, sulfide and $\mathrm{pH}$ varied greatly, but tended to be bracketed between the profiles for bromide and oxygen. The only consistent depth dependent trend 
observed was that of the dissolved oxygen's $\mathrm{C} / \mathrm{C}_{\mathrm{o}}$ steady state value increasing with depth.

The steady state consumption rate (SSR) may be calculated using Equation 2. The resulting values at each steady state dissolved oxygen concentration and depth interval can be seen in Table 3. To explore for a possible trend between sediment depth and SSR, $\mathrm{C}_{\mathrm{o}}$ and SSR were plotted as a function of sediment depth for both the untreated and azide treatment groups (Figures 20 and 21). For the untreated group, over the concentration ranges examined, the $0-1 \mathrm{~cm}$ depth interval had the highest overall SSRs, and the SSRs decreased with increasing depth, such that $4-5 \mathrm{~cm}$ had the lowest rates. The slopes for the linear fits of the individual depth intervals follow a similar depth dependent trend as in the case of the SSRs, with the exception that the slope of $1-2 \mathrm{~cm}$ is the lowest overall. For the azide treated group, there is a depth dependent trend with the greatest SSRs at the surface and the lowest SSRs at depth.

Recent work done on the kinetics of sulfate in plug flow-through reactors suggested that a major limitation of the technique was an inability to know the exact value of the concentration of the solution that is in contact with the sediment inside the reactor (Pallud, et al. 2007). Pallud's work suggests that as a means to compensate for this uncertainty, the average solute concentration $\left(\mathrm{C}_{\mathrm{OEA}}\right)$ could be approximated as $\left(\mathrm{C}_{\text {out }}+\right.$ $\left.\mathrm{C}_{\mathrm{o}}\right) / 2$. The estimated average solute concentration was plotted against SSR, as a function of depth (Figures 22 and 23). The same depth dependent trends as seen with SSR vs $\mathrm{C}_{\mathrm{o}}$ are present. The only noticeable differences are the values of $\mathrm{R}^{2}$, which are improved slightly with the use of $\mathrm{C}_{\mathrm{OEA}}$, indicating that $\mathrm{C}_{\mathrm{OEA}}$ aids in explaining some of the variability associated with the SSRs as a function of depth. It was determined by Pallud 
et al. (2007) that if $\mathrm{C}_{\mathrm{o}} /\left(\mathrm{C}_{\mathrm{o}}-\mathrm{C}_{\mathrm{out}}\right) \geq 2$, then the average solute concentration $\left(\mathrm{C}_{\mathrm{oEA}}\right)$ should be used over $\mathrm{C}_{\mathrm{o}}$. This relationship was developed for sulfate kinetics, but does not appear to hold true for dissolved oxygen, since $\mathrm{C}_{\mathrm{oEA}}$ produces erroneous results.

The SSRs obtained through the use of $\mathrm{C}_{\mathrm{o}}$ are displayed with depth dependency in Table 4. The SSRs were then converted to fluxes by multiplying the SSR by the volume of the reactor $\left(15.5 \mathrm{~cm}^{3}\right)$, resulting in moles $/ \mathrm{hr}$ and dividing this rate by the area of the sediment $\left(15.5 \mathrm{~cm}^{2}\right)$ that the solution is passing through for the determination of SOD based off of $\mathrm{C}_{\mathrm{o}}$ and depth (Table 5). The average SOD, for all depth intervals and $\mathrm{C}_{\mathrm{o}}$ for the untreated group was $4.04 \times 10^{-12} \mathrm{moles} / \mathrm{cm}^{2} / \mathrm{sec}$ and for the azide treated group was $2.16 \times 10^{-12} \mathrm{moles} / \mathrm{cm}^{2} / \mathrm{sec}$.

BRNS Model: A sensitivity analysis of the BRNS model reveals that the two most sensitive parameters are the concentration of organic matter and the imposed SOD. We are most concerned with dissolved oxygen; therefore we show the resultant dissolved oxygen profiles plotted as functions for varying values of SOD and organic matter (Figure 24 and Figure 25). It appears that an SOD on the order of $1 \times 10^{-10}$ moles $/ \mathrm{cm}^{2} / \mathrm{sec}$ is required to obtain an oxygen profile where the penetration depth is at or below $1 \mathrm{~cm}$. There appears to be a critical value for organic matter of approximate $1 \mathrm{x}$ $10^{-5} \mathrm{moles} / \mathrm{g}$ solid, in order to produce an oxygen concentration profile that will continuously decrease with depth.

The BRNS model was run using sediment solid, pore-water, and microprofile data as the major constraints (Figure $26 \mathrm{a}-\mathrm{e}$ ); in most cases the model was able to reproduce similar trends as those seen in the field data. The model was able to very accurately reproduce the profile of the dissolved oxygen microprofiles (Figure 26a). The BRNS was 
not as precise reproducing the $\left[\mathrm{NO}_{3}{ }^{-}\right]$trends (Figure $26 \mathrm{~b}$ ). The $\left[\mathrm{NO}_{3}{ }^{-}\right]$profile produced by the BRNS has lower concentrations at every depth, than those of the pore water profile. The BRNS shows a very similar trend to that of the actual $\left[\mathrm{SO}_{4}{ }^{-2}\right]$ data, lying nearly on top of the concentrations at depth, but predicts slightly elevated concentrations above $5 \mathrm{~cm}$. The BRNS matches the trend of the $\left[\mathrm{NH}_{4}{ }^{+}\right]$profile rather accurately. The solid-phase iron data is scattered. However, the model does not match any possible trend, predicting elevated concentrations near the surface and going to zero, when the data clearly does not show this trend (Figure 26c). The trend of the solid-phase manganese profile is reproduced by the model, but predicts lower than actual values and goes to zero by approximately $2 \mathrm{~cm}$ (Figure 26d). The soluble forms of ferrous iron $\left(\mathrm{Fe}^{+2}\right)$ and manganese $\left(\mathrm{Mn}^{+2}\right)$ are in reasonable agreement among the model results and those of the pore water (Figure 26e). These profiles and predicted reaction rates, when converted from $\mathrm{L}$ to $\mathrm{cm}^{3}$, multiplied by the depth $(\mathrm{cm})$, and multiplied by 10 years, the time step of the model, result in an SOD of $3.47 \times 10^{-12}$ moles $/ \mathrm{cm}^{2} / \mathrm{sec}$ over the top $5 \mathrm{~cm}$ and $7.87 \times 10^{-12} \mathrm{moles} / \mathrm{cm}^{2} / \mathrm{sec}$ over the top $10 \mathrm{~cm}$. 


\section{Discussion}

The BRNS is most sensitive to the imposed SOD of the model and the amount of organic matter. It appears that an SOD on the order of $1 \times 10^{-10} \mathrm{moles} / \mathrm{cm}^{2} / \mathrm{sec}$ is required to obtain an oxygen profile where the penetration depth is less than $1 \mathrm{~cm}$. There appears to be a threshold value for organic matter of approximately $1.0 \times 10^{-5} \mathrm{moles} / \mathrm{g}$ solid. Below or at this value of organic matter the oxygen profile that results never reaches zero; instead the concentrations exhibit a minimum and the concentrations at are depth are similar to the surface concentration of oxygen. An organic matter concentration of $1.0 \times 10^{-3} \mathrm{moles} / \mathrm{g}$ solid is required to confine the oxygen penetration depth to approximately $2 \mathrm{~cm}$. The organic matter concentration that was used for modeling, $2.5 \mathrm{x}$ $10^{-3} \mathrm{moles} / \mathrm{g}$ solid, was not obtained as part of our data set, and was instead taken from an EPA report from 1977 (Matisoff, Fisher, and Lick 1977). It is clear that if this concentration is higher than what was actually in the sediment in 2006 , then the calculated oxygen penetration depth would be too shallow. If the value of organic matter used in the calculations was lower than the 2006 conditions, then the calculated oxygen penetration depth would be too deep. The BRNS profiles show similar trends and reproduce the experimentally obtained profiles rather well, for the most part, so it appears that there is no major difference in the concentration of organic matter that was used in the BRNS simulations and the actual organic matter in the sediments in 2006.

There is a rather large discrepancy between the concentrations of nitrate $\left(\mathrm{NO}_{3}{ }^{-}\right)$ obtained in the pore waters and those obtained by direct microprofiling. This is most likely a sampling artifact due to consumption of the nitrate in the pore water core. The microprofile concentrations are much higher, with concentrations of approximately $1.0 \mathrm{x}$ 
$10^{-4} \mathrm{M}$, than the porewater concentrations, which are on the order of two magnitudes lower. The microprofiles were obtained upon the R/V Lake Guardian within a few hours of collection of the cores. Those cores that were not being profiled were kept in a walkin refrigerator on board at ambient bottom water temperatures, approximately $12^{\circ} \mathrm{C}$. During the microprofile measurements, the core was submerged in a water bath at the same bottom water temperatures. These are not the same conditions that the pore water core was exposed to. The $45+\mathrm{cm}$ long core was stored in the same walk-in refrigerator as the microprofile cores over night on board the ship; however, the following morning the core was moved to a large refrigerator at ambient conditions at the university. The core then sat for a day until it was brought into the laboratory for sectioning. During the subcoring process and the glove box procedure, the core was exposed to room temperatures and inevitably exposed to light. The temperature and time that was required for the transport and subsequent sectioning of the porewater core may have allowed ammonium $\left(\mathrm{NH}_{4}{ }^{+}\right)$to build up, while nitrate was reduced. This did not occur in the microprofiles due to the near in situ conditions they were kept at and the immediacy at which they were obtained. While these observations suggest that the microprofile data are best, it was not used in the BRNS modeling. Instead, the pore water were used because the pore water data represents a deeper set of data, going down over $40 \mathrm{~cm}$, and that the BRNS even when constrained by the elevated data of the microprofiles, still predicts nitrate concentrations below those values of the porewater concentrations.

The plug flow-through experiment is the only experimental design, in comparison to the $\mathrm{O}_{2}$ diffusion model and whole core incubation experiment, where the reactions are essentially reaction limited; in the other two cases the reactions are diffusion and reaction 
limited. The $\mathrm{O}_{2}$ diffusion model, as the name implies, assumes that the diffusion of oxygen into the sediments due to the aerobic respiration of the microorganisms is the major driving force behind the reactions leading to SOD. Whole core incubation experiments incorporate all occurring reactions and reaction rates into an overall SOD, but through the guise of diffusing oxygen leading to the degradation of organic matter. In both of these latter cases nearly all of the dissolved oxygen that is present in the core and water column is consumed. The design of the flow-through experiments is such that there is a constant supply of fresh oxygen into the sediments. The oxygen supply is never extinguished, allowing microbes to mediate the reactions, at every depth interval with a seemingly limitless supply of oxygen. This is not the case on the bottom of the lake; instead the oxygen is consumed before one centimeter depth is reached and other oxidant species become more involved in the degradation of organic matter. One of the only ways that dissolved oxygen would penetrate further than $1 \mathrm{~cm}$ is through bioirrigation and bioturbation caused by the macrobenthos.

From the very nature and design of the plug-flow through experiments, including the elevated temperatures compared to the other techniques, it was hypothesized that this method would produce an upper bound upon the SOD for the central basin. The $\mathrm{O}_{2}$ diffusion model was hypothesized as a potential lower bound for SOD, due to only allowing the diffusion of oxygen into the sediment and a lack of other reactions. It was further believed that the whole core incubations and BRNS would lie somewhere between those two bounds. The rates and SODs determined through the flow-through experiment were thought be exaggerated and artificially enhanced with a constant supply of the nutrient, whether it is dissolved oxygen, this work, or sulfate in previous works 
(Pallud and Van Cappellen 2006, Pallud et al. 2007, and Roychoudhury, Viollier, and Van Cappellen 1998). During non-stratified periods there would be a seemingly limitless supply of dissolved oxygen in the water column for the sediment to consume; even under these conditions the oxygen should be consumed before $1 \mathrm{~cm}$ depth was reached. There would be no real opportunity for depths below $1 \mathrm{~cm}$ to obtain a supply of dissolved oxygen. In a similar fashion the sulfate of the water column would not be able to penetrate to great depths in the ocean without it first being consumed at shallow depths through the degradation of organic matter. The experimental design enhances contact and should create more reaction sites between the sediment and the inflowing solution. The design of the reactors is such that the sediment plug is essentially turned into a fluidized bed reactor; turning the sediment plug from semi-solid to a state more resembling a liquid. This enhancement of the porosity would not naturally occur, but should create artificially high reaction rates due to the creation of more reaction sites. Not only would the constant supply of oxygen lead to elevated kinetic values, but so would the elevated temperature of the plug flow-through experiments. These experiments were performed at approximately $10^{\circ} \mathrm{C}$ higher than ambient conditions, in hopes of achieving maximum rates of consumption. It can be assumed, though, that the $10^{\circ} \mathrm{C}$ increase in temperature will result in a two to three fold increase in the metabolic rates at which the microbes will force the reactions to proceed (Levinton 1982, Gillooly et al. 2001, and Bidle et al 2002).

Elevated SOD values were not produced in the plug-flow experiments; instead they were the lowest with the $\mathrm{O}_{2}$ diffusion model having the highest values. The exact opposite as what was hypothesized. The whole core incubation experiment results in an 
average SOD of $7.40 \times 10^{-12} \mathrm{moles} / \mathrm{cm}^{2} / \mathrm{sec}$ for the central basin (Table 6). In comparison, the $\mathrm{O}_{2}$ diffusion model (Matisoff and Neeson 2005) results in an average SOD for the central basin of $8.29 \times 10^{-12} \mathrm{moles} / \mathrm{cm}^{2} / \mathrm{sec}$. Over the top $10 \mathrm{~cm}$ of sediment, the BRNS predicts an SOD of $7.87 \times 10^{-12}$ moles $/ \mathrm{cm}^{2} / \mathrm{sec}$, and over the top $5 \mathrm{~cm}$ of sediment an SOD of $3.47 \times 10^{-12} \mathrm{moles} / \mathrm{cm}^{2} / \mathrm{sec}$, through the incorporation of all of the primary redox reaction rates. The average for the untreated group of the flow-through experiment results in an SOD of $4.04 \times 10^{-12} \mathrm{moles} / \mathrm{cm}^{2} / \mathrm{sec}$ and an SOD of $2.16 \times 10^{-12}$ moles $/ \mathrm{cm}^{2} / \mathrm{sec}$ for the azide treated group. These are on the order of half and a quarter of the values, respectively, determined from the other techniques; however, the stated SOD for the flow-through experiments incorporates all of the rate values for oxygen from the 0 $-5 \mathrm{~cm}$ intervals and, as illustrated in the dissolved oxygen microprofiles, the oxygen does not penetrate into the sediment more than $1 \mathrm{~cm}$. If the average SSR value of 16.67 $\mu \mathrm{mol} / \mathrm{L} / \mathrm{hr}$ for the depth interval of $0-1 \mathrm{~cm}$ of the untreated group is used to determine an SOD based on the flow-through experiments, then an SOD of $4.63 \times 10^{-12}$ moles $/ \mathrm{cm}^{2} / \mathrm{sec}$ results. If we further correct for the elevated temperature by dividing the rate by two, an SOD of $2.31 \times 10^{-12} \mathrm{moles} / \mathrm{cm}^{2} / \mathrm{sec}$ results. This then might represent a more accurate interpretation of the SOD based off the flow-through experiments. 


\section{Conclusions}

All the techniques employed in this work to calculate an SOD for the central basin of Lake Erie are in reasonable agreement (Table 6). Many of the previous estimates of SOD for Lake Erie have been reported in the units of $\mathrm{g} \mathrm{O}_{2} / \mathrm{m}^{2} / \mathrm{d}$, for proper comparison the SODs of this work have been converted to the same units. It is clear that the BRNS (over the top $10 \mathrm{~cm}$ of sediment), whole core incubation, and the $\mathrm{O}_{2}$ diffusion model all provide estimates in good agreement with one another for an SOD of the central basin of Lake Erie. The oxygen demand values reported by the flow-through experiments are smaller in comparison to the other methods of this work. The azide treatment should have incapacitated nearly, if not, all of the biological activity present in the sediment so this value should provide a geochemical demand for the sediment. This may mean that the sediment, void of any biological activity, is consuming less oxygen than the sediments were over 30 years ago. Even with the addition of the biology at place in the sediments, it appears that the SOD may have declined over the past 35 years. The International Great Lakes Water Quality Agreement has placed severe restrictions upon the dumping of chemicals, fertilizers, and municipal wastes with the hope of alleviating the dead zone of Lake Erie and improving the overall water quality. The values of SOD determined throughout this work would serve to illustrate the claims that Lake Erie is experiencing positive change and responding to the decrease in chemical loading. Even though the SOD appears to be decreasing there is an expanding dead zone in the central basin.

This presents a paradox with no one single simple explanation. If the SOD is decreasing, then the hypolimnion should contain more dissolved oxygen. The Dreissena 
invasion is believed to be responsible for the apparently contradictory observation of decreased phosphorus loading to the lake, and an increase in the dissolved phosphorus in the near shore environment (Hecky, et al 2004). The Dreissena invasion is also causing chemical compositions closer to oligotrophic, not eutrophic, conditions in the open surface waters of Lake Erie (Makarewicz, et al 2000). These would lead to decreases in the load of organic matter for burial into the sediments of the central basin, and not serve to further enhance the zone of anoxia. Perhaps the bathymetry of the central basin is such that, the hypolimnion has and will always be so thin that during periods of stratification, a zone of anoxia will be present. There has been an increase in the temperature of the surface waters of the Great Lakes, associated with Global Warming, but this relatively small change in temperature would not dramatically decrease the solubility of dissolved gases.

It is possible that the sediment's response to changes in nutrient loading may take over 60 years to fully equilibrate to one full step change in concentration of a nutrient, such as phosphorus. The amount of organic material that is in downflux towards the hypolimnion is lower than the oxygen demand of the hypolimnion. This carbon source may be supplemented by resuspension of sediment organic matter that is stored during unstratified periods, which may result in a non-fluctuating rate of oxygen consumption in the sediment. The SODs have not decreased even though the depositional flux of organic matter has (presumably) decreased in response to decreased P loadings suggests that the residence time of organic matter in the upper, bioturbated mixed surface sediment is long relative to our 20 year time of observation. In other words, the SOD won't necessarily respond quickly to changes in loading and only after many years (residence time $=$ mixed 
layer thickness $/$ sedimentation rate $=10 \mathrm{~cm} / 0.2 \mathrm{~cm} / \mathrm{yr}=50$ years) can we expect to see a decrease in SOD in response to decreased loadings. Here we present findings that suggest the SOD has begun to change, and in the way we had hoped, but the zone of anoxia in the central basin still remains. 


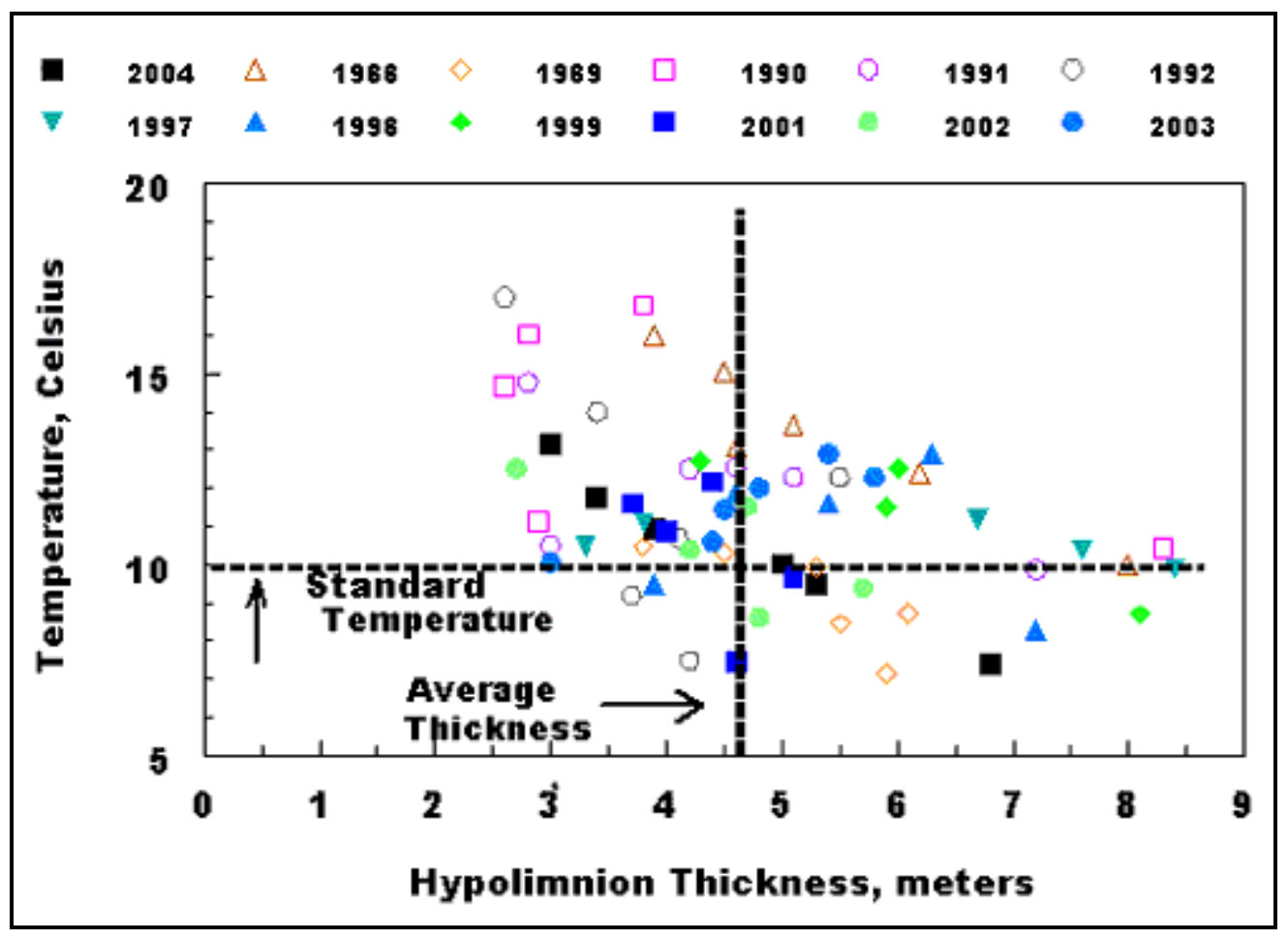

Figure 1. Temperature and thickness of the hypolimnion for almost forty years yield an average thickness of $4.6 \mathrm{~m}$ and average temperature of $10^{\circ} \mathrm{C}$. These averages were used in dissolved oxygen rate calculations for the EPA (i.e., Rockwell et al 2005). (Source: GLNPO 2007) 


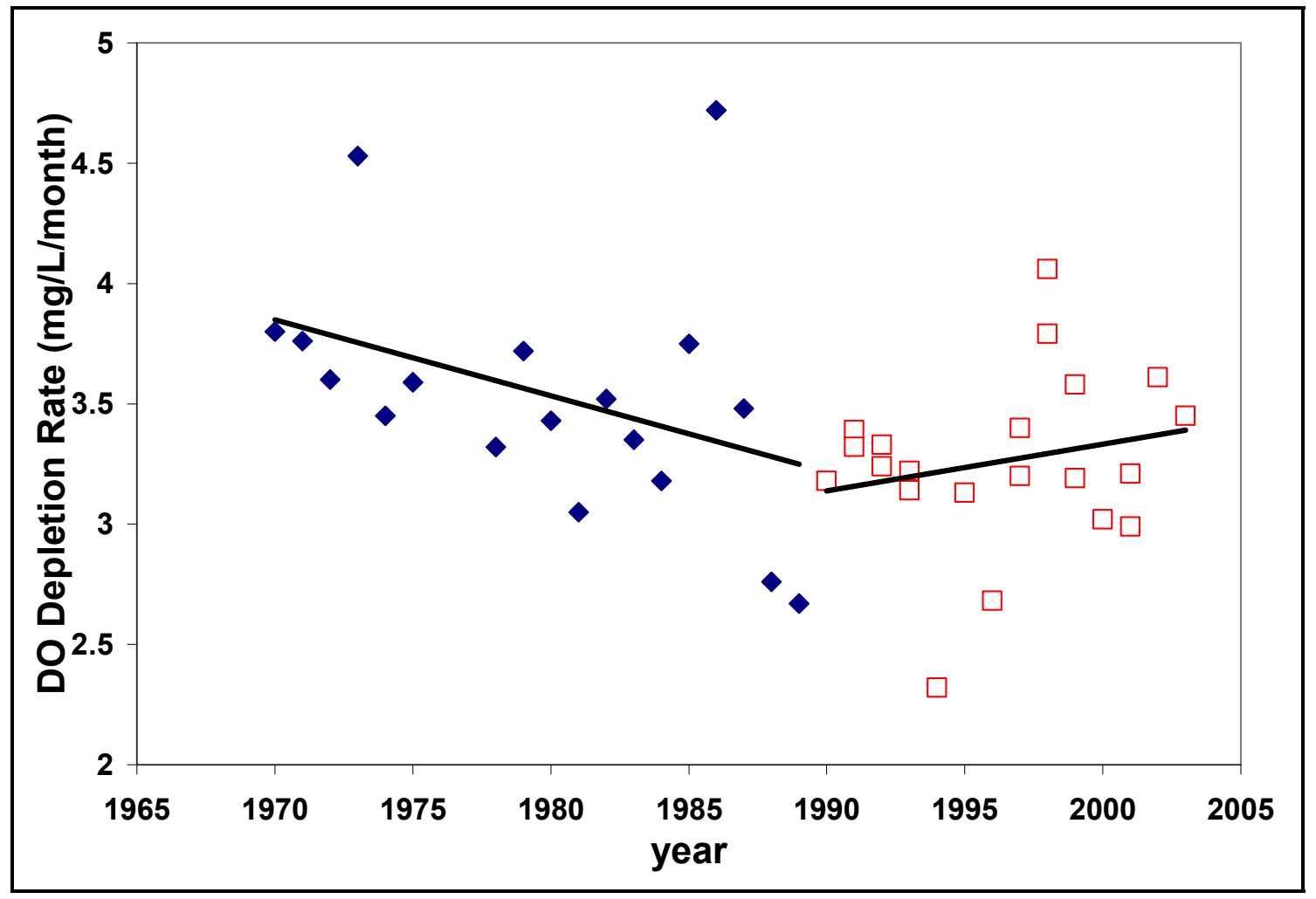

Figure 2. This depicts the rate at which oxygen is consumed in the Central basin of Lake Erie. There was a declining trend from 1970-1989 reflecting phosphorous load reductions; however, in recent years the rate has been rising. (Figure from Burns, et al. 2005) 


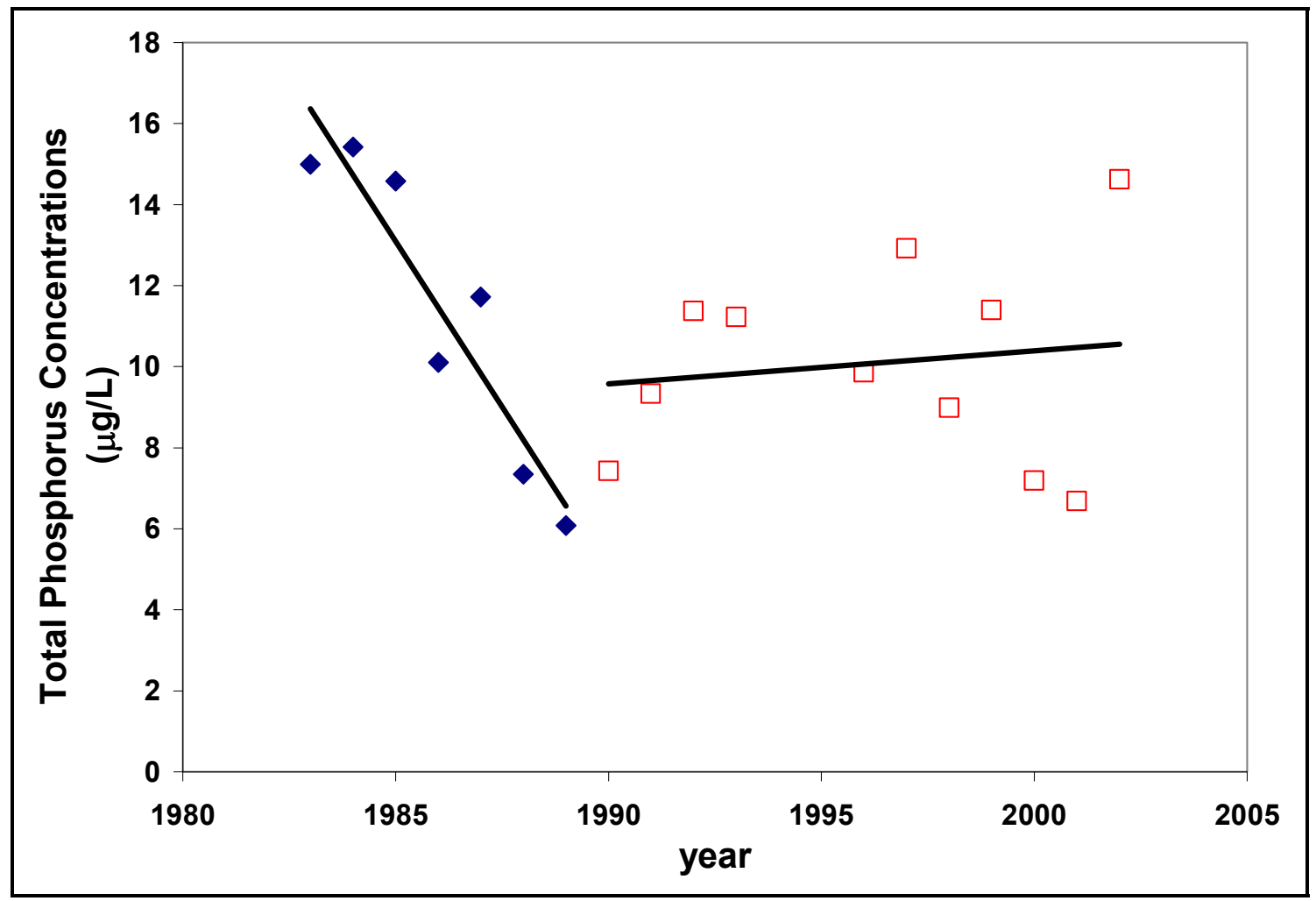

Figure 3. Total phosphorus concentrations in the central basin of Lake Erie during the spring monitoring cruises. Note that during the 1980s there was an overall declining trend, but since 1990 the total phosphorus concentration of the lake has been increasing. (Figure from Rockwell, et al. 2005) 


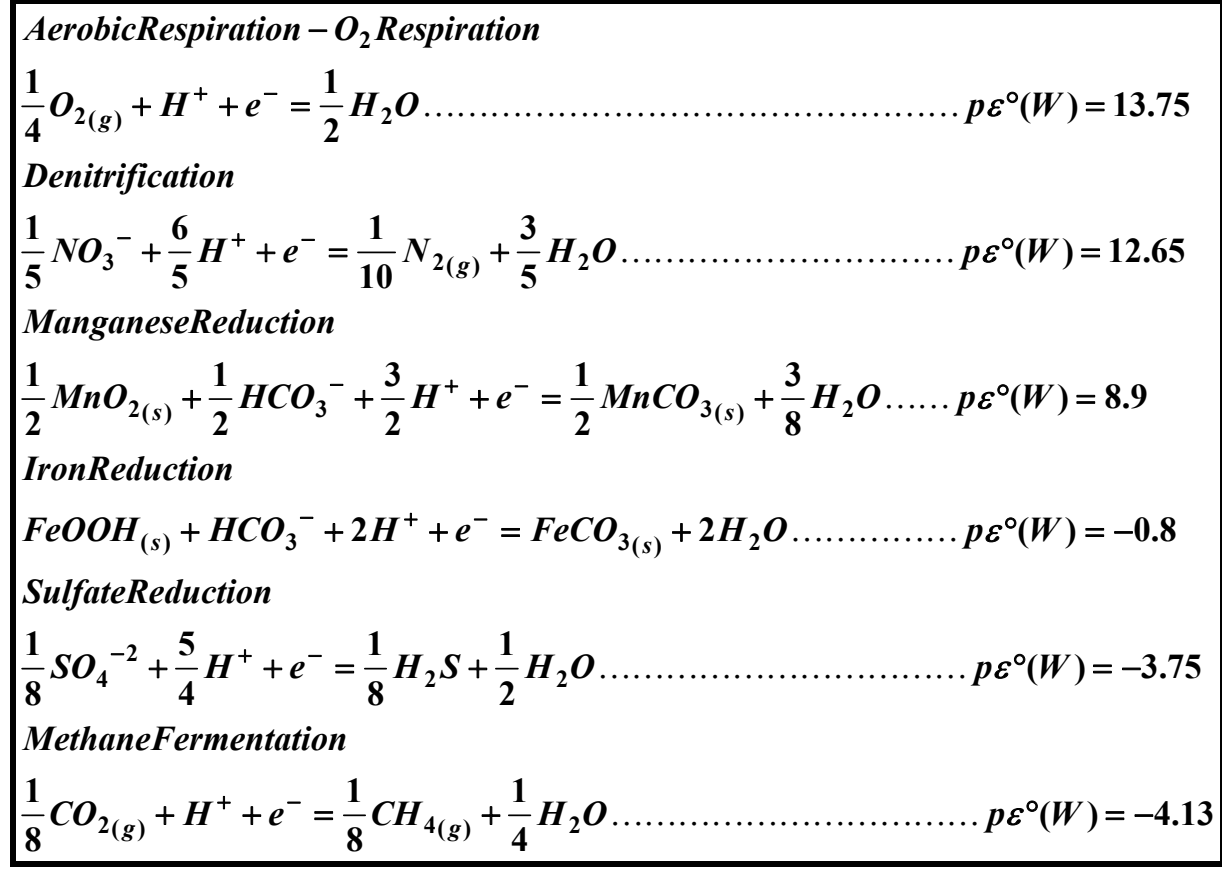

Table 1. Sequence of reduction reactions at place at the sediment water interface, leading to the decomposition of organic matter (Stumm and Morgan 1981). Each reaction is written to show the transfer of one electron. 


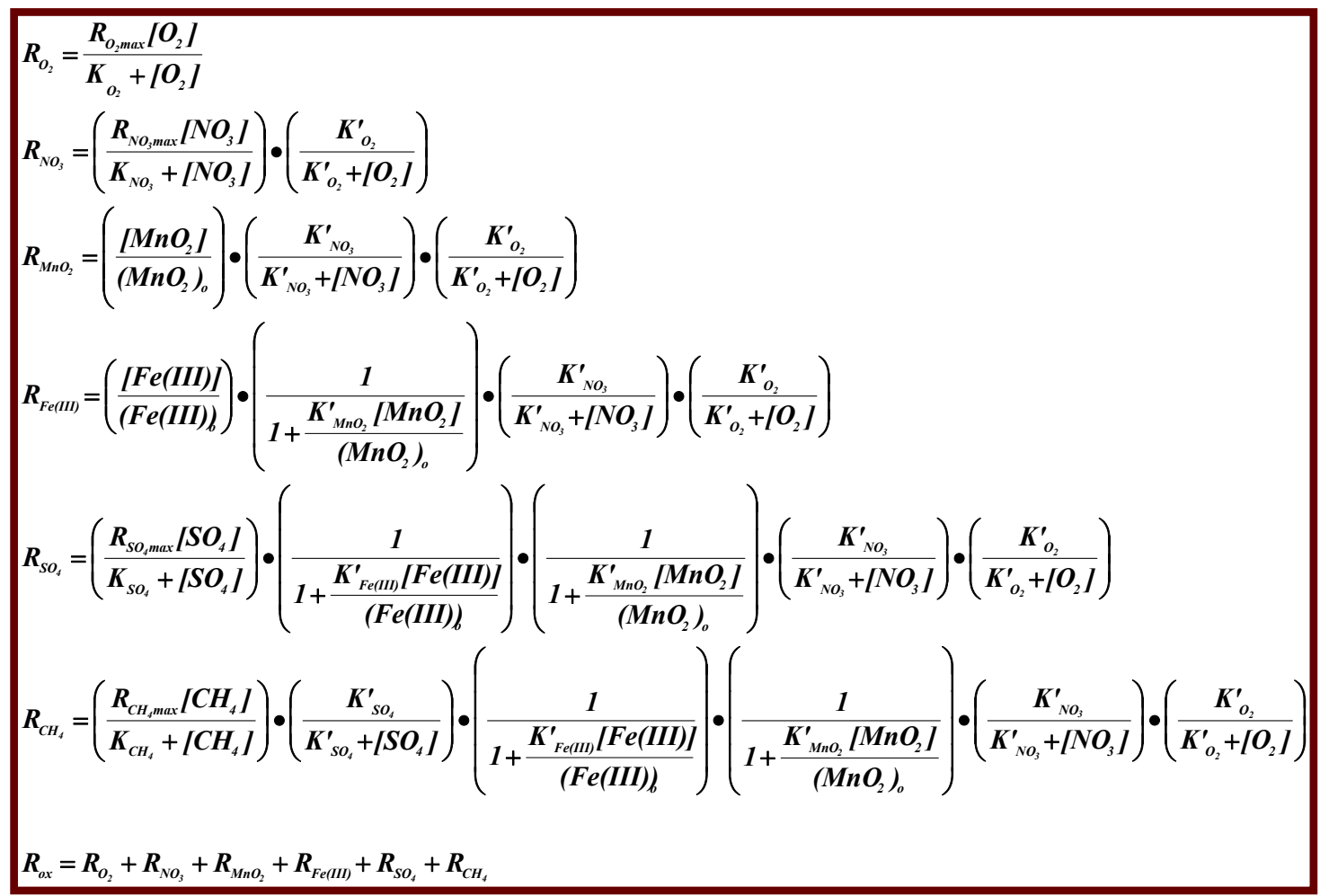

Table 2. Reaction rate expressions for the oxidation and reduction reactions that comprise the sediment oxygen demand, represented here by $\mathrm{R}_{\mathrm{ox}}$. Note that in this formulation each sequential reaction rate depends on all previous reactions, permitting some overlap of the reaction zones. 


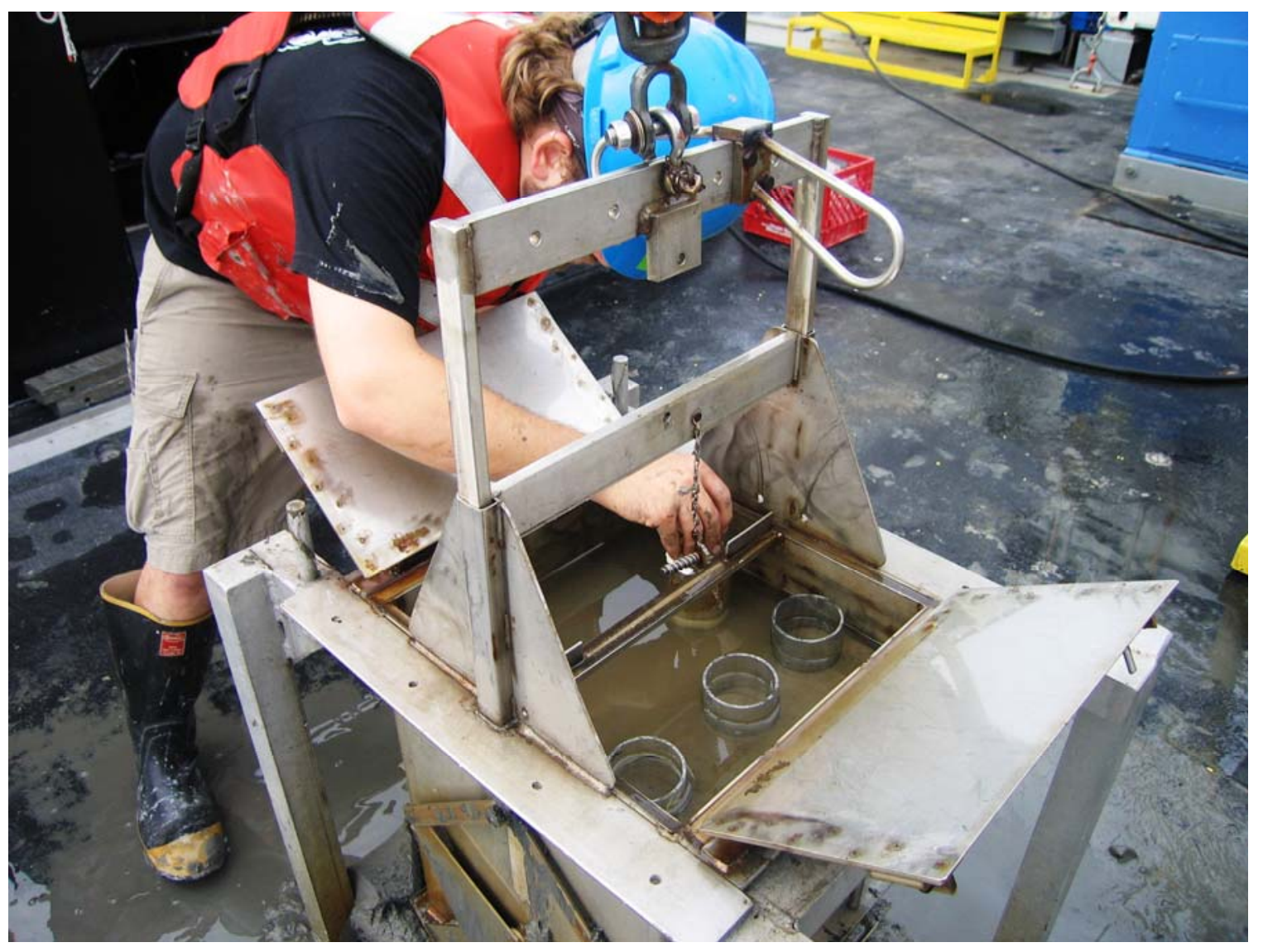

Figure 4: The $30 \mathrm{~cm}$ x $30 \mathrm{~cm}$ x $30 \mathrm{~cm}$ Ekman box corer was subcored with three sub cores for micro-profiles and one altered BOD bottle for the whole core incubation experiments. Sub-cores are capped on the bottom and then capped on the top prior to removal from Ekman box core. 


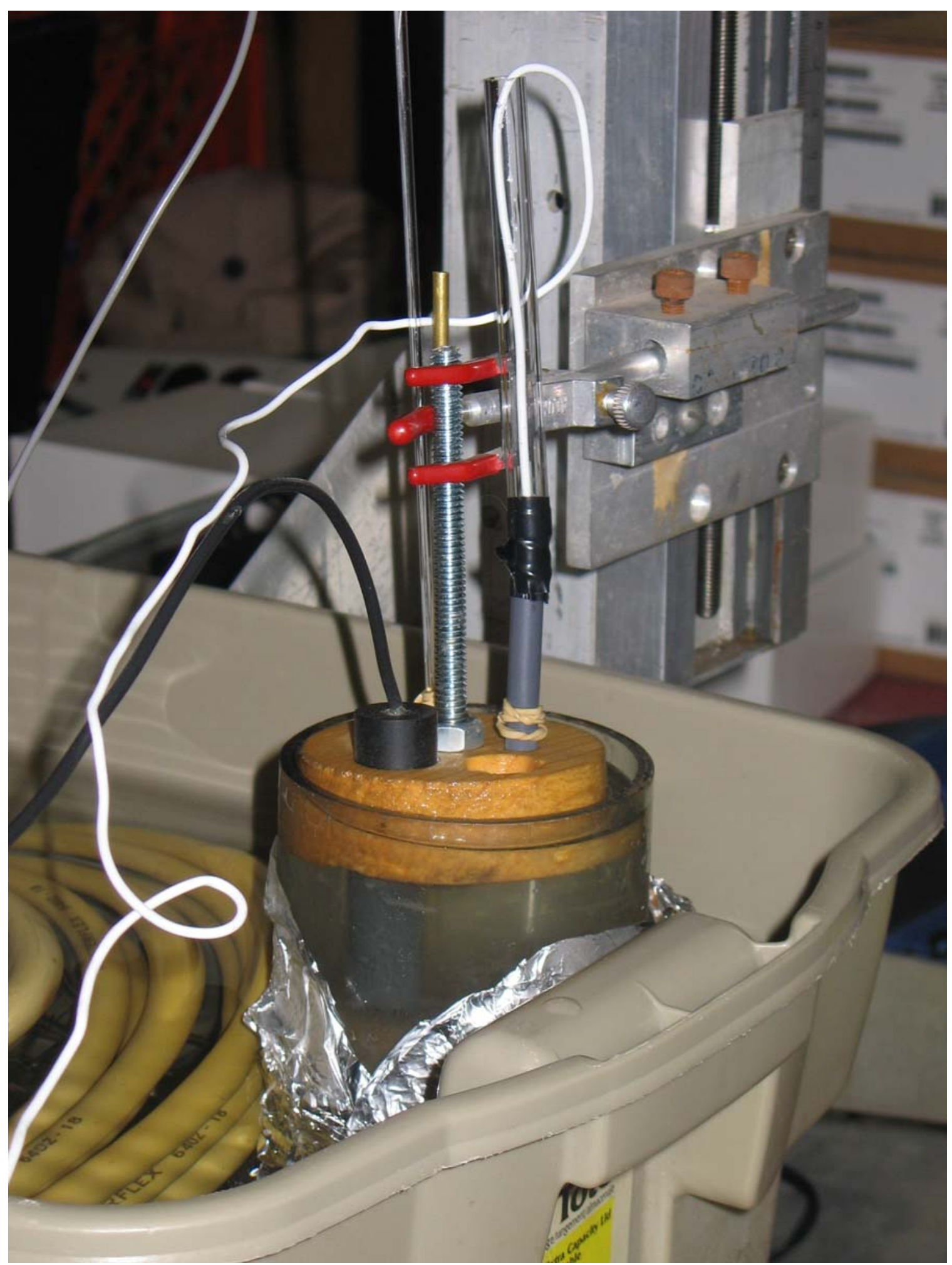

Figure 5: Micro-profile platform with the housed reference, nitrate, and oxygen electrodes. The tips of the electrodes are not visible, since they are submerged in the sediment. The Velmex precision screw slide can be seen in the background. The core is placed in a constant temperature water bath and covered with aluminum foil to maintain dark conditions. 


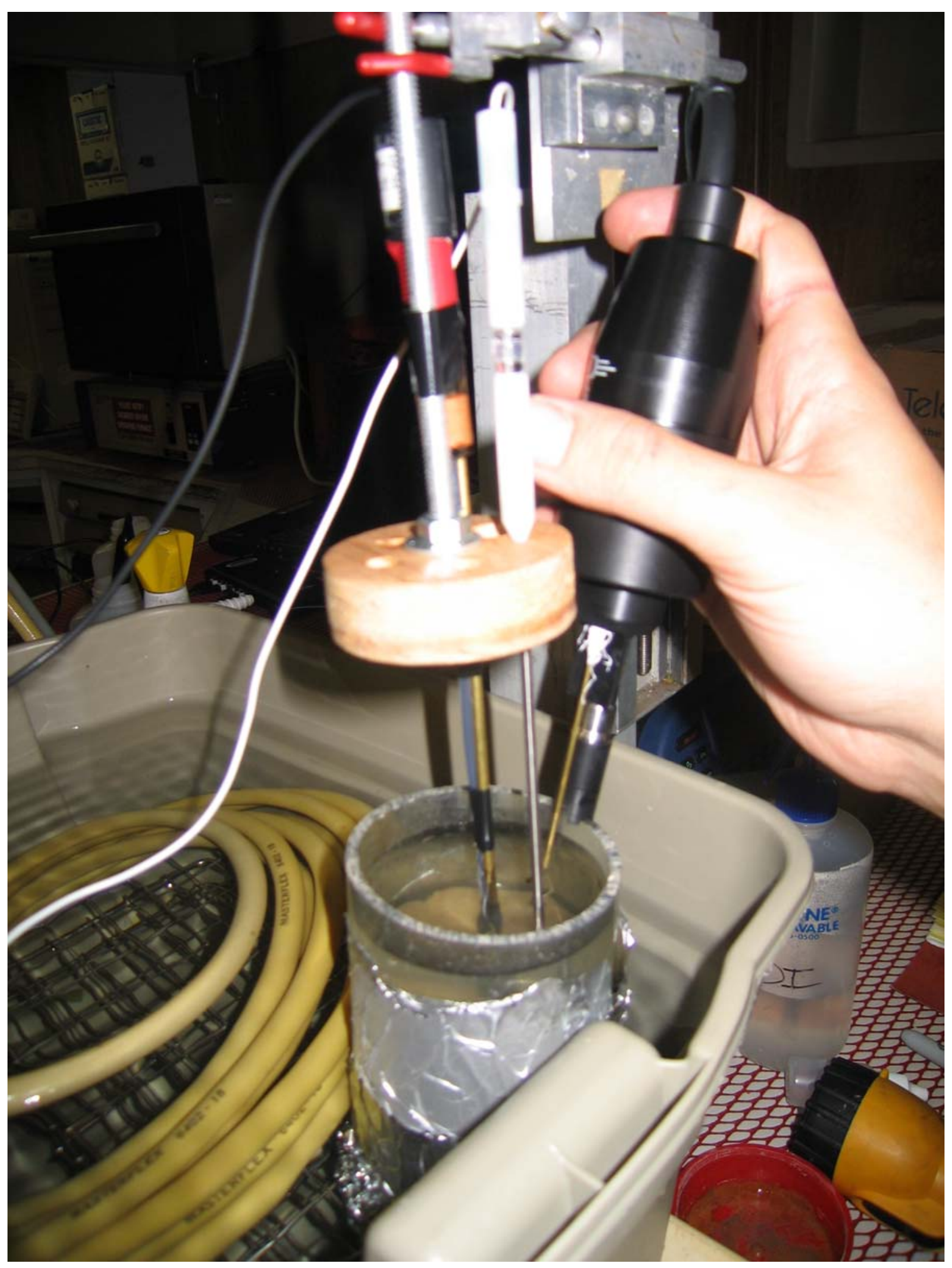

Figure 6: The micro-profiling platform housing the sulfide and $\mathrm{pH}$ electrode. The WTW StirOx can be seen being used for its stirring capabilities. 

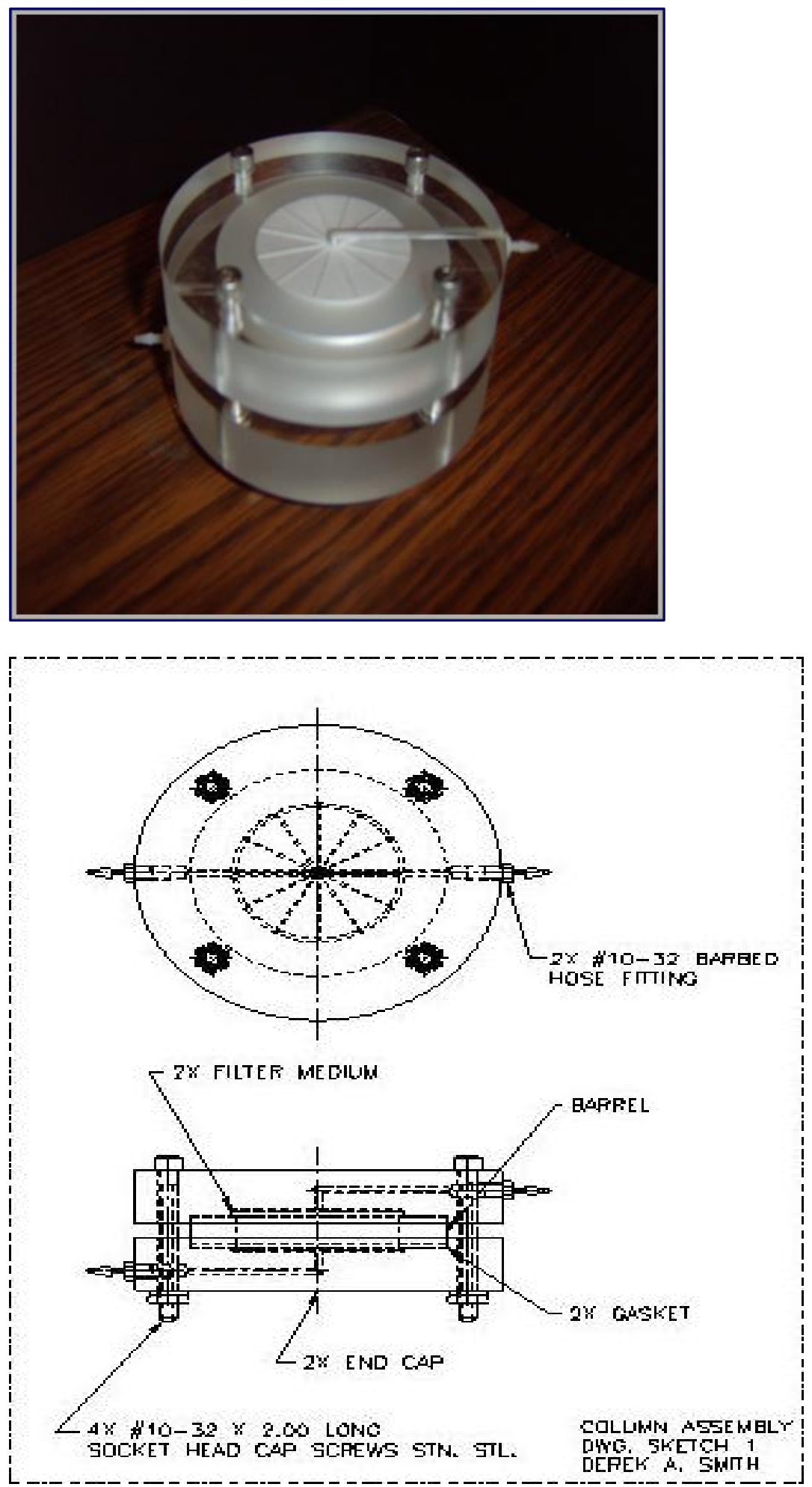

Figure 7: Both of the images are of an acrylic plug-flow through reactor. The top image is an actual picture taken of the reactor once assembled; during an experiment there would be a hose attached to each of the barb fittings. The bottom image is an AutoCAD drawing showing the schematics of the reactor. 


\begin{tabular}{|c|c|c|c|c|c|}
\hline Species & $D_{0}$ & $\alpha$ & Upper Bound & Lower Bound & $\begin{array}{l}\text { Initial } \\
\text { Conditi } \\
\text { on }\end{array}$ \\
\hline $\mathrm{CH}_{2} \mathrm{O}(\mathrm{s})$ & 0 & 0 & conc $-2.5 e-3$ & conc $-1.0 e-3$ & $2.50 \mathrm{E}-03$ \\
\hline $\mathrm{CH}_{4}(\mathrm{aq})$ & 235 & 0.052 & conc $-0.36 e-3$ & conc $-0.89 e-3$ & $3.60 \mathrm{E}-03$ \\
\hline $\mathrm{CO}_{2}(\mathrm{aq})$ & 249 & 0.06 & conc $-0.2 e-4$ & conc -0.0 & $2.00 \mathrm{E}-04$ \\
\hline $\begin{array}{c}\mathrm{Fe}(\mathrm{II}) \\
(\mathrm{aq})\end{array}$ & 106 & 0.044 & conc $-3.81 e-5$ & conc $-7.69 e-5$ & $3.81 \mathrm{E}-05$ \\
\hline $\begin{array}{c}\mathrm{Fe}(\mathrm{OH})_{3} \\
(\mathrm{~s})\end{array}$ & 0 & 0 & conc $-4.562 e-5$ & conc $-5.518 e-5$ & 4.56E-05 \\
\hline $\mathrm{H}_{2} \mathrm{~S}(\mathrm{aq})$ & 258 & 0.06 & conc - 1e-3 & conc -0.0 & $1.00 \mathrm{E}-03$ \\
\hline $\begin{array}{c}\mathrm{HCO}_{3}^{-} \\
(\mathrm{aq})\end{array}$ & 169 & 0.048 & conc $-9.88 e-4$ & conc - $1.448 \mathrm{e}-3$ & $9.88 \mathrm{E}-04$ \\
\hline $\begin{array}{c}\mathrm{HPO}_{4}{ }^{-2} \\
(\mathrm{aq})\end{array}$ & 150 & 0.05 & conc - $12.353 e-6$ & conc - 40.294e-6 & $1.24 \mathrm{E}-05$ \\
\hline $\begin{array}{c}\operatorname{Mn}(I I) \\
(\mathrm{aq})\end{array}$ & 96 & 0.05 & conc $1.365 \mathrm{e}-6$ & conc $-2.87 e-5$ & 1.37E-06 \\
\hline $\mathrm{MnO}_{2}(\mathrm{~s})$ & 0 & 0 & conc $-1.032 \mathrm{e}-6$ & conc $-6.289 e-8$ & 1.03E-06 \\
\hline $\mathrm{NH}_{4}^{+}(\mathrm{aq})$ & 308 & 0.041 & conc $-1.742 \mathrm{e}-4$ & conc $-3.727 e-4$ & 1.74E-04 \\
\hline $\mathrm{NO}_{3}^{-}(\mathrm{aq})$ & 307 & 0.038 & conc $-4.28 e-6$ & conc $-5.4 e-6$ & 4.28E-06 \\
\hline $\mathrm{O}_{2}(\mathrm{aq})$ & 296 & 0.06 & conc - $1.413 e-4$ & grad -0.0 & 1.41E-04 \\
\hline
\end{tabular}

Table 3: The input values used for the BRNS complete with upper and lower bounds, and initial conditions. The values for solid species (s) are given in the form of moles/g solid and soluble species (aq) are given as moles/L pore water. Model input permits upper and lower bounds to be of the form flux (moles $/ \mathrm{cm}^{2} / \mathrm{yr}$ ), concentration (moles/L or moles $/ \mathrm{g}$ ), or gradient (moles $/ \mathrm{L} / \mathrm{cm})$. The values for the molecular diffusion coefficients $\left(D_{0}\right)$ are given in $\mathrm{cm}^{2} / \mathrm{yr}$ and the temperature correction factor $(\alpha)$ in ${ }^{\circ} \mathrm{C}^{-1}$. 


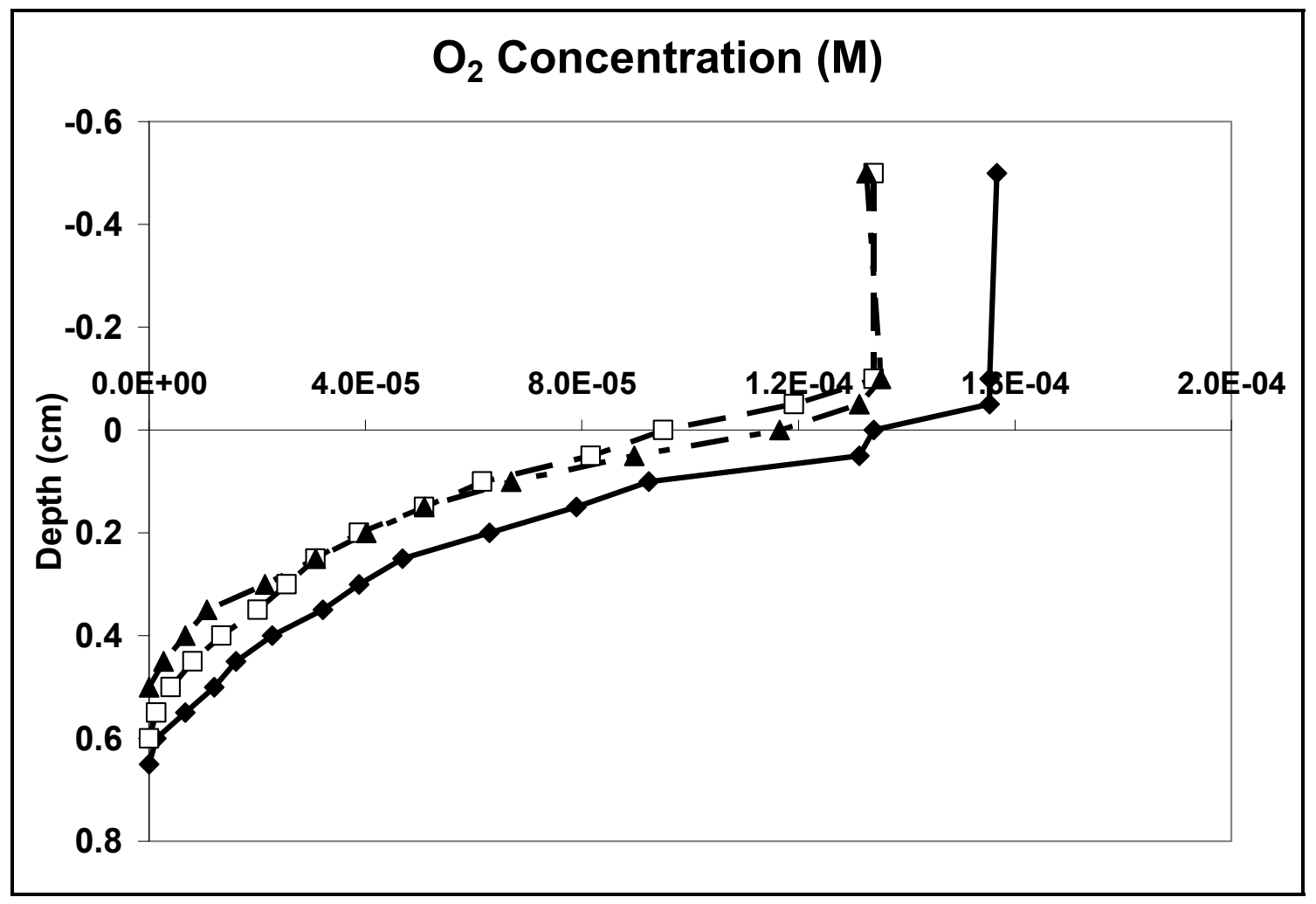

Figure 8: Triplicate oxygen profiles for ER-43M in the central basin of Lake Erie, collected at the same time as $\mathrm{NO}_{3}{ }^{-}$. The oxygen concentrations approach 0 at depth of less than $0.7 \mathrm{~cm}$. 


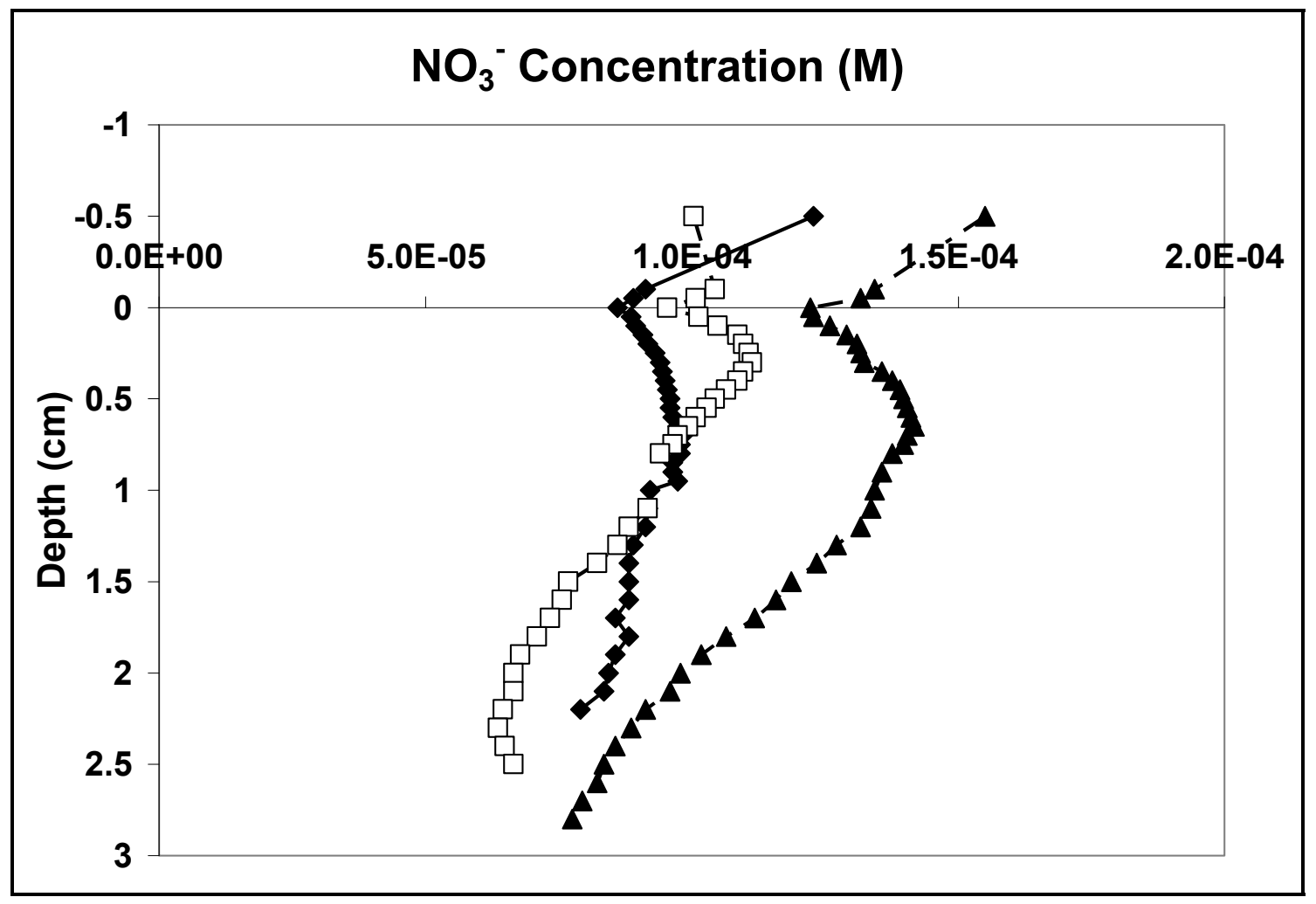

Figure 9: Triplicate nitrate profiles for ER-43M in the central basin of Lake Erie, collected at the same time as $\mathrm{O}_{2}$. The profiles agree reasonably well with an initially low value at the surface followed by a gradual increase then a decrease until the end of the profile. 


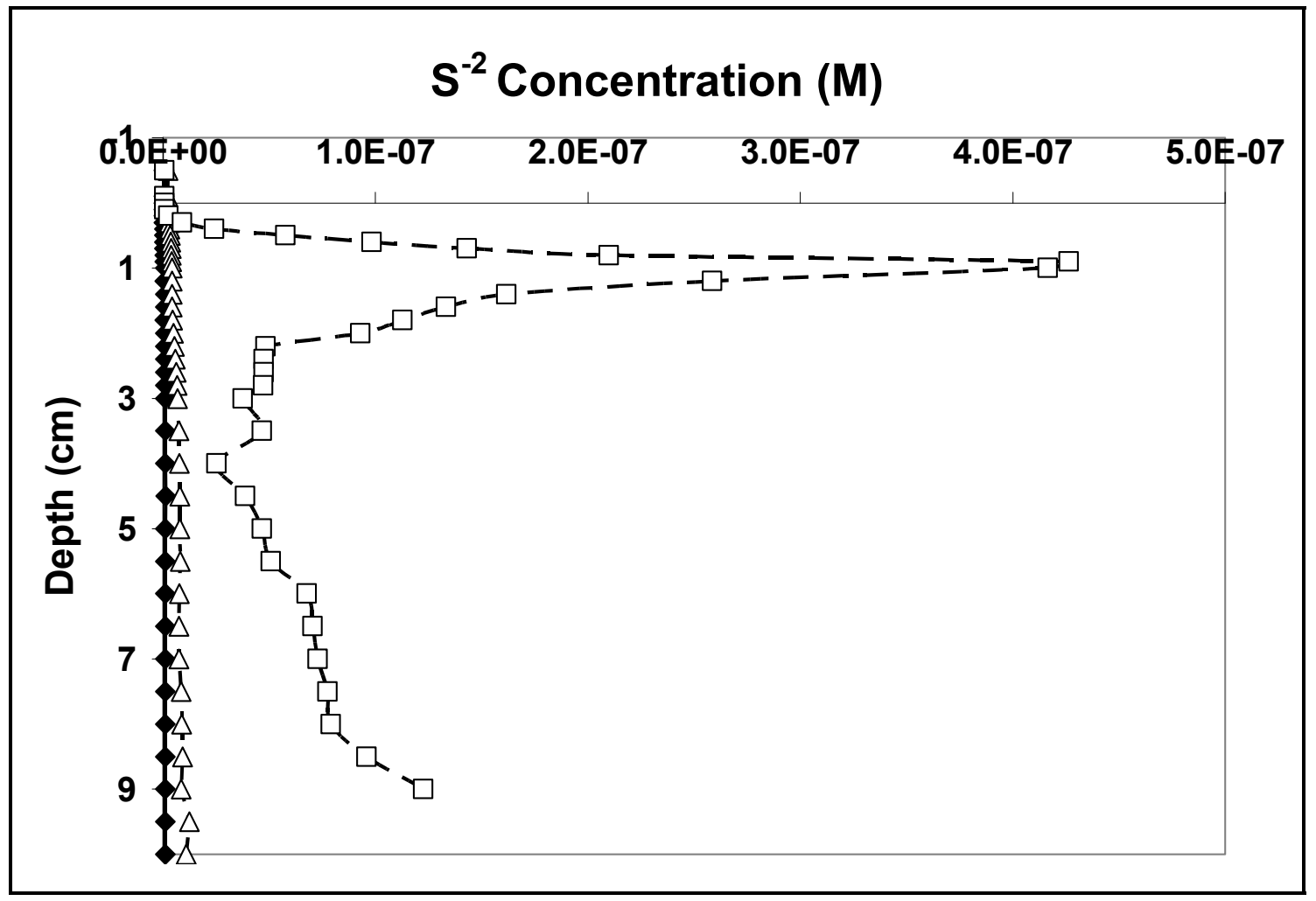

Figure 10: Triplicate profiles of $\left[\mathrm{S}^{-2}\right]$ for ER-43M in the central basin of Lake Erie, collected at the same time as the $\mathrm{pH}$ profile. Two of the three profiles are in reasonable agreement, while the third shows a major spike at $1 \mathrm{~cm}$ and higher overall concentrations. 


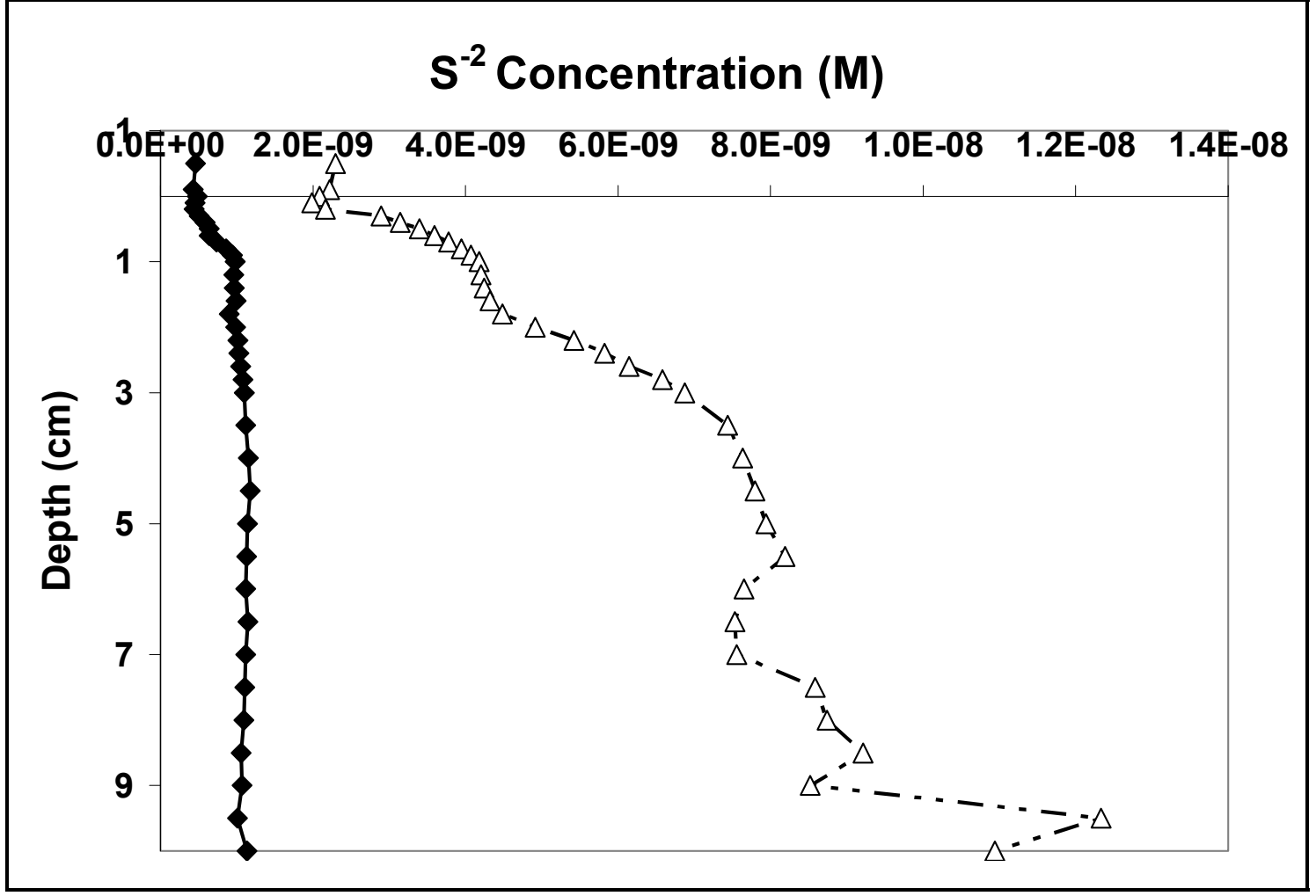

Figure 11: The same two profiles shown on the left hand side of Figure 10, rescaled to permit visualizing. In all profiles of $\left[\mathrm{S}^{-2}\right]$ the lowest values are at the sediment-water interface and the highest concentrations are at depth. 


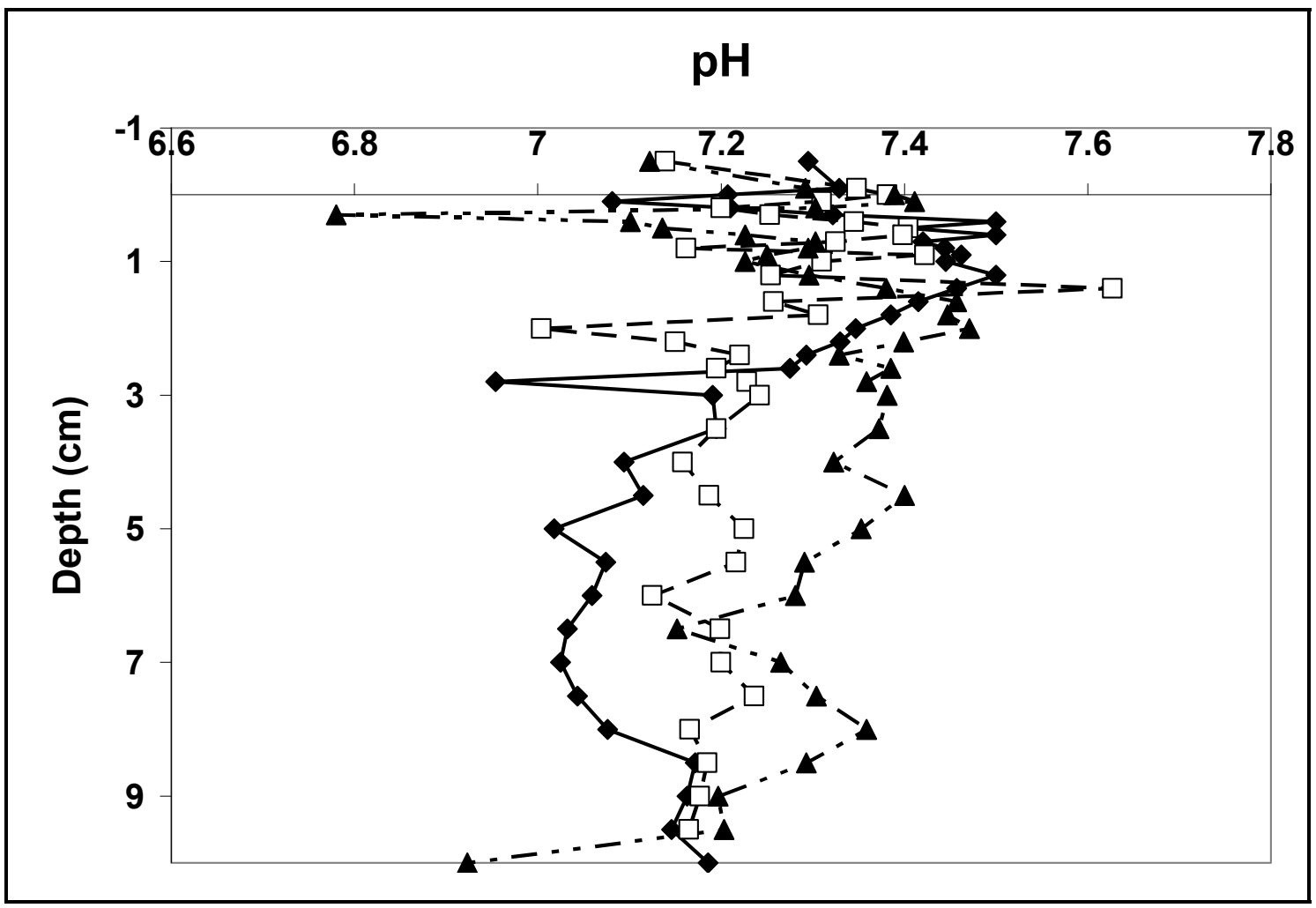

Figure 12: Triplicate $\mathrm{pH}$ profiles in a core collected at ER-43M in the central basin of Lake Erie. Numerous maxima and minima can be seen in all profiles. $\mathrm{pH}$ tends to decrease from about 7.4 near the surface to about 7.2 at a depth of $10 \mathrm{~cm}$. 


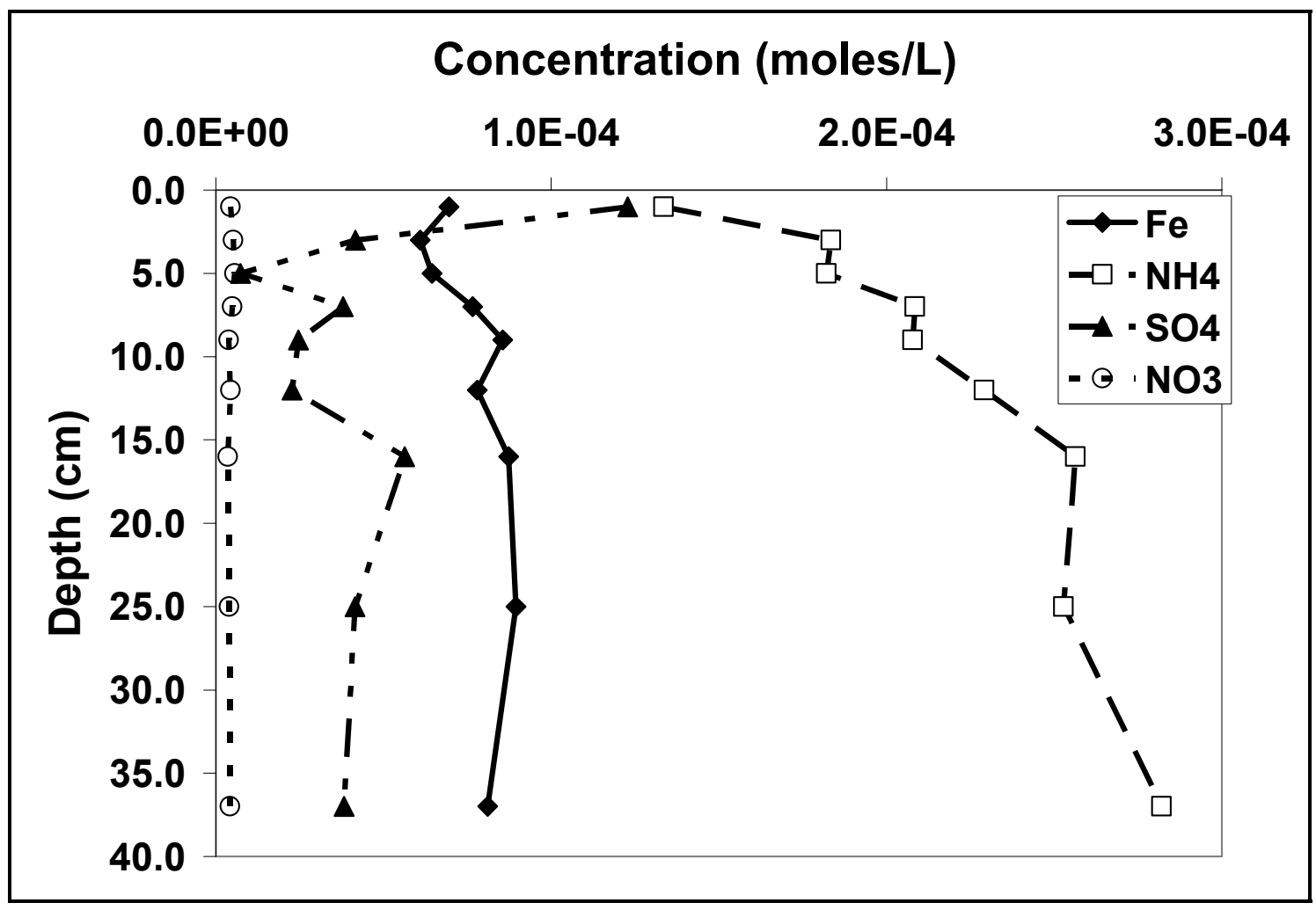

Figure 13: Concentration profiles of $\left[\mathrm{Fe}^{+2}\right],\left[\mathrm{NH}_{4}^{+}\right],\left[\mathrm{SO}_{4}{ }^{-2}\right]$, and $\left[\mathrm{NO}_{3}{ }^{-}\right]$in pore waters from a core collected in June 2006 at ER-43M in the central basin of Lake Erie. The midpoint of each depth interval was used to plot the data: 0-2, 2-4, 4-6, 6-8, 8-10, 10-14, 14-18, 18-22, 22-28, and 34-40 cm. 


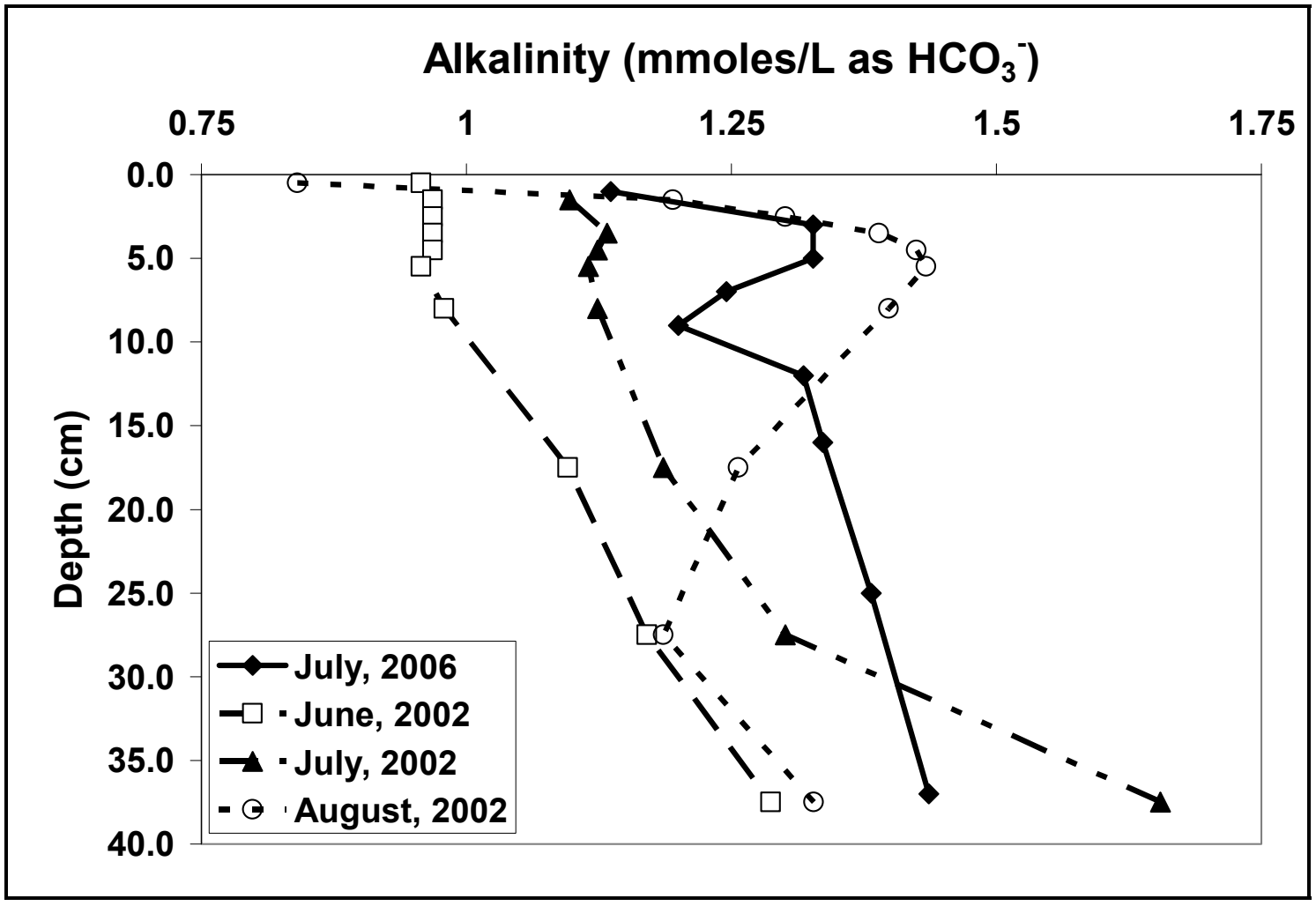

Figure 14: The alkalinity concentrations from porewaters at ER-43M obtained in June, 2006 compared with those obtained during the summer of 2002 for comparative purposes. The 2006 data seems to agree reasonably well with the previous data. 


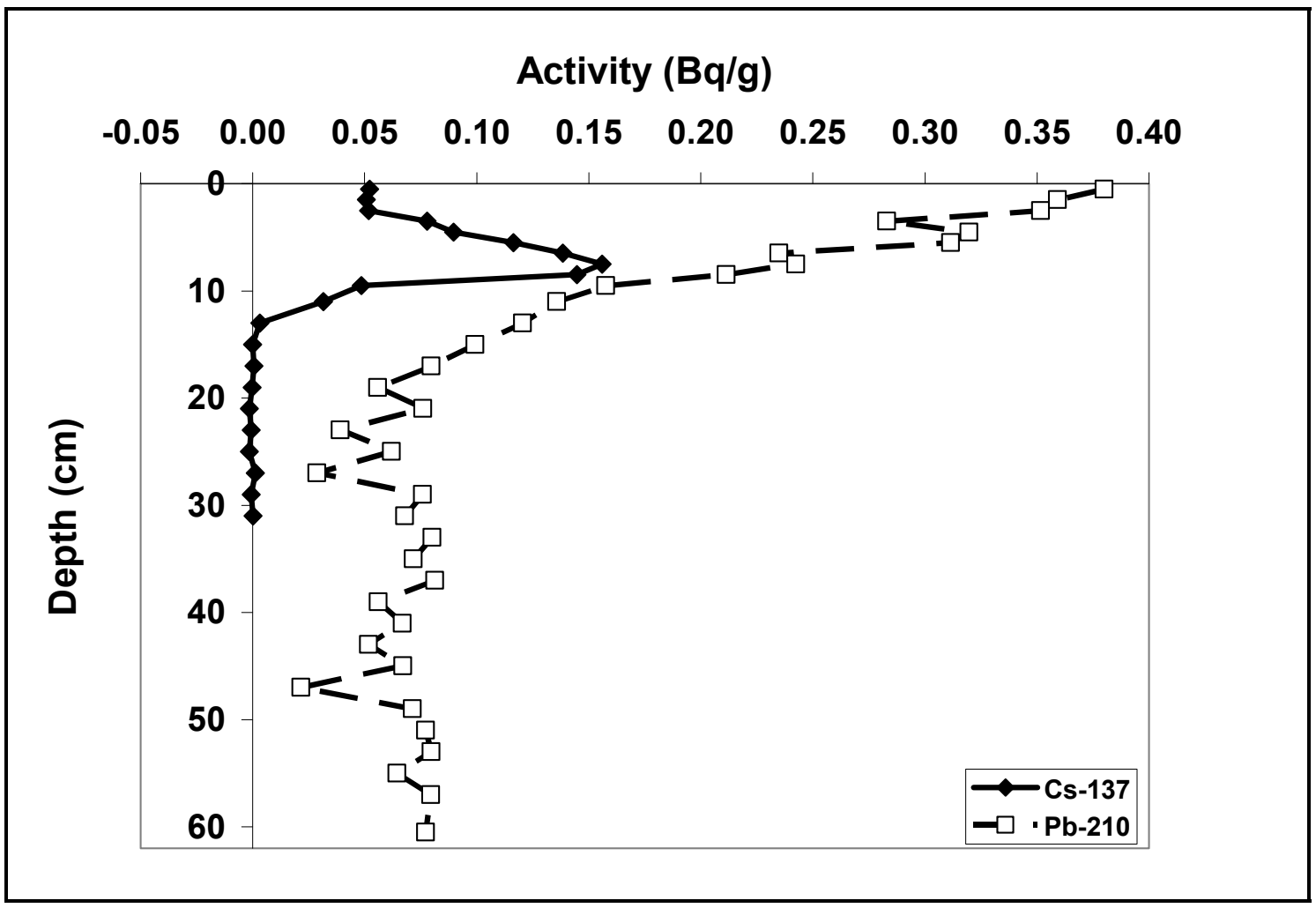

Figure 15: Activity of $\mathrm{Cs}-137$ and $\mathrm{Pb}-210$ plotted against depth. The spike of cesium at the depth interval of $7-8 \mathrm{~cm}$, corresponds to the fall out maximum that occurred during the 1963 testing of the atomic bomb. This yields a burial velocity of $0.174 \mathrm{~cm} / \mathrm{yr}$. 


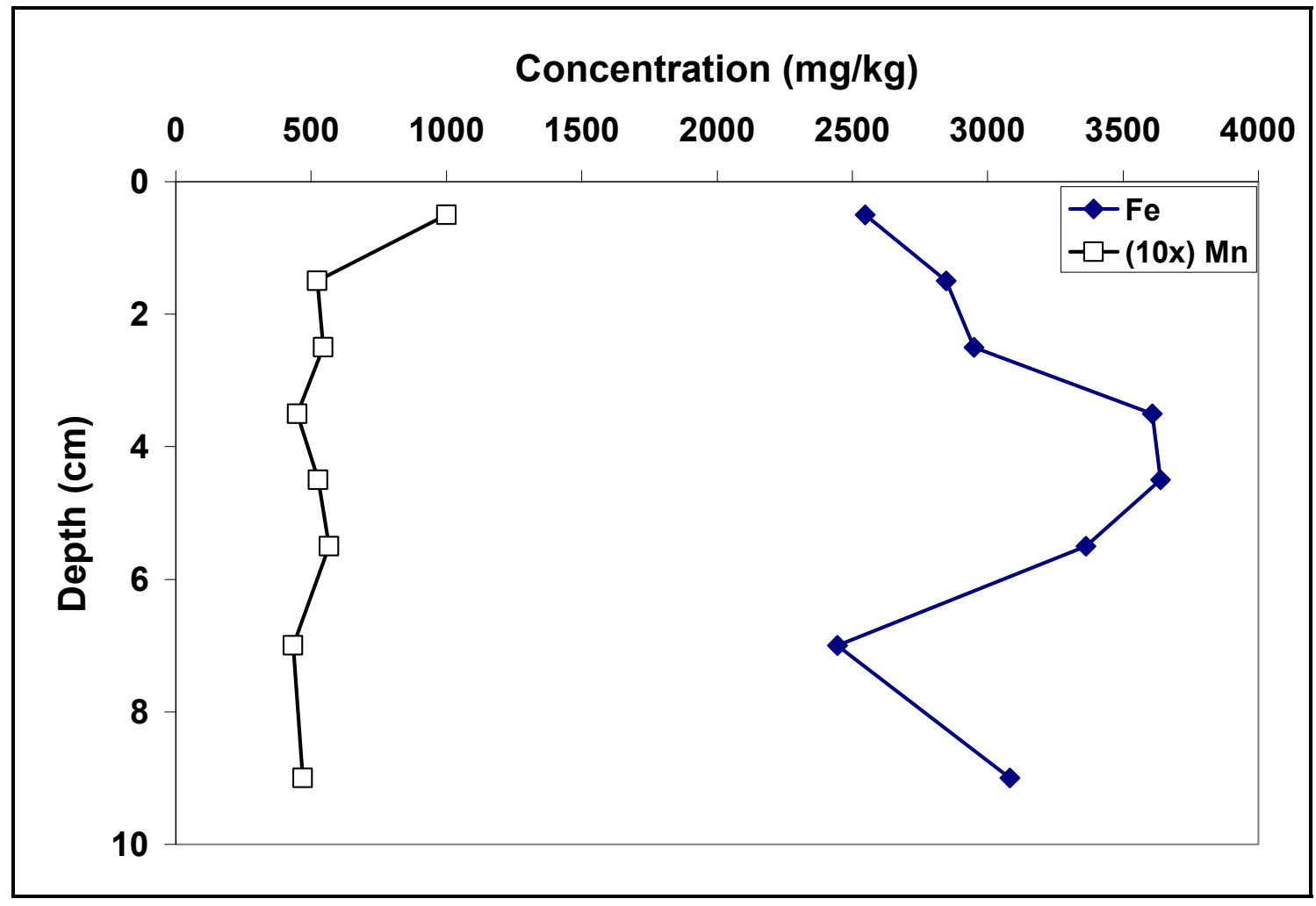

Figure 16: The sediment solid concentration of total Mn (plotted as $10 \mathrm{x}$ actual values) and total Fe at Station ER-43M in the central basin of Lake Erie. The midpoint of each depth interval was plotted: $0-1,1-2,2-3,3-4,4-5,5-6,6-8,8-10 \mathrm{~cm}$. 


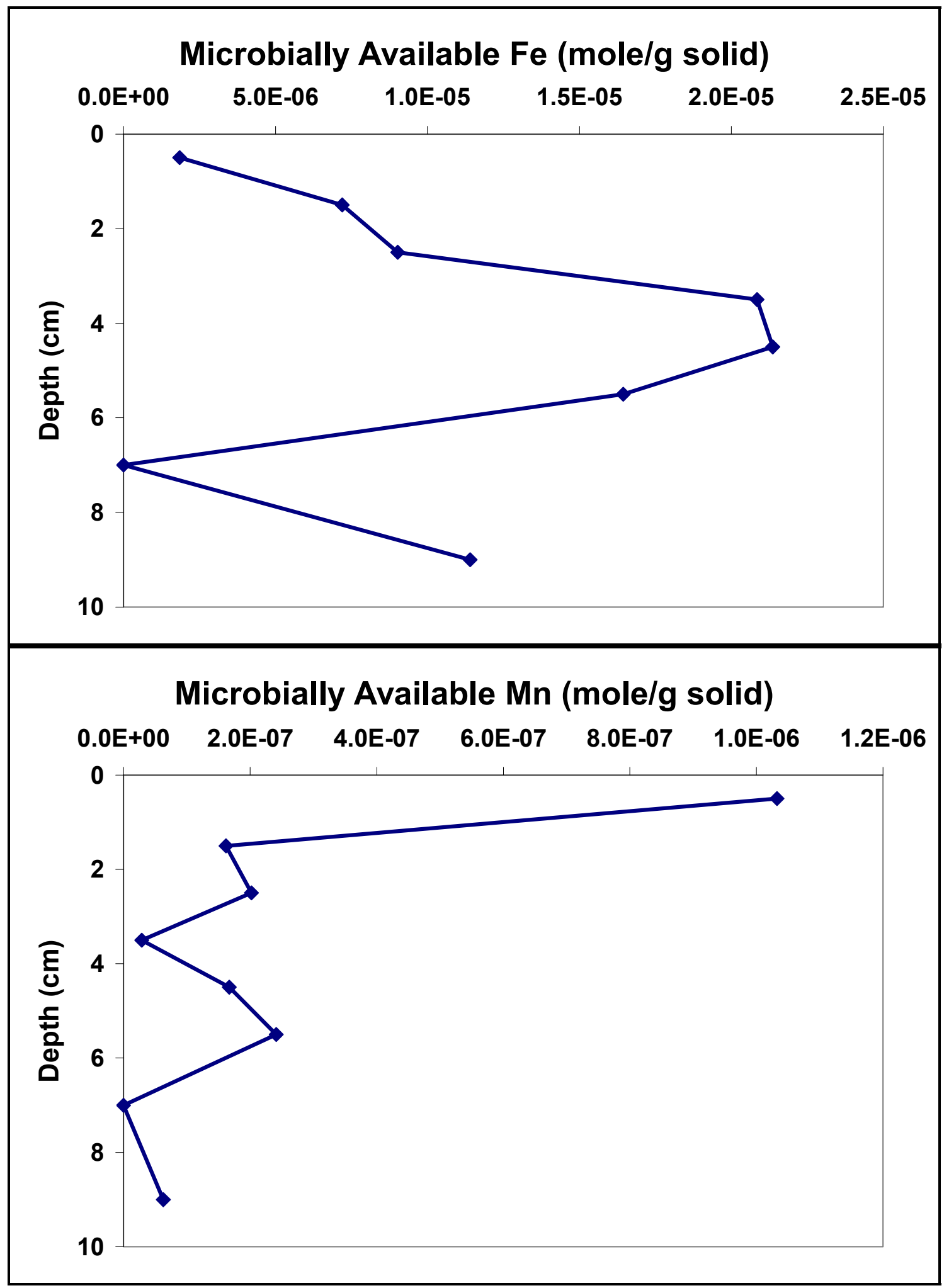

Figure 17: Microbially available Fe and Mn plotted against depth. Microbially available (hydr)oxides were determined by subtracting the total sediment solid concentration for iron or manganese at depth from the rest of the core's values. 


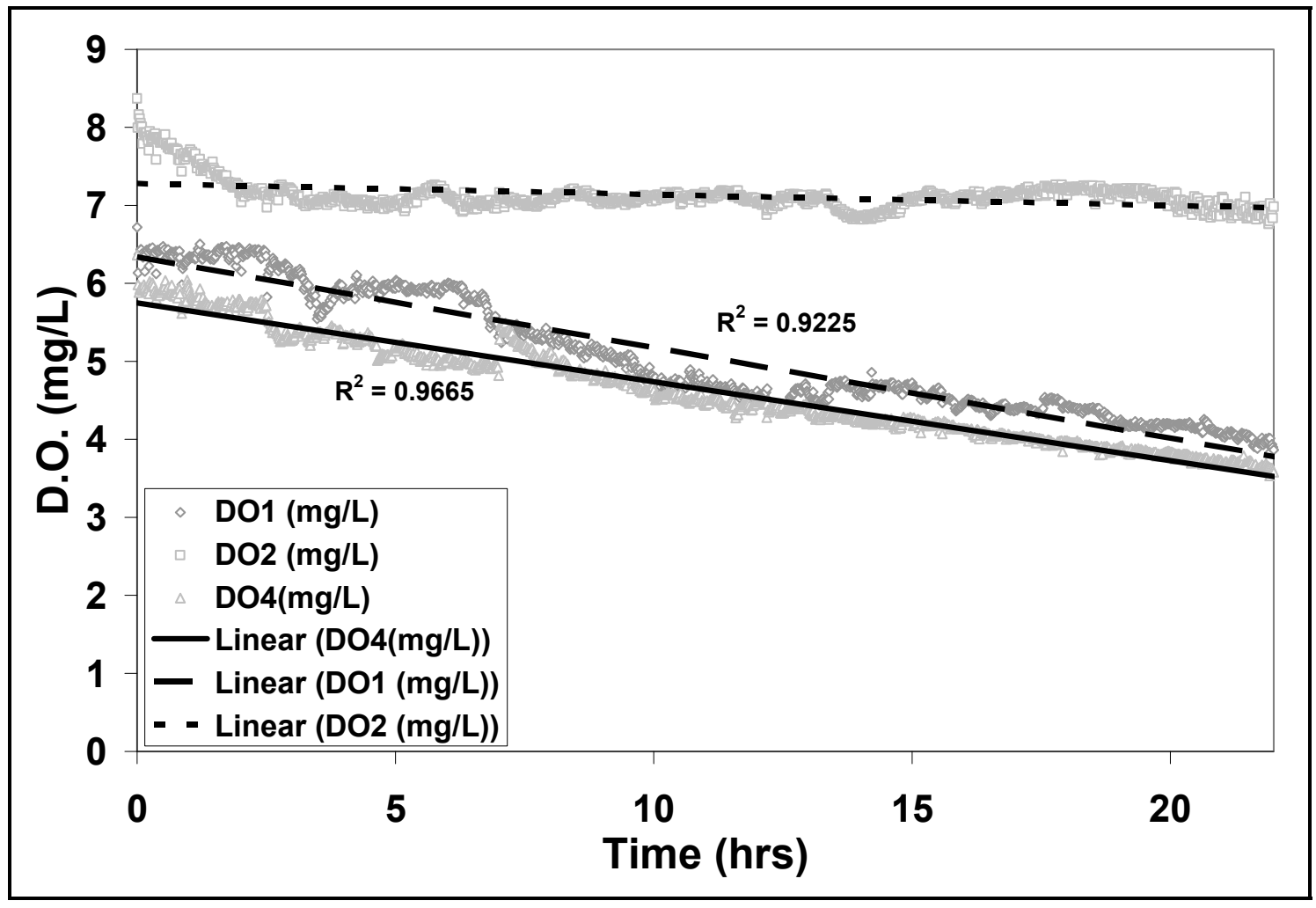

Figure 18: Whole core incubation experiment performed July 2006 on board R/V Lake Guardian for station ER-43M in the central basin of Lake Erie. The line centered at approximately $7.0 \mathrm{mg} / \mathrm{L}$ (DO 2) is a measurement of probe and water column consumption, while DO 1 and DO 4 are incubations of probe, water and a sediment core. 


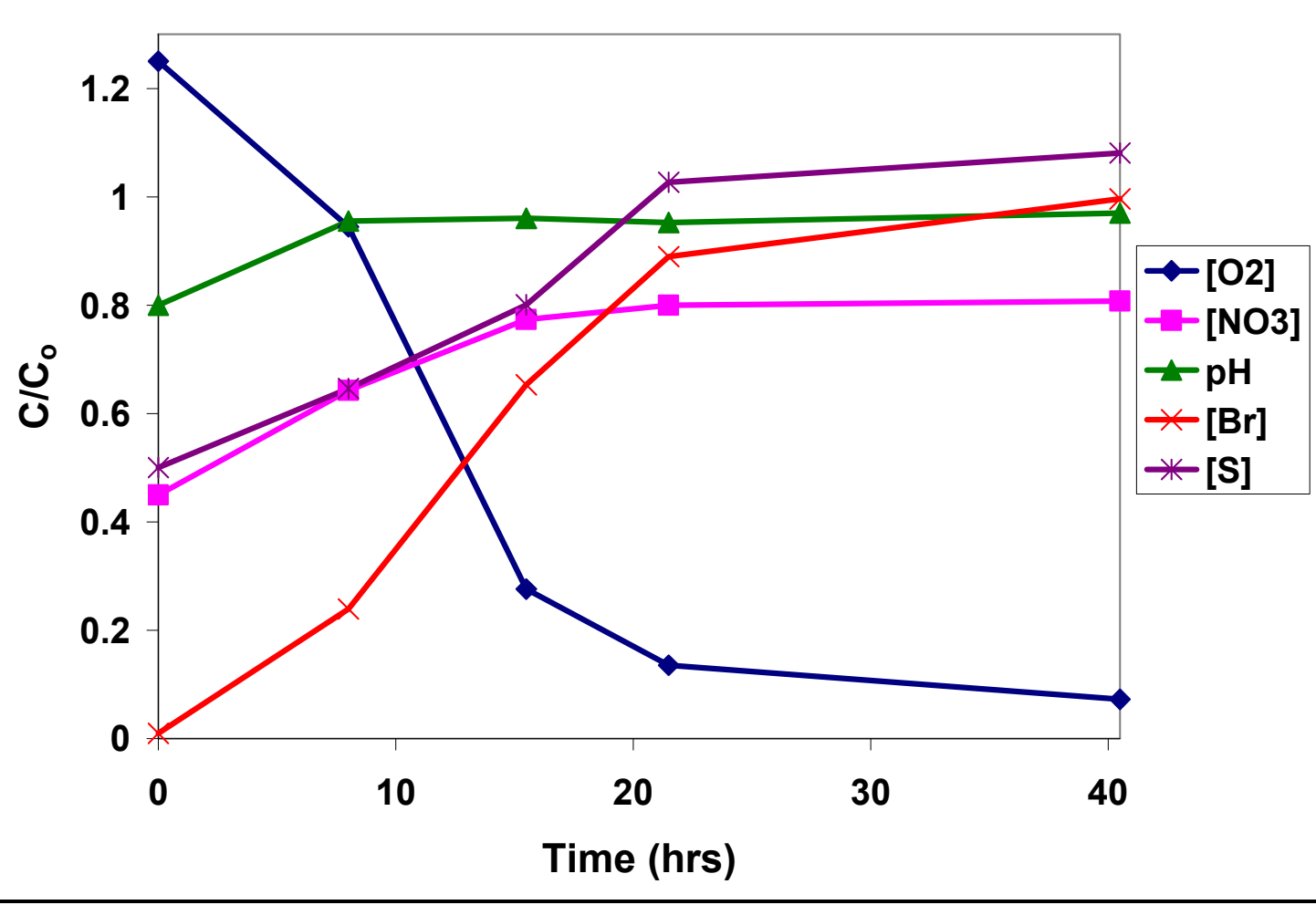

Figure 19: A representative plug-flow through experiment monitoring of reactants and products for a given $1 \mathrm{~cm}$ sediment sample. Steady state, defined as where the effluent concentration $(\mathrm{C})$ was equivalent to the influent concentration $\left(\mathrm{C}_{\mathrm{o}}\right)$ of bromide, was achieved in $15-48$ hours depending on the influent concentration of oxygen and depth interval. 


\begin{tabular}{lrrrrr}
$C_{o}(\boldsymbol{\mu m o l} / \mathrm{L})$ & $\mathbf{1 7 6 . 7 3}$ & $\mathbf{4 0 . 1 7}$ & $\mathbf{1 2 0 . 5 0}$ & $\mathbf{1 4 0 . 5 8}$ & $\mathbf{1 1 5 . 1 4}$ \\
\hline 0 - 1 A & 23.04 & 0.26 & 8.80 & 10.09 & 10.61 \\
1 - 2 A & 23.04 & -0.52 & 7.25 & 7.25 & 9.58 \\
2 - 3 A & 23.55 & -3.11 & 3.62 & 4.40 & 8.80 \\
3 - 4 A & 23.29 & -5.18 & 2.33 & 3.36 & 8.28 \\
4 - 5 A & 22.26 & -7.76 & 1.81 & 1.81 & 7.76 \\
$C_{\text {o }}(\boldsymbol{\mu m o l} / \mathrm{L})$ & $\mathbf{1 7 6 . 7 3}$ & $\mathbf{4 0 . 1 7}$ & $\mathbf{1 3 6 . 5 6}$ & $\mathbf{1 4 9 . 9 5}$ & $\mathbf{9 1 . 0 4}$ \\
\hline $0-1$ & 30.54 & 4.40 & 18.64 & 19.15 & 10.61 \\
$1-2$ & 27.95 & 4.14 & 16.82 & 17.60 & 10.09 \\
$2-3$ & 29.25 & 3.62 & 16.31 & 15.27 & 7.51 \\
$3-4$ & 29.25 & 3.11 & 14.49 & 13.46 & 6.99 \\
$4-5$ & 29.25 & 2.85 & 13.20 & 12.68 & 6.73
\end{tabular}

Table 4: Steady state reduction rates (SSRs), in $\mu \mathrm{mol} / \mathrm{L} / \mathrm{hr}$, based off of influent steady state concentrations of dissolved oxygen $\left(\mathrm{C}_{\mathrm{o}}\right)$. The "A" refers to those samples that were treated with sodium azide. 
SOD $\left(\mathrm{mol} / \mathrm{cm}^{2} / \mathrm{sec}\right)$ based off SSR

\begin{tabular}{lrrrrr}
\hline $\mathbf{C}_{\mathrm{o}}(\boldsymbol{\mu \mathbf { m o l }} / \mathrm{L})$ & $\mathbf{1 7 6 . 7 3}$ & $\mathbf{4 0 . 1 7}$ & $\mathbf{1 2 0 . 5 0}$ & $\mathbf{1 4 0 . 5 8}$ & $\mathbf{1 1 5 . 1 4}$ \\
\hline $0-1 \mathrm{~A}$ & $6.40 \mathrm{E}-12$ & $7.19 \mathrm{E}-14$ & $2.44 \mathrm{E}-12$ & $2.80 \mathrm{E}-12$ & $2.95 \mathrm{E}-12$ \\
$1-2 \mathrm{~A}$ & $6.40 \mathrm{E}-12$ & $-1.44 \mathrm{E}-13$ & $2.01 \mathrm{E}-12$ & $2.01 \mathrm{E}-12$ & $2.66 \mathrm{E}-12$ \\
2 - 3 A & $6.54 \mathrm{E}-12$ & $-8.63 \mathrm{E}-13$ & $1.01 \mathrm{E}-12$ & $1.22 \mathrm{E}-12$ & $2.44 \mathrm{E}-12$ \\
$3-4 \mathrm{~A}$ & $6.47 \mathrm{E}-12$ & $-1.44 \mathrm{E}-12$ & $6.47 \mathrm{E}-13$ & $9.35 \mathrm{E}-13$ & $2.30 \mathrm{E}-12$ \\
$4-5 \mathrm{~A}$ & $6.18 \mathrm{E}-12$ & $-2.16 \mathrm{E}-12$ & $5.03 \mathrm{E}-13$ & $5.03 \mathrm{E}-13$ & $2.16 \mathrm{E}-12$ \\
$\mathrm{C}_{\mathrm{o}}(\boldsymbol{\mu \mathrm { mol } / \mathrm { L } )}$ & 176.7264041 & 40.1650918 & 136.561312 & 149.949676 & 91.0408749 \\
\hline $0-1$ & $8.48 \mathrm{E}-12$ & $1.22 \mathrm{E}-12$ & $5.18 \mathrm{E}-12$ & $5.32 \mathrm{E}-12$ & $2.95 \mathrm{E}-12$ \\
$1-2$ & $7.76 \mathrm{E}-12$ & $1.15 \mathrm{E}-12$ & $4.67 \mathrm{E}-12$ & $4.89 \mathrm{E}-12$ & $2.80 \mathrm{E}-12$ \\
$2-3$ & $8.12 \mathrm{E}-12$ & $1.01 \mathrm{E}-12$ & $4.53 \mathrm{E}-12$ & $4.24 \mathrm{E}-12$ & $2.09 \mathrm{E}-12$ \\
$3-4$ & $8.12 \mathrm{E}-12$ & $8.63 \mathrm{E}-13$ & $4.03 \mathrm{E}-12$ & $3.74 \mathrm{E}-12$ & $1.94 \mathrm{E}-12$ \\
$4-5$ & $8.12 \mathrm{E}-12$ & $7.91 \mathrm{E}-13$ & $3.67 \mathrm{E}-12$ & $3.52 \mathrm{E}-12$ & $1.87 \mathrm{E}-12$
\end{tabular}

\section{$\operatorname{SOD}\left(\mathrm{g} \mathrm{O}_{2} / \mathrm{m}^{2} / \mathrm{d}\right)$}

\begin{tabular}{lrrrrr}
\hline $\mathrm{C}_{\mathrm{o}}(\boldsymbol{\mu \mathrm { mol } / \mathrm { L } )}$ & $\mathbf{1 7 6 . 7 3}$ & $\mathbf{4 0 . 1 7}$ & $\mathbf{1 2 0 . 5 0}$ & $\mathbf{1 4 0 . 5 8}$ & $\mathbf{1 1 5 . 1 4}$ \\
\hline 0 - 1 A & 0.1769 & 0.0020 & 0.0676 & 0.0775 & 0.0815 \\
1 - 2 A & 0.1769 & -0.0040 & 0.0557 & 0.0557 & 0.0735 \\
2 - 3 A & 0.1809 & -0.0239 & 0.0278 & 0.0338 & 0.0676 \\
3 - 4 A & 0.1789 & -0.0398 & 0.0179 & 0.0258 & 0.0636 \\
$4-5 \mathrm{~A}$ & 0.1709 & -0.0596 & 0.0139 & 0.0139 & 0.0596 \\
$\mathrm{C}_{\mathrm{o}}(\boldsymbol{\mu m o l} / \mathrm{L})$ & $\mathbf{1 7 6 . 7 3}$ & $\mathbf{4 0 . 1 7}$ & $\mathbf{1 3 6 . 5 6}$ & $\mathbf{1 4 9 . 9 5}$ & $\mathbf{9 1 . 0 4}$ \\
\hline $0-1$ & 0.2346 & 0.0338 & 0.1431 & 0.1471 & 0.0815 \\
$1-2$ & 0.2147 & 0.0318 & 0.1292 & 0.1352 & 0.0775 \\
$2-3$ & 0.2246 & 0.0278 & 0.1252 & 0.1173 & 0.0576 \\
$3-4$ & 0.2246 & 0.0239 & 0.1113 & 0.1034 & 0.0537 \\
$4-5$ & 0.2246 & 0.0219 & 0.1014 & 0.0974 & 0.0517
\end{tabular}

Table 5: SODs for the plug flow-through experiments based on treatment and depth. 


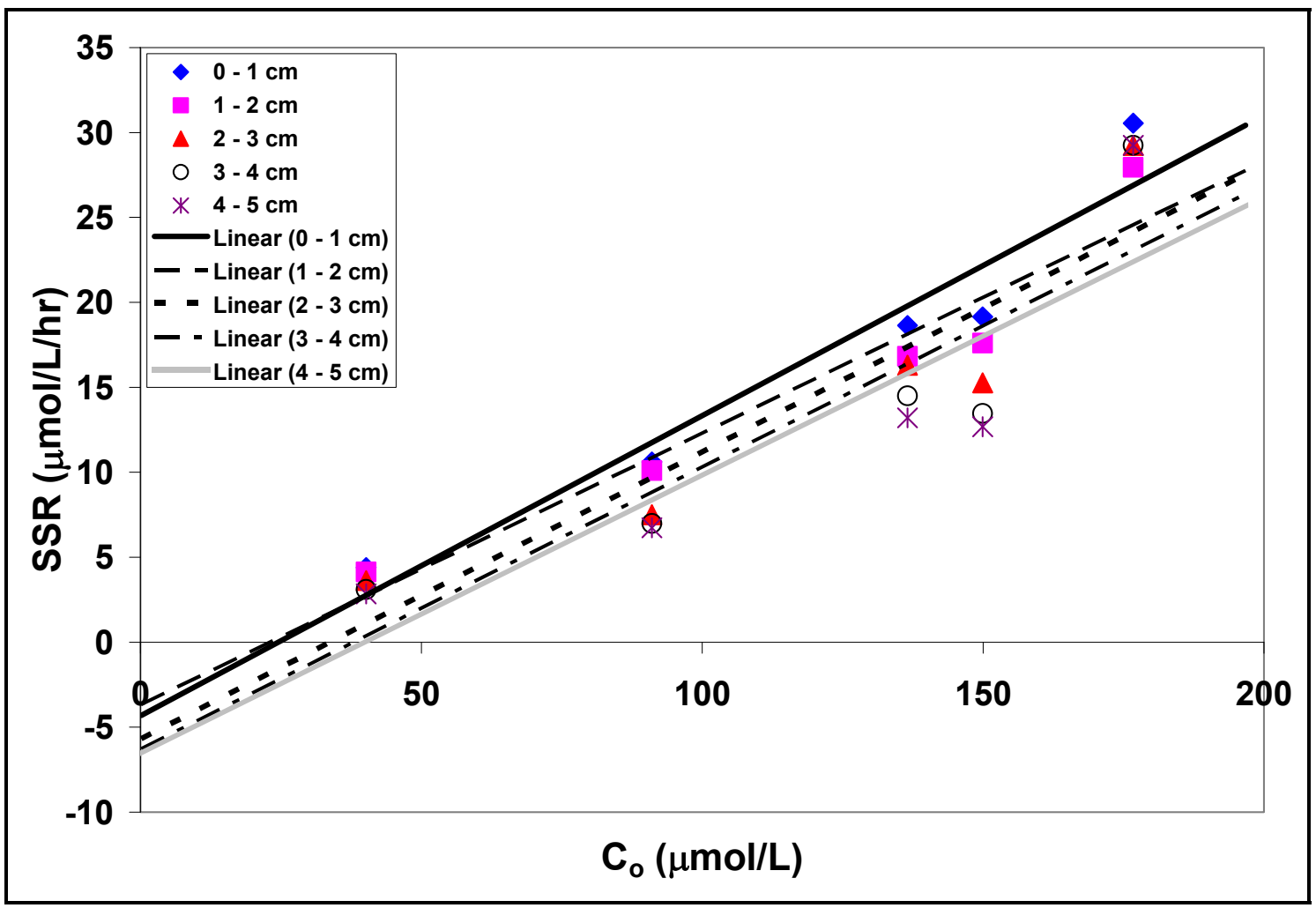

Figure 20: Steady state reduction rates for the untreated group in the plug-flow through experiment plotted against measured steady state dissolved oxygen concentrations $\left(\mathrm{C}_{\mathrm{o}}\right)$ as a function of depth, average $\mathrm{R}^{2}=0.8566$. 


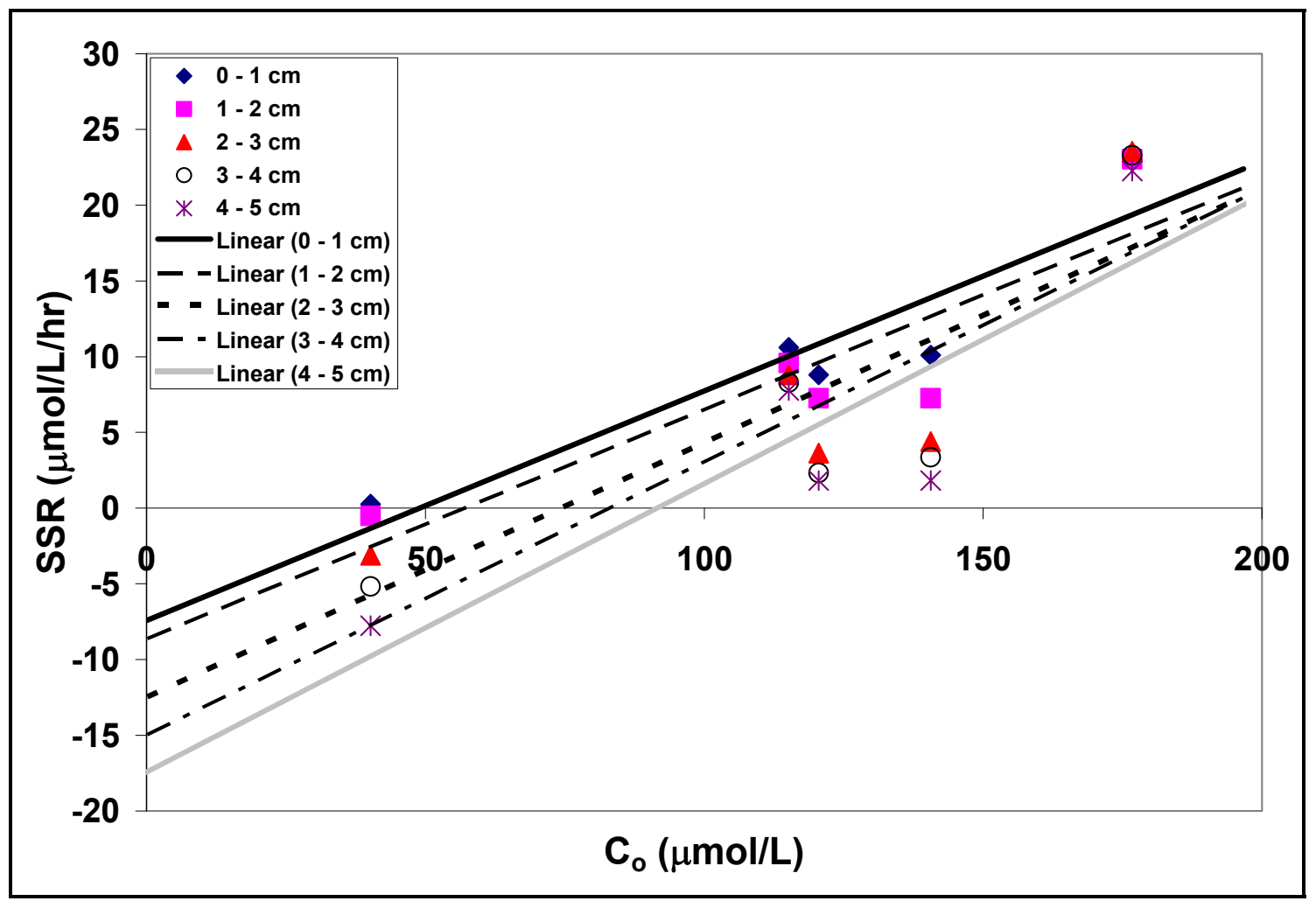

Figure 21: Steady state reduction rates for the azide treated group in the plug-flow through experiment plotted against measured steady state dissolved oxygen concentrations $\left(C_{0}\right)$ and as a function of depth, average $R^{2}=0.7688$. 


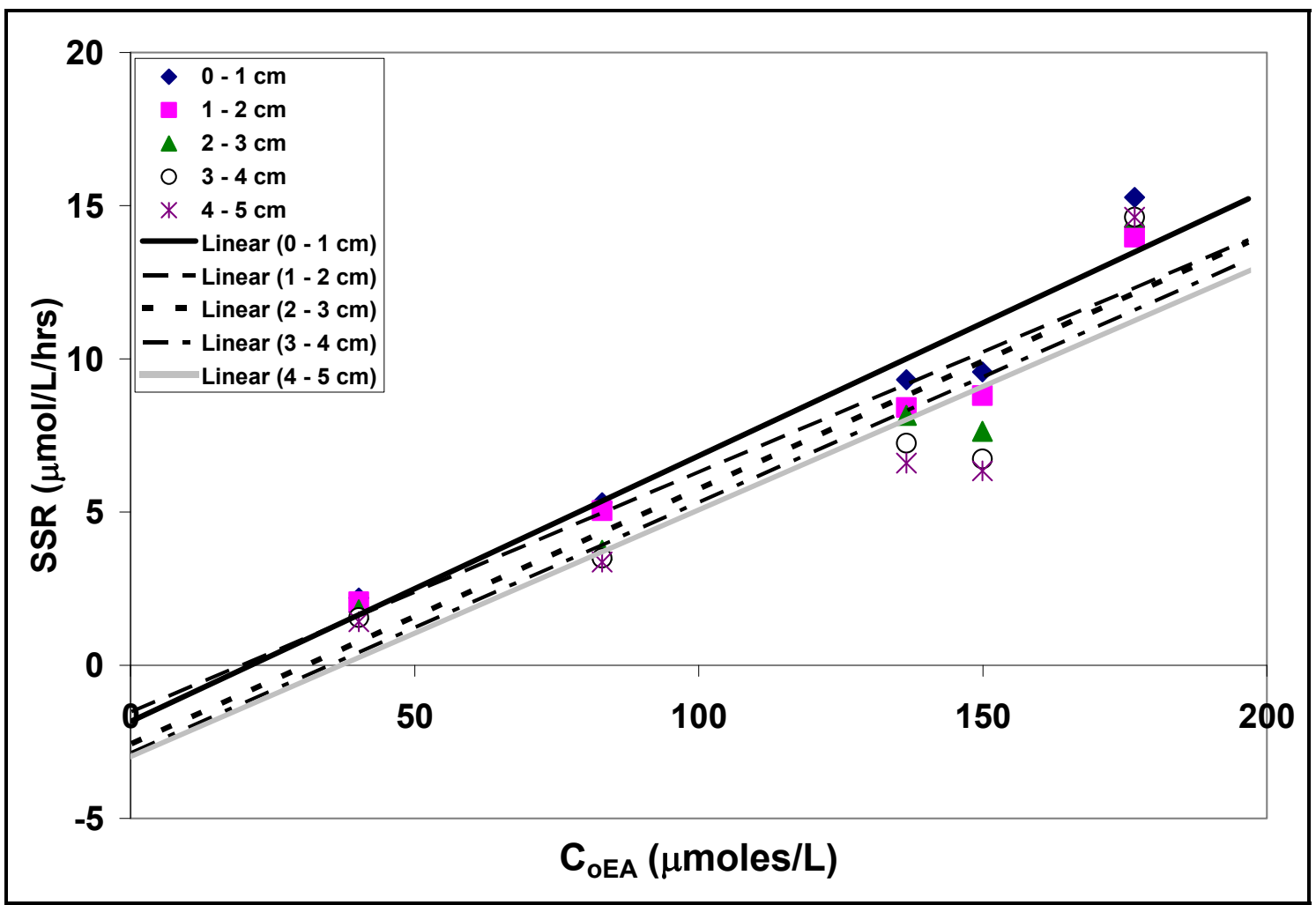

Figure 22: Steady state reduction rates for the untreated group in the plug-flow through experiment plotted against estimated steady state dissolved oxygen concentrations $\left(\mathrm{C}_{\mathrm{oEA}}\right)$ as a function of depth, average $\mathrm{R}^{2}=0.8635$. 


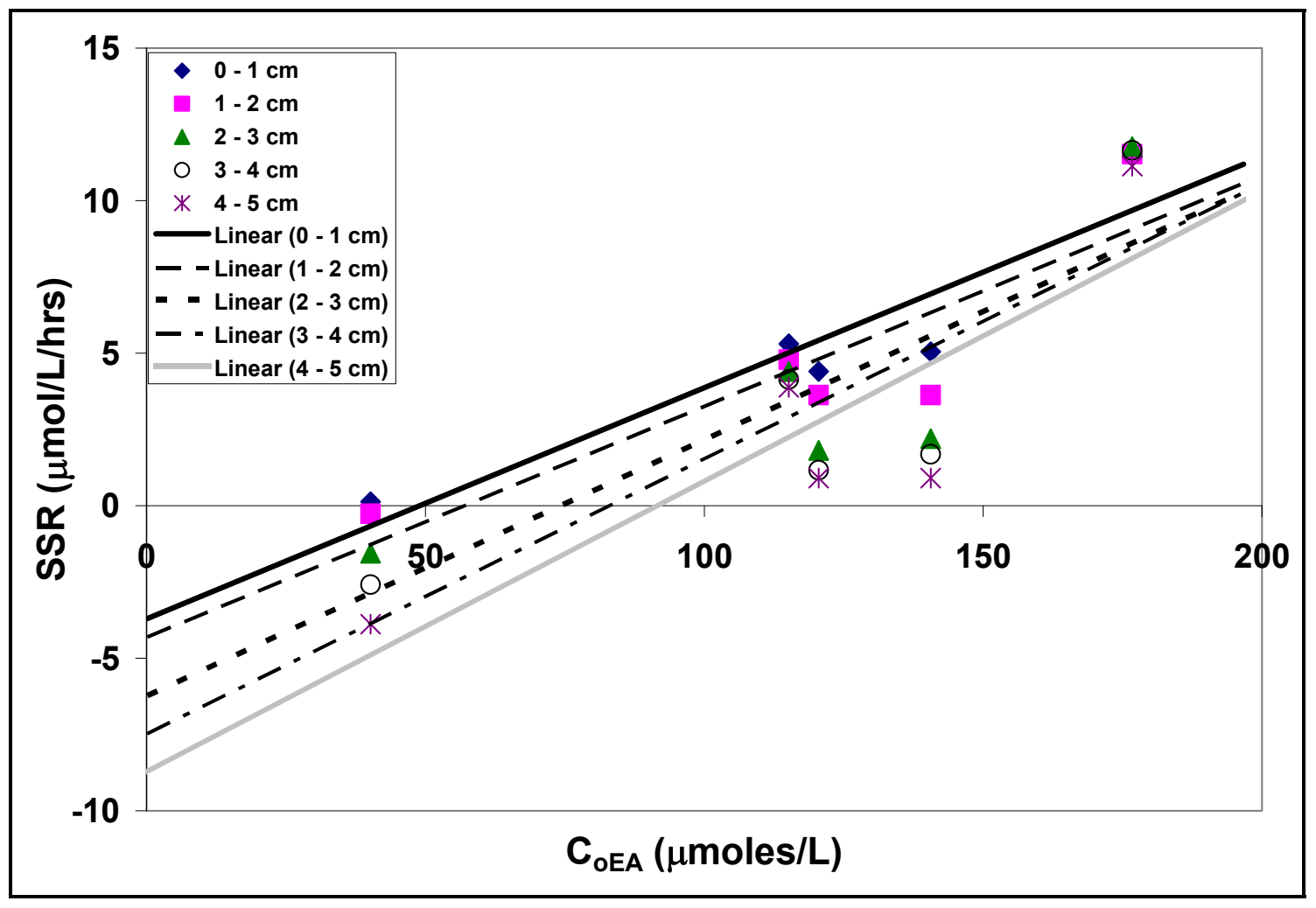

Figure 23: Steady state reduction rates for the azide treated group in the plug-flow through experiment plotted against estimated steady state dissolved oxygen concentrations $\left(\mathrm{C}_{\mathrm{OEA}}\right)$ and as a function of depth, average $\mathrm{R}^{2}=0.7688$. 


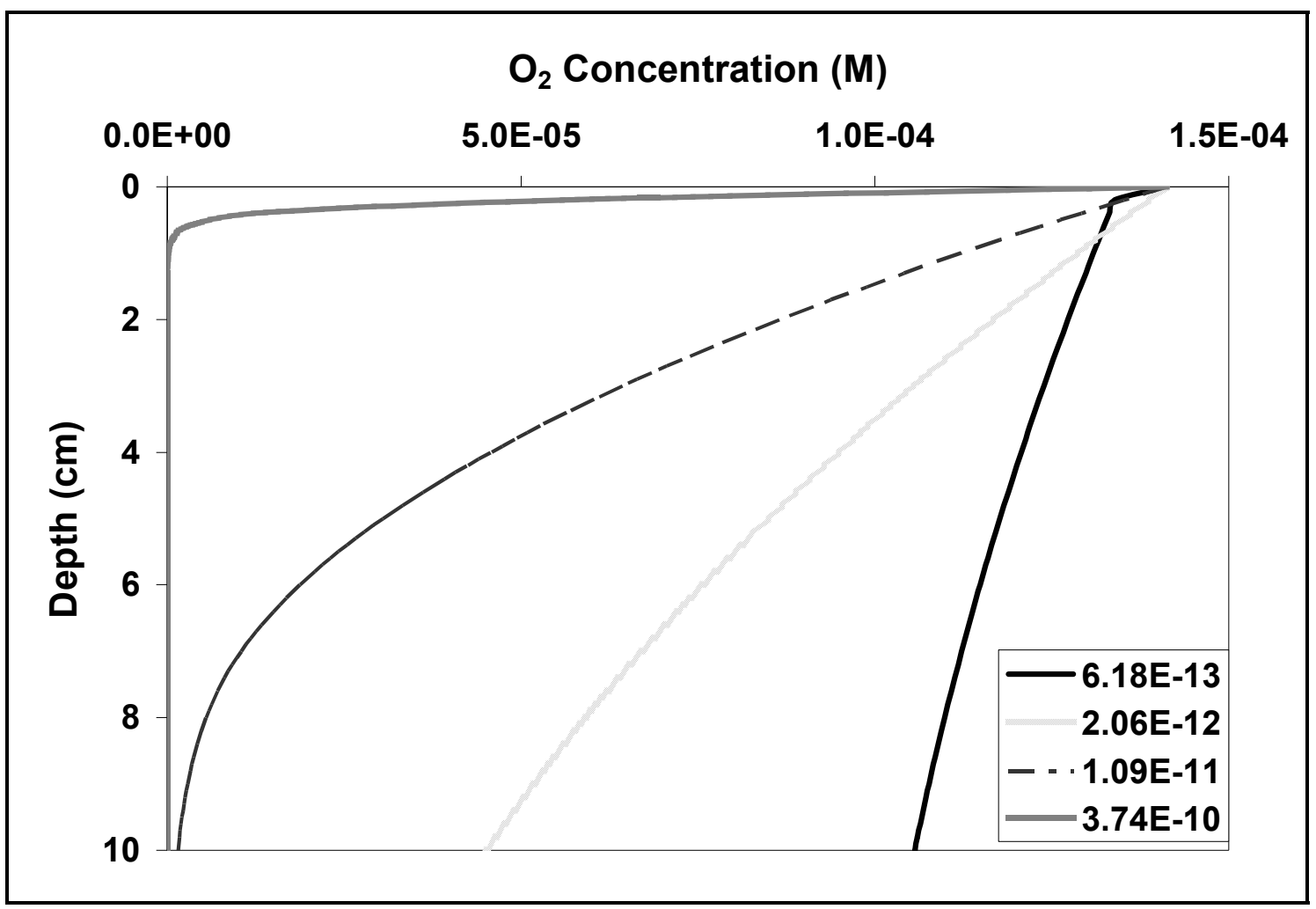

Figure 24: Sensitivity analysis for the resulting dissolved oxygen profile of the BRNS model based off imposed SOD in units of moles $/ \mathrm{cm}^{2} / \mathrm{sec}$. 


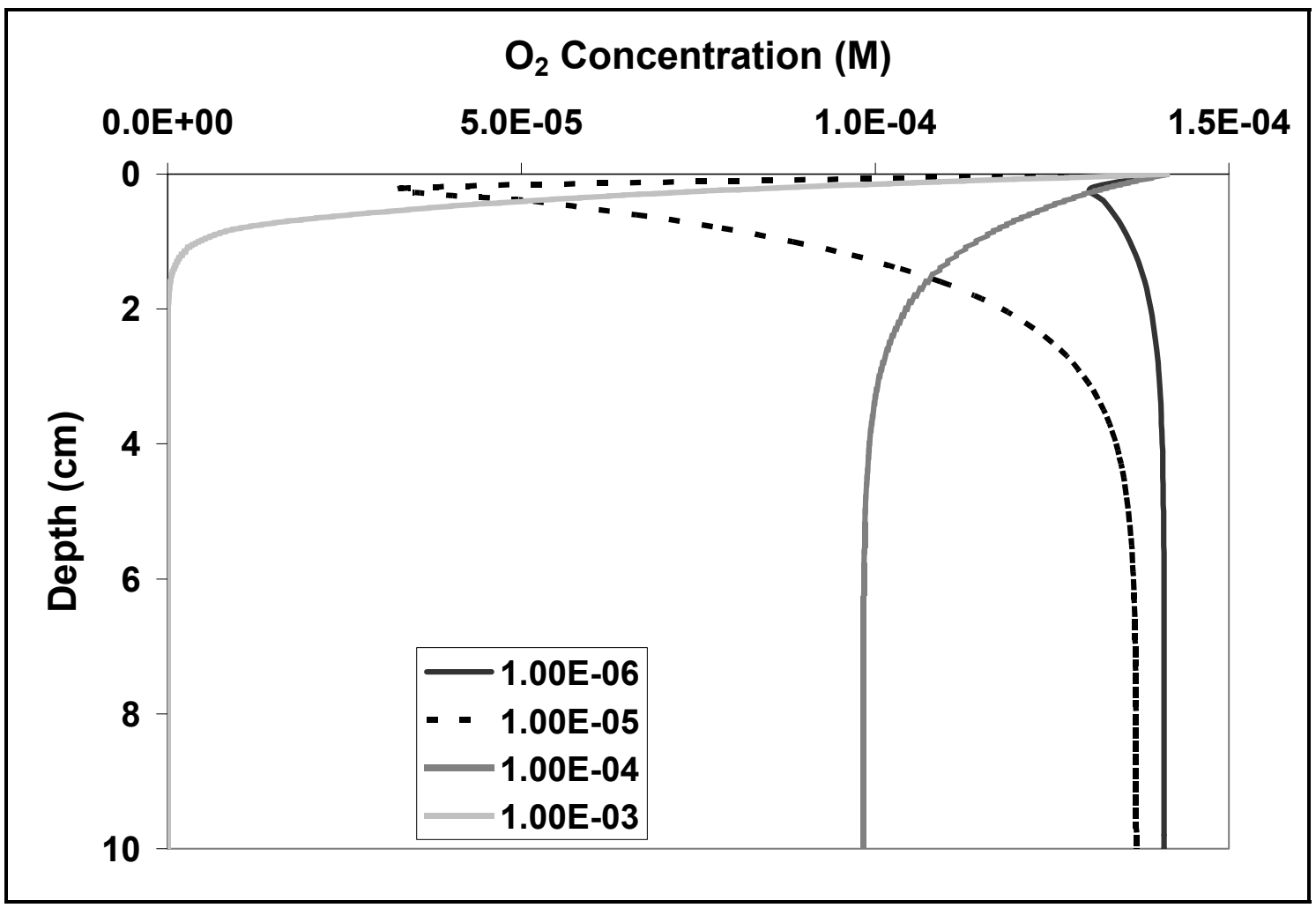

Figure 25: Sensitivity analysis for the resulting dissolved oxygen profile of the BRNS model based off concentration of organic matter in units of moles/g solid. 
Figure 26: BRNS model results: (a) oxygen profile, (b) ammonium, nitrate, and sulfate profiles, (c) solid iron profile, (d) solid manganese profile, and (e) soluble iron and manganese profiles.

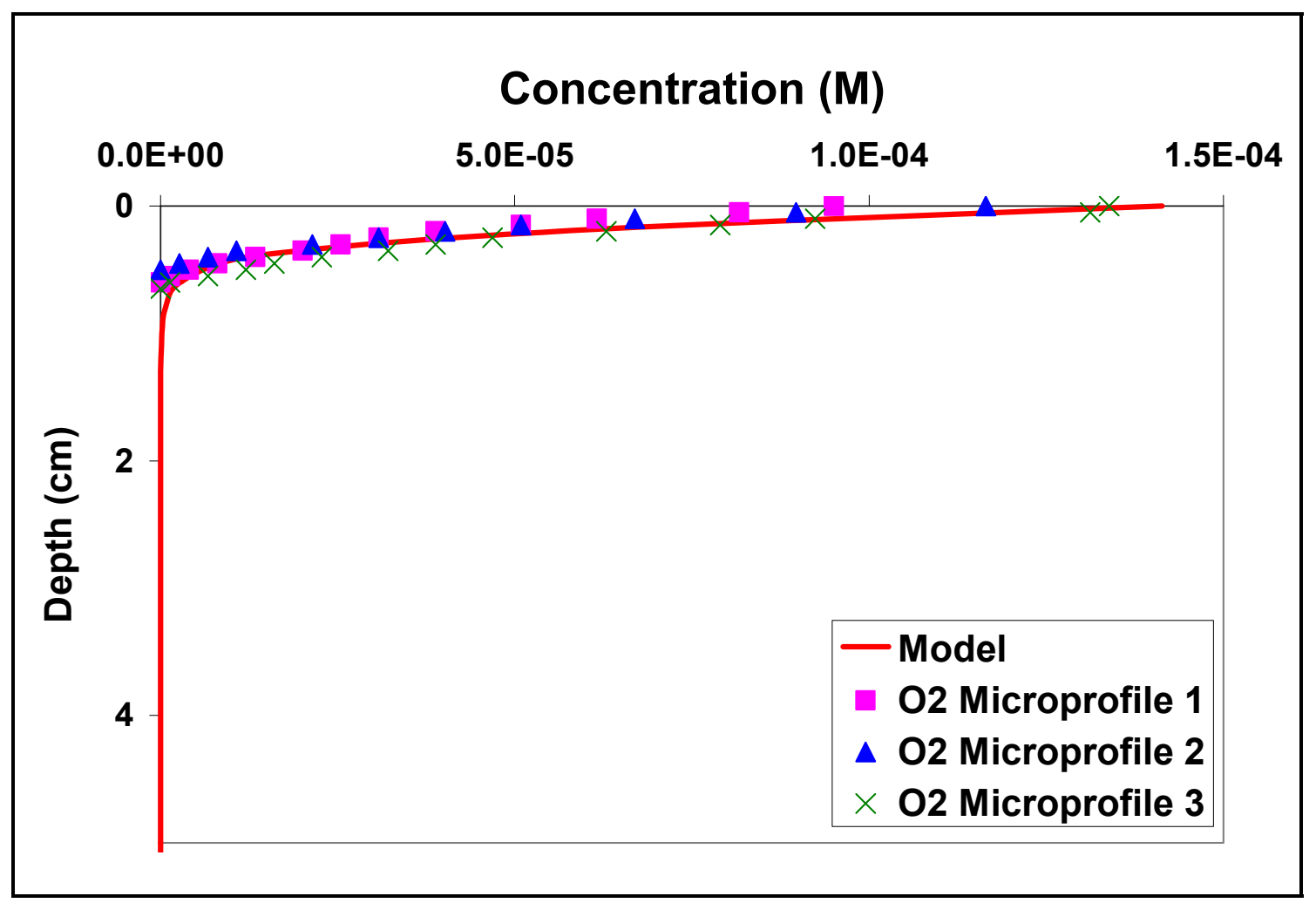

a). BRNS model results for dissolved $\mathrm{O}_{2}$. 


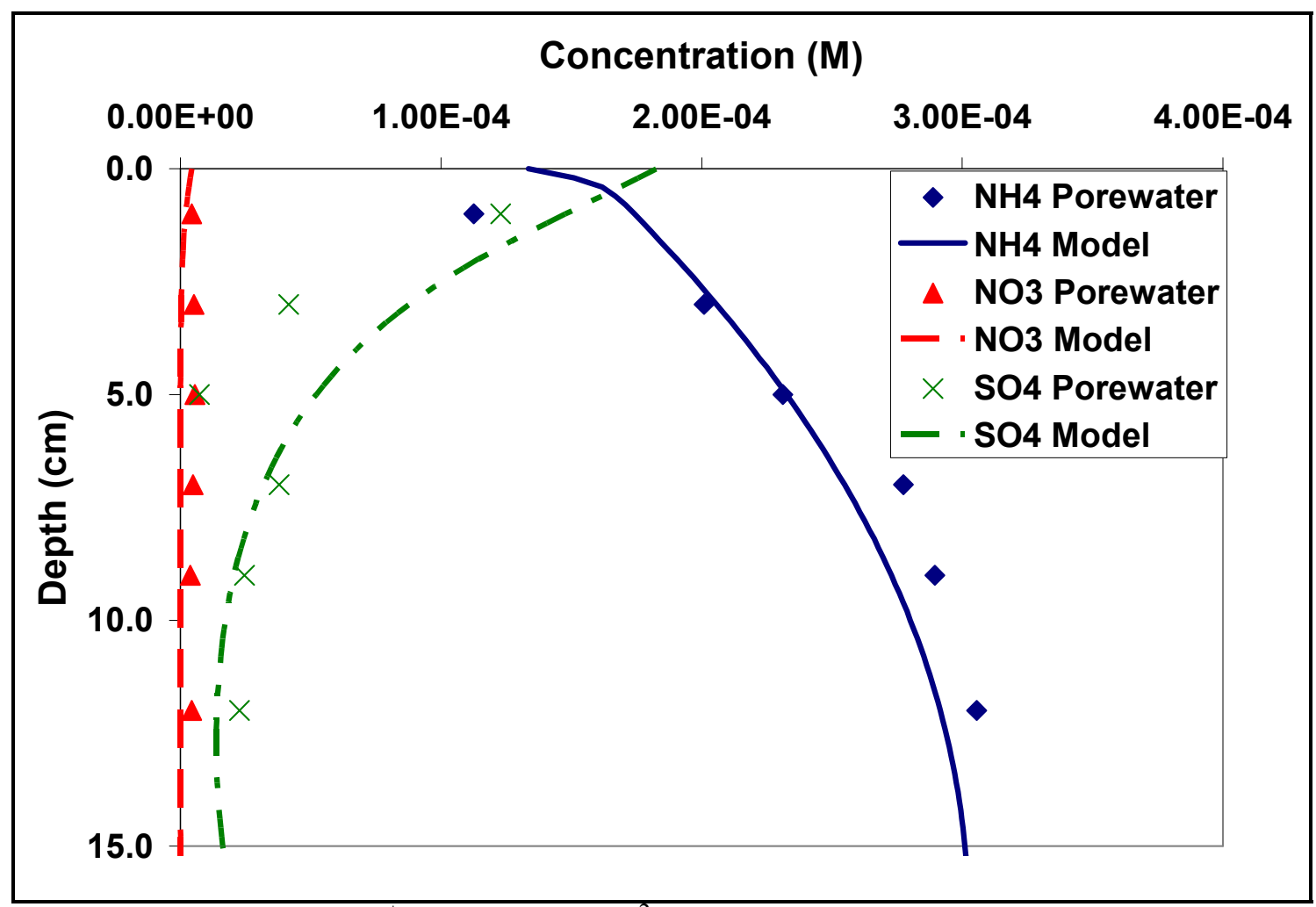

b). BRNS results for $\mathrm{NH}_{4}{ }^{+}, \mathrm{NO}_{3}{ }^{-}$, and $\mathrm{SO}_{4}{ }^{-2}$.

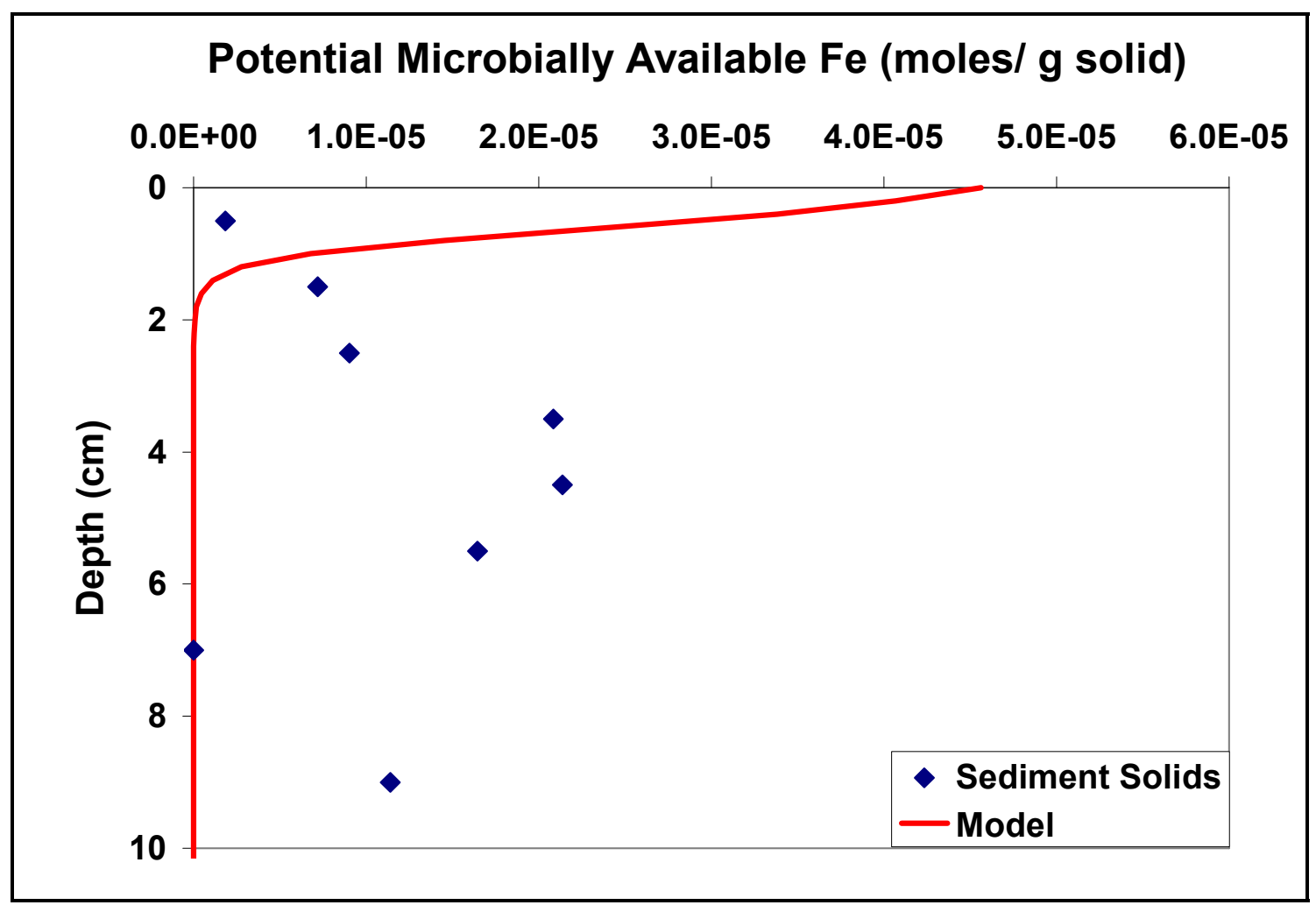

c). BRNS model results for solid-phase iron. 


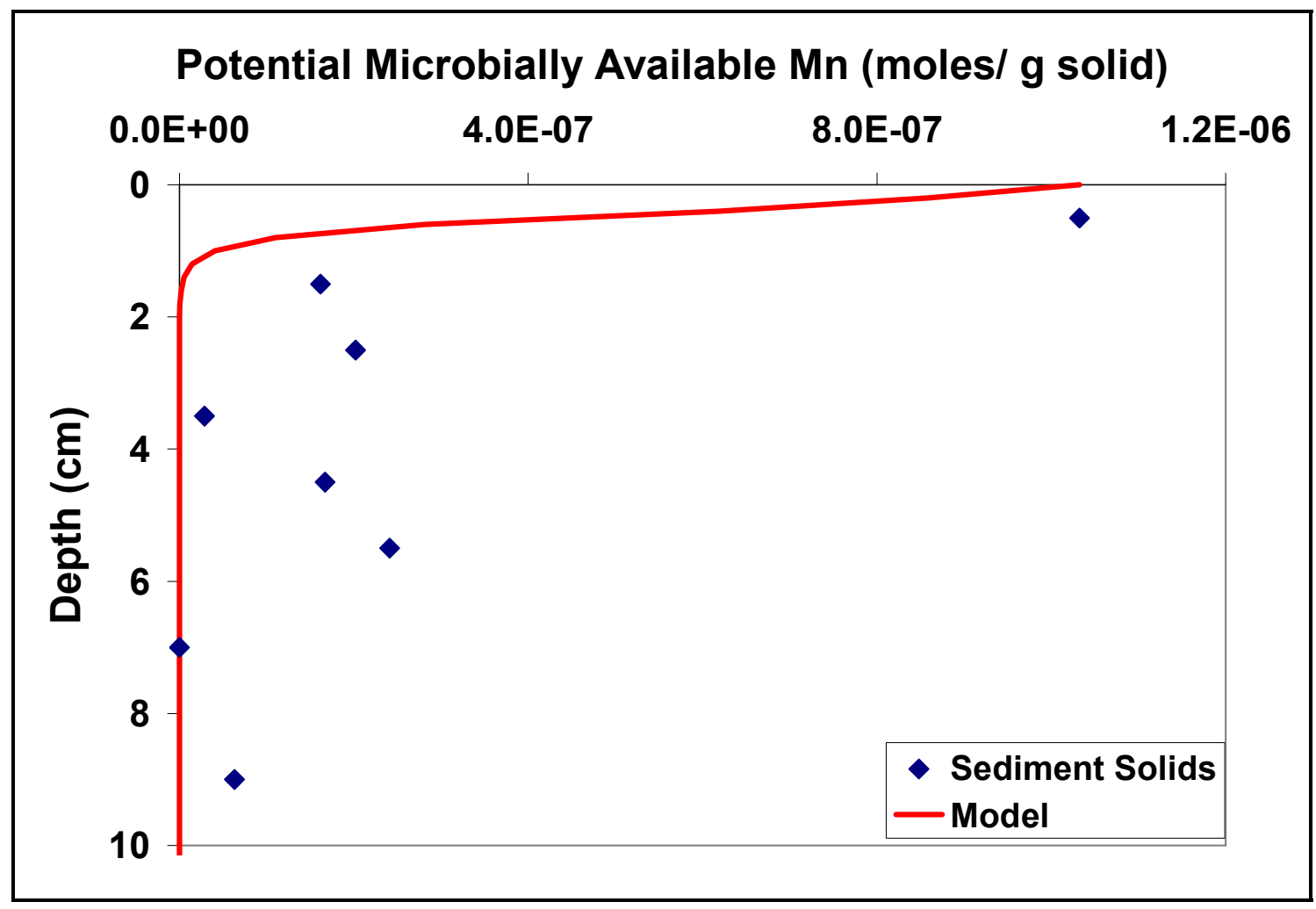

d). BRNS model results for solid phase manganese.

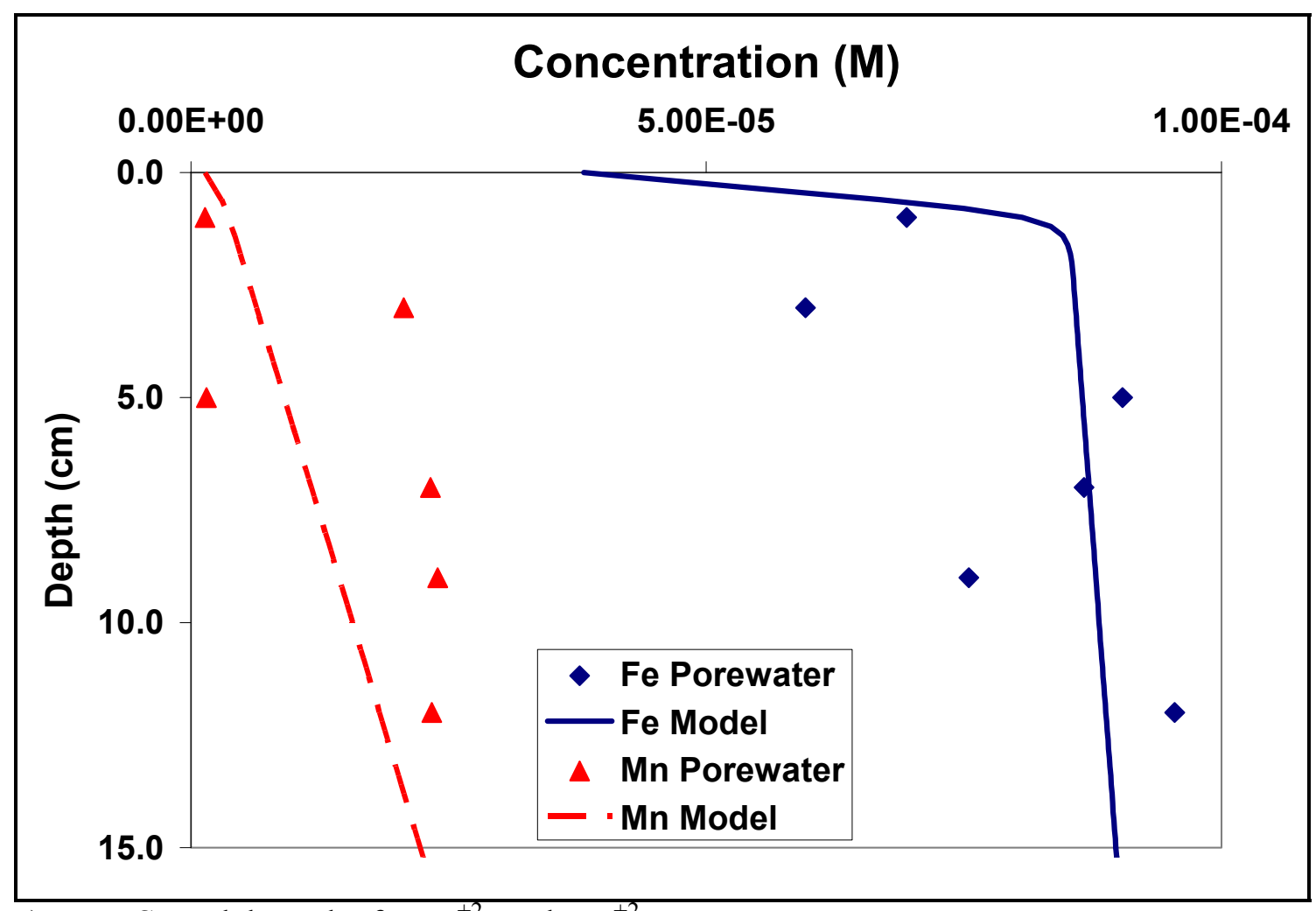

e). BRNS model results for $\mathrm{Fe}^{+2}$, and $\mathrm{Mn}^{+2}$. 


\begin{tabular}{|c|c|c|c|}
\hline $\begin{array}{l}\text { SOD } \\
\left(\mathrm{g} \mathrm{O}_{2} / \mathrm{m}^{2} / \mathrm{d}\right)\end{array}$ & $\begin{array}{c}\text { SOD } \\
\left(\times 10^{-12} \text { moles }\right. \\
\left.\mathrm{O}_{2} / \mathrm{cm}^{2} / \mathrm{sec}\right) \\
\end{array}$ & Method & Reference \\
\hline 0.888 & 32.1 & dark chamber & Herdendorf (1980) \\
\hline 0.360 & 13.0 & chamber experiments & $\begin{array}{l}\text { Lucas and Thomas } \\
\qquad(1972)\end{array}$ \\
\hline $0.2-0.3$ & $7.23-10.9$ & dome chamber experiment & $\begin{array}{l}\text { Snodgrass (1987) } \\
\text { Blanton and }\end{array}$ \\
\hline 0.28 and 0.32 & $10.85-11.6$ & - & Winkhofer (1972) \\
\hline 0.290 & 10.5 & modeling & $\begin{array}{l}\text { DiToro (1980) } \\
\text { Matisoff and }\end{array}$ \\
\hline 0.229 & 8.29 & $\begin{array}{l}\text { O2 diffusion model } \\
\text { flow-through experiment biocide }\end{array}$ & Neeson (2005) \\
\hline 0.0598 & 2.16 & $\begin{array}{c}(0-5 \mathrm{~cm}) \\
\text { flow-through experiment }\end{array}$ & this work \\
\hline 0.112 & 4.04 & $\begin{array}{l}\text { untreated }(0-5 \mathrm{~cm}) \\
\text { flow-through experiment }\end{array}$ & this work \\
\hline 0.128 & 4.63 & untreated $(0-1 \mathrm{~cm})$ & this work \\
\hline 0.103 & 3.47 & BRNS model $(0-5 \mathrm{~cm})$ & this work \\
\hline 0.218 & 7.87 & $\begin{array}{l}\text { BRNS model }(0-10 \mathrm{~cm}) \\
\text { whole core incubation }\end{array}$ & this work \\
\hline 0.204 & 7.40 & (average) & this work \\
\hline
\end{tabular}

Table 6: SOD for Lake Erie, as reported by Snodgrass (1987) and the current work. 


\section{Appendix}

\section{Determination of $\mathrm{Fe}^{+2}$ (Ferrozine Method)}

\section{Reagents}

1. $6 \mu \mathrm{M}$ ferrozine: dissolve $3.06 \mathrm{~g}$ ferrozine in $100 \mathrm{~mL}$ deionized water (DI)

2. $1 \mathrm{M} \mathrm{NaAc}$ - HAc buffer, $\mathrm{pH}$ 3.6: $51.7 \mathrm{~mL}$ glacial acetic acid and $100 \mathrm{~mL} 1 \mathrm{M}$ sodium acetate, diluted to $1 \mathrm{~L}$

3. $10 \% \mathrm{NH}_{2} \mathrm{OH} \cdot \mathrm{HCl}$ - hydroxylamine hydrochloride

4. 15 ppm Fe standard: dilute $15 \mathrm{~mL} 100 \mathrm{ppm}$ Fe to $100 \mathrm{~mL}$ with DI

5. $0.1 \mathrm{~N} \mathrm{HCl}: 82.5 \mathrm{~mL}$ of $12 \mathrm{M} \mathrm{HCl}$ diluted to $1 \mathrm{~L}$

\section{Procedure}

1. Make a mixed reagent solution as follows: $0.4 \mathrm{~mL} 6 \mu \mathrm{M}$ ferrozine, $1.6 \mathrm{~mL} \mathrm{DI}$,

$2.0 \mathrm{~mL} 0.1 \mathrm{~N} \mathrm{HCl}$, and $2.0 \mathrm{~mL} 10 \% \mathrm{NH}_{2} \mathrm{OH} \cdot \mathrm{HCl}$

2. In a test tube mix $6 \mathrm{~mL}$ of mixed reagent and $0.6 \mathrm{~mL}$ of sample, standard, or blank (DI)

3. Wait 5-10 minutes, then add $1 \mathrm{~mL}$ of $1 \mathrm{M} \mathrm{NaAc}-$ HAc buffer, mix

4. Read absorbance on UV/Vis after 5 minutes at $562 \mathrm{~nm}$

5. Construct a calibration curve through the known $0-15 \mathrm{ppm}$ standards and fit a linear regression through the standards. Calculate the concentration of the unknown samples from the regression curve. 


\section{Determination of Total Carbonate Alkalinity}

\section{Apparatus}

Microburet, small vials, magnetic stir bars, magnetic stir plate, $1 \mu \mathrm{L}$ pipet gun and $\mathrm{P} 20$ pipet gun

\section{Reagents}

1. Titrant: $0.02 \mathrm{~N} \mathrm{HCl}$

2. Indicator: Mixed broncresol green - methyl red indicator solution

3. Standard: $0.002 \mathrm{~N} \mathrm{Na}_{2} \mathrm{CO}_{3}$, made by diluting $0.02 \mathrm{~N}$ stock solution

\section{Procedure}

4. $\mathrm{pH}$ buffers: $\mathrm{pH} 4.6$ and $\mathrm{pH} 4.8$

1. Pipet $1 \mathrm{~mL}$ of $\mathrm{pH} 4.6$ buffer into 1 vial, and $1 \mathrm{~mL}$ of $\mathrm{pH} 4.8$ buffer into a separate vial

2. Add $20 \mu \mathrm{L}$ of indicator. The endpoint of the titration is less pink than the $\mathrm{pH}$ 4.6 buffer and more purple than the $\mathrm{pH} 4.8$ buffer.

3. Pipet $1 \mu \mathrm{L}$ of sodium carbonate, DI, and sample into labeled separate vials

4. Pipet $20 \mu \mathrm{L}$ of indicator into each of these vials

5. Place a clean magnetic stir bar into each vial

6. Place the vial containing DI and indicator on the center of the stir plate and set speed of stirring to a moderate rate. From the graduated buret, add $0.2 \mathrm{~N}$ $\mathrm{HCl}$ drop-wise to the vial and record the number of $\mu \mathrm{L}$ required to reach the endpoint (delta $\mathrm{V}$ )

7. Follow the same procedure for the standard. The number of $\mu \mathrm{L}$ of $\mathrm{HCl}$ is the amount required to neutralize $0.002 \mathrm{~N}$ or $2 \mathrm{meq} / \mathrm{L}$ of $\mathrm{Na}_{2} \mathrm{CO}_{3}$. From this relationship the alkalinity of the sample is calculated from the measured amount of the titrant needed to reach the equivalence point.

8. Follow the same procedure for each sample recording the delta v's.

9. Calculate the total carbonate alkalinity from the known ratio of delta $\mathrm{v} /(2 \mathrm{meq} / \mathrm{l})$

$\frac{2 \mathrm{meq} / \mathrm{LNa} \mathrm{CO}_{3}}{? \mathrm{mLHCl}(\text { standard })} \bullet ? \mathrm{mLHCl}($ sample $) \bullet \frac{1 e q \mathrm{HCO}_{3}}{2 e q \mathrm{CO}_{3}}=? \mathrm{mMoles}_{3} / \mathrm{HCO}_{3}$ 


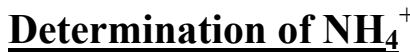

\section{Reagents}

1. Alkaline solution $-100 \mathrm{~g}$ trisodium citrate and $5 \mathrm{~g} \mathrm{NaOH}$ in $500 \mathrm{~mL}$ DI

2. Phenol $-10 \mathrm{~g}$ phenol in $100 \mathrm{~mL}$ ethanl

3. Nitroprusside $-1 \mathrm{~g}$ sodium nitroprusside in $200 \mathrm{~mL}$ DI (light sensitive)

4. $\mathrm{NaOCl}$ (Chlorox) kept refrigerated

5. Oxidizing solution - prepared just prior to use from 4 parts alkaline solution (1) and 1 part (4)

6. Stock standard $-10,000 \mu \mathrm{M} \mathrm{NH}_{4}-$ nitrogen $(0.5353 \mathrm{~g}$ of oven dried and dessicated $\mathrm{NH}_{4} \mathrm{Cl}$ in $1,000 \mathrm{~mL}$ DI)

7. Secondary standards $-20,50,100 \mu \mathrm{M}$. Dilute $10,000 \mu \mathrm{M}$ stock.

\section{Procedure}

1. Pipet $5 \mathrm{~mL}$ of standards, blank (DI), or diluted $(\sim 1: 10)$ sample into test tubes

2. Add with mixing between each addition (Note: order of addition is crucial):

$0.2 \mathrm{~mL}$ phenol, $0.2 \mathrm{~mL}$ nitroprusside, $0.5 \mathrm{~mL}$ oxidizing solution

3. Wait at least $1 \mathrm{hr}$, but no more than $24 \mathrm{hrs}$, before reading absorbance on a

$\mathrm{UV} / \mathrm{V}$ is at $640 \mathrm{m \mu}$ 


\begin{tabular}{|c|c|c|c|c|c|c|}
\hline $\begin{array}{c}\text { Depth } \\
\text { (cm) }\end{array}$ & $\begin{array}{l}\text { D.O. } \\
\text { (M) }\end{array}$ & $\mathrm{NO}_{3}^{-}(\mathrm{M})$ & $\begin{array}{l}\text { D.O. } \\
\text { (M) }\end{array}$ & $\mathrm{NO}_{3}^{-}(\mathrm{M})$ & $\begin{array}{l}\text { D.O. } \\
\text { (M) }\end{array}$ & $\mathrm{NO}_{3}^{-}(\mathrm{M})$ \\
\hline-0.5 & 0.000157 & 0.000123 & 0.000134 & 0.000100297 & 0.000133 & 0.000155 \\
\hline-0.1 & 0.000155 & $9.13 \mathrm{E}-05$ & 0.000134 & 0.000104349 & 0.000135 & 0.000134 \\
\hline-0.05 & 0.000155 & $8.91 \mathrm{E}-05$ & 0.000119 & 0.000100795 & 0.000131 & 0.000132 \\
\hline 0 & 0.000134 & $8.6 \mathrm{E}-05$ & $9.51 \mathrm{E}-05$ & $9.54539 \mathrm{E}-05$ & 0.000116 & 0.000122 \\
\hline 0.05 & 0.000131 & $8.86 \mathrm{E}-05$ & $8.17 \mathrm{E}-05$ & 0.000101295 & $8.97 \mathrm{E}-05$ & 0.000123 \\
\hline 0.1 & $9.24 \mathrm{E}-05$ & $8.95 \mathrm{E}-05$ & $6.16 \mathrm{E}-05$ & 0.000104866 & $6.69 \mathrm{E}-05$ & 0.000126 \\
\hline 0.15 & $7.9 \mathrm{E}-05$ & $9.08 \mathrm{E}-05$ & $5.09 \mathrm{E}-05$ & 0.000108563 & $5.09 \mathrm{E}-05$ & 0.000129 \\
\hline 0.2 & $6.29 \mathrm{E}-05$ & $9.17 \mathrm{E}-05$ & $3.88 \mathrm{E}-05$ & 0.000109643 & $4.02 \mathrm{E}-05$ & 0.000131 \\
\hline 0.25 & $4.69 \mathrm{E}-05$ & $9.31 \mathrm{E}-05$ & $3.08 \mathrm{E}-05$ & 0.000110734 & $3.08 \mathrm{E}-05$ & 0.000132 \\
\hline 0.3 & $3.88 \mathrm{E}-05$ & $9.4 \mathrm{E}-05$ & $2.54 \mathrm{E}-05$ & 0.000111284 & $2.14 \mathrm{E}-05$ & 0.000132 \\
\hline 0.35 & $3.21 \mathrm{E}-05$ & $9.45 \mathrm{E}-05$ & $2.01 \mathrm{E}-05$ & 0.000109643 & $1.07 \mathrm{E}-05$ & 0.000136 \\
\hline 0.4 & $2.28 \mathrm{E}-05$ & $9.5 \mathrm{E}-05$ & $1.34 \mathrm{E}-05$ & 0.000108563 & $6.69 \mathrm{E}-06$ & 0.000138 \\
\hline 0.45 & $1.61 \mathrm{E}-05$ & $9.55 \mathrm{E}-05$ & $8.03 \mathrm{E}-06$ & 0.000106435 & $2.68 \mathrm{E}-06$ & 0.000139 \\
\hline 0.5 & $1.2 \mathrm{E}-05$ & $9.59 \mathrm{E}-05$ & $4.02 \mathrm{E}-06$ & 0.000104349 & 0 & 0.00014 \\
\hline 0.55 & $6.69 \mathrm{E}-06$ & $9.59 \mathrm{E}-05$ & $1.34 \mathrm{E}-06$ & 0.000102811 & & 0.00014 \\
\hline 0.6 & $1.34 \mathrm{E}-06$ & $9.64 \mathrm{E}-05$ & 0 & 0.000100795 & & 0.000141 \\
\hline 0.65 & 0 & $9.74 \mathrm{E}-05$ & & 9.93094E-05 & & 0.000142 \\
\hline 0.7 & & $9.83 \mathrm{E}-05$ & & $9.73626 \mathrm{E}-05$ & & 0.00014 \\
\hline 0.75 & & $9.78 \mathrm{E}-05$ & & $9.64035 \mathrm{E}-05$ & & 0.00014 \\
\hline 0.8 & & $9.78 \mathrm{E}-05$ & & $9.4047 \mathrm{E}-05$ & & 0.000138 \\
\hline 0.85 & & $9.64 \mathrm{E}-05$ & & & & \\
\hline 0.9 & & $9.64 \mathrm{E}-05$ & & $9.1748 \mathrm{E}-05$ & & 0.000136 \\
\hline 0.95 & & $9.74 \mathrm{E}-05$ & & & & \\
\hline 1 & & $9.22 \mathrm{E}-05$ & & $8.8186 \mathrm{E}-05$ & & 0.000134 \\
\hline 1.1 & & $9.17 \mathrm{E}-05$ & & $8.60304 \mathrm{E}-05$ & & 0.000134 \\
\hline 1.2 & & $9.13 \mathrm{E}-05$ & & $8.22821 \mathrm{E}-05$ & & 0.000132 \\
\hline 1.3 & & $8.91 \mathrm{E}-05$ & & 7.67734E-05 & & 0.000127 \\
\hline 1.4 & & $8.82 \mathrm{E}-05$ & & $7.56418 \mathrm{E}-05$ & & 0.000123 \\
\hline 1.5 & & $8.82 \mathrm{E}-05$ & & $7.34284 \mathrm{E}-05$ & & 0.000119 \\
\hline 1.6 & & $8.56 \mathrm{E}-05$ & & $7.09279 \mathrm{E}-05$ & & 0.000116 \\
\hline 1.7 & & $8.43 \mathrm{E}-05$ & & $6.78376 \mathrm{E}-05$ & & 0.000112 \\
\hline 1.8 & & $8.35 \mathrm{E}-05$ & & $6.65077 \mathrm{E}-05$ & & 0.000106 \\
\hline 1.9 & & 7.91E-05 & & $6.65077 \mathrm{E}-05$ & & 0.000102 \\
\hline 2 & & $7.68 \mathrm{E}-05$ & & $6.45616 \mathrm{E}-05$ & & $9.78 \mathrm{E}-05$ \\
\hline 2.1 & & 7.49E-05 & & $6.361 \mathrm{E}-05$ & & $9.59 \mathrm{E}-05$ \\
\hline 2.2 & & $7.53 \mathrm{E}-05$ & & $6.48819 \mathrm{E}-05$ & & $9.13 \mathrm{E}-05$ \\
\hline 2.3 & & & & $6.65077 \mathrm{E}-05$ & & $8.86 \mathrm{E}-05$ \\
\hline 2.4 & & & & $6.61793 \mathrm{E}-05$ & & $8.56 \mathrm{E}-05$ \\
\hline 2.5 & & & & $6.26724 \mathrm{E}-05$ & & $8.35 \mathrm{E}-05$ \\
\hline 2.6 & & & & & & $8.23 \mathrm{E}-05$ \\
\hline 2.7 & & & & & & $7.95 \mathrm{E}-05$ \\
\hline 2.8 & & & & & & $7.75 \mathrm{E}-05$ \\
\hline
\end{tabular}

Table displaying values of dissolved oxygen and nitrate, in moles/L, microprofiles. 


\begin{tabular}{|c|c|c|c|c|c|c|}
\hline $\begin{array}{c}\text { Depth } \\
\text { (cm) }\end{array}$ & $\mathbf{p H}$ & $\mathbf{S}^{-2}(\mathrm{M})$ & $\mathbf{p H}$ & $S^{-2}(M)$ & pH & $\mathbf{S}^{-2}(\mathrm{M})$ \\
\hline-0.5 & 7.295 & $4.58 \mathrm{E}-10$ & 7.139 & $6.6 \mathrm{E}-10$ & 7.122 & $2.29 \mathrm{E}-09$ \\
\hline-0.1 & 7.329 & $4.3 \mathrm{E}-10$ & 7.348 & $5.64 \mathrm{E}-10$ & 7.292 & $2.22 \mathrm{E}-09$ \\
\hline 0 & 7.207 & $4.84 \mathrm{E}-10$ & 7.381 & $5.99 \mathrm{E}-10$ & 7.389 & 2.09E-09 \\
\hline 0.1 & 7.081 & $4.52 \mathrm{E}-10$ & 7.31 & $6.57 \mathrm{E}-10$ & 7.411 & $1.98 \mathrm{E}-09$ \\
\hline 0.2 & 7.21 & $4.43 \mathrm{E}-10$ & 7.2 & $2.64 \mathrm{E}-09$ & 7.303 & $2.16 \mathrm{E}-09$ \\
\hline 0.3 & 7.322 & $5.1 \mathrm{E}-10$ & 7.253 & $9.07 \mathrm{E}-09$ & 6.78 & $2.89 \mathrm{E}-09$ \\
\hline 0.4 & 7.5 & $5.88 \mathrm{E}-10$ & 7.345 & $2.42 \mathrm{E}-08$ & 7.101 & $3.15 \mathrm{E}-09$ \\
\hline 0.5 & 7.403 & $6.4 \mathrm{E}-10$ & 7.404 & $5.76 \mathrm{E}-08$ & 7.136 & 3.39E-09 \\
\hline 0.6 & 7.5 & $6.41 \mathrm{E}-10$ & 7.398 & 9.82E-08 & 7.226 & 3.59E-09 \\
\hline 0.7 & 7.42 & $7.38 \mathrm{E}-10$ & 7.325 & $1.43 \mathrm{E}-07$ & 7.303 & $3.78 \mathrm{E}-09$ \\
\hline 0.8 & 7.444 & $8.61 \mathrm{E}-10$ & 7.162 & $2.1 \mathrm{E}-07$ & 7.295 & $3.95 \mathrm{E}-09$ \\
\hline 0.9 & 7.462 & $9.46 \mathrm{E}-10$ & 7.422 & $4.26 \mathrm{E}-07$ & 7.25 & 4.07E-09 \\
\hline 1 & 7.445 & $9.81 \mathrm{E}-10$ & 7.31 & $4.16 \mathrm{E}-07$ & 7.226 & $4.18 \mathrm{E}-09$ \\
\hline 1.2 & 7.5 & $9.61 \mathrm{E}-10$ & 7.254 & $2.58 \mathrm{E}-07$ & 7.296 & $4.2 \mathrm{E}-09$ \\
\hline 1.4 & 7.457 & $9.66 \mathrm{E}-10$ & 7.627 & $1.62 \mathrm{E}-07$ & 7.38 & $4.25 \mathrm{E}-09$ \\
\hline 1.6 & 7.415 & $9.91 \mathrm{E}-10$ & 7.257 & $1.33 \mathrm{E}-07$ & 7.457 & 4.32E-09 \\
\hline 1.8 & 7.385 & $9 \mathrm{E}-10$ & 7.306 & $1.13 \mathrm{E}-07$ & 7.447 & $4.48 \mathrm{E}-09$ \\
\hline 2 & 7.347 & $9.89 \mathrm{E}-10$ & 7.004 & $9.28 \mathrm{E}-08$ & 7.471 & 4.91E-09 \\
\hline 2.2 & 7.33 & $1.01 \mathrm{E}-09$ & 7.15 & $4.83 \mathrm{E}-08$ & 7.399 & $5.42 \mathrm{E}-09$ \\
\hline 2.4 & 7.293 & $1.03 \mathrm{E}-09$ & 7.22 & $4.73 \mathrm{E}-08$ & 7.329 & 5.82E-09 \\
\hline 2.6 & 7.275 & $1.05 \mathrm{E}-09$ & 7.195 & $4.73 \mathrm{E}-08$ & 7.385 & $6.15 \mathrm{E}-09$ \\
\hline 2.8 & 6.954 & $1.08 \mathrm{E}-09$ & 7.228 & $4.71 \mathrm{E}-08$ & 7.359 & $6.58 \mathrm{E}-09$ \\
\hline 3 & 7.191 & $1.1 \mathrm{E}-09$ & 7.242 & $3.76 \mathrm{E}-08$ & 7.381 & $6.88 \mathrm{E}-09$ \\
\hline 3.5 & 7.195 & $1.12 \mathrm{E}-09$ & 7.195 & $4.65 \mathrm{E}-08$ & 7.372 & 7.44E-09 \\
\hline 4 & 7.094 & $1.16 \mathrm{E}-09$ & 7.158 & $2.51 \mathrm{E}-08$ & 7.323 & $7.63 \mathrm{E}-09$ \\
\hline 4.5 & 7.115 & 1.18E-09 & 7.187 & $3.87 \mathrm{E}-08$ & 7.4 & 7.79E-09 \\
\hline 5 & 7.018 & $1.14 \mathrm{E}-09$ & 7.225 & $4.65 \mathrm{E}-08$ & 7.353 & 7.94E-09 \\
\hline 5.5 & 7.074 & $1.13 \mathrm{E}-09$ & 7.216 & $5.08 \mathrm{E}-08$ & 7.291 & 8.19E-09 \\
\hline 6 & 7.059 & 1.12E-09 & 7.125 & $6.77 \mathrm{E}-08$ & 7.281 & $7.65 \mathrm{E}-09$ \\
\hline 6.5 & 7.032 & $1.15 \mathrm{E}-09$ & 7.199 & $7.04 \mathrm{E}-08$ & 7.152 & $7.53 \mathrm{E}-09$ \\
\hline 7 & 7.025 & $1.12 \mathrm{E}-09$ & 7.2 & $7.28 \mathrm{E}-08$ & 7.265 & $7.55 \mathrm{E}-09$ \\
\hline 7.5 & 7.043 & $1.11 \mathrm{E}-09$ & 7.236 & $7.75 \mathrm{E}-08$ & 7.304 & 8.58E-09 \\
\hline 8 & 7.076 & $1.09 \mathrm{E}-09$ & 7.166 & 7.89E-08 & 7.359 & $8.74 \mathrm{E}-09$ \\
\hline 8.5 & 7.172 & $1.06 \mathrm{E}-09$ & 7.185 & $9.6 \mathrm{E}-08$ & 7.293 & $9.21 \mathrm{E}-09$ \\
\hline 9 & 7.163 & $1.07 \mathrm{E}-09$ & 7.177 & $1.23 \mathrm{E}-07$ & 7.197 & 8.52E-09 \\
\hline 9.5 & 7.146 & $1.01 \mathrm{E}-09$ & 7.165 & $6.38 \mathrm{E}-06$ & 7.203 & $1.23 \mathrm{E}-08$ \\
\hline 10 & 7.186 & $1.14 \mathrm{E}-09$ & & & 6.923 & $1.09 \mathrm{E}-08$ \\
\hline
\end{tabular}

Table of $\mathrm{pH}$ and sulfide (moles/L) concentrations in microprofiles. 


\begin{tabular}{|c|c|c|c|c|c|c|}
\hline $\begin{array}{r}\text { Depth } \\
\text { Interval } \\
(\mathbf{c m}) \\
\end{array}$ & {$\left[\mathrm{NO}_{3}\right](\mathrm{M})$} & $\mathrm{pH}$ & {$\left[\mathrm{S}^{-2}\right](\mathrm{M})$} & {$\left[\mathrm{Fe}^{+2}\right](\mathrm{M})$} & {$\left[\mathrm{NH}_{4}^{+}\right](\mathrm{M})$} & {$\left[\mathrm{SO}_{4}^{-2}\right](\mathrm{M})$} \\
\hline $0-2$ & 4.28E-06 & 7.16 & 8.63E-10 & 6.94E-05 & 0.000134 & 0.000123 \\
\hline $2-4$ & 5.19E-06 & 7.245 & 1.09E-09 & $6.09 E-05$ & 0.000184 & 4.16E-05 \\
\hline $4-6$ & 5.59E-06 & 7.195 & 1.04E-09 & $6.45 E-05$ & 0.000182 & 7.39E-06 \\
\hline $6-8$ & 4.87E-06 & 7.296 & 1E-09 & 7.66E-05 & 0.000209 & 3.79E-05 \\
\hline $8-10$ & 3.86E-06 & 7.309 & 9E-10 & 8.55E-05 & 0.000208 & 2.47E-05 \\
\hline $10-14$ & 4.28E-06 & 7.175 & 7.84E-10 & 7.79E-05 & 0.000229 & 2.27E-05 \\
\hline $14-18$ & $3.58 \mathrm{E}-06$ & 7.379 & 6.83E-10 & 8.73E-05 & 0.000256 & 5.63E-05 \\
\hline $18-22$ & 3.93E-06 & 6.992 & 7.23E-10 & 8.95E-05 & 0.000253 & 4.14E-05 \\
\hline $22-28$ & 4.23E-06 & 7.4 & 6.65E-10 & 8.1E-05 & 0.000282 & 3.82E-05 \\
\hline $34-40$ & 5.37E-06 & 7.304 & 5.87E-10 & 7.93E-05 & 0.000297 & 4.38E-05 \\
\hline
\end{tabular}

\begin{tabular}{|r|r|}
$\begin{array}{r}\text { Depth } \\
\text { Interval } \\
\text { (cm) }\end{array}$ & $\begin{array}{r}\text { Alkalinity } \\
\text { (mmoles/1 } \mathbf{H C O}_{\mathbf{3}} \text { ) }\end{array}$ \\
\hline $0-2$ & 1.136363636 \\
\hline $2-4$ & 1.327272727 \\
\hline $4-6$ & 1.327272727 \\
\hline $6-8$ & 1.245454545 \\
\hline $8-10$ & 1.2 \\
\hline $10-14$ & 1.318181818 \\
\hline $14-18$ & 1.336363636 \\
\hline $18-22$ & 1.381818182 \\
\hline $22-28$ & 1.436363636 \\
\hline $34-40$ & 1.572727273 \\
\hline
\end{tabular}

Molar concentrations for $\left[\mathrm{NO}_{3}{ }^{-}\right],\left[\mathrm{S}^{-2}\right],\left[\mathrm{Fe}^{+2}\right],\left[\mathrm{NH}_{4}{ }^{+}\right],\left[\mathrm{SO}_{4}^{-2}\right], \mathrm{pH}$ and total carbonate alkalinity $\left(\mathrm{mmoles} / \mathrm{HCO}_{3}\right)^{-}$) for each depth interval used for the porewater profiling. 


\begin{tabular}{|rrrrr|}
\hline $\begin{array}{r}\text { Depth } \\
\text { Interval (cm) }\end{array}$ & $\begin{array}{r}\text { Fe conc } \\
\text { (mol/g solid) }\end{array}$ & $\begin{array}{r}\text { Mn conc } \\
\text { (mol/g_solid) }\end{array}$ & $\begin{array}{r}\text { Microbially } \\
\text { Available Fe } \\
\text { (mol/g solid) }\end{array}$ & $\begin{array}{r}\text { Microbially } \\
\text { Available Mn } \\
\text { (mol/g_solid) }\end{array}$ \\
\hline $0-1$ & $4.56207 \mathrm{E}-05$ & $1.82227 \mathrm{E}-06$ & $1.84435 \mathrm{E}-06$ & $1.03252 \mathrm{E}-06$ \\
\hline $1-2$ & $5.0967 \mathrm{E}-05$ & $9.51803 \mathrm{E}-07$ & $7.19066 \mathrm{E}-06$ & $1.62051 \mathrm{E}-07$ \\
\hline $2-3$ & $5.28019 \mathrm{E}-05$ & $9.91895 \mathrm{E}-07$ & $9.02563 \mathrm{E}-06$ & $2.02144 \mathrm{E}-07$ \\
\hline $3-4$ & $6.46161 \mathrm{E}-05$ & $8.1843 \mathrm{E}-07$ & $2.08397 \mathrm{E}-05$ & $2.86778 \mathrm{E}-08$ \\
\hline $4-5$ & $6.51372 \mathrm{E}-05$ & $9.56611 \mathrm{E}-07$ & $2.13609 \mathrm{E}-05$ & $1.66859 \mathrm{E}-07$ \\
\hline $5-6$ & $6.02147 \mathrm{E}-05$ & $1.03092 \mathrm{E}-06$ & $1.64384 \mathrm{E}-05$ & $2.41167 \mathrm{E}-07$ \\
\hline $6-8$ & $4.37763 \mathrm{E}-05$ & $7.89752 \mathrm{E}-07$ & 0 & 0 \\
\hline $8-10$ & $5.51767 \mathrm{E}-05$ & $8.52649 \mathrm{E}-07$ & $1.14004 \mathrm{E}-05$ & $6.28976 \mathrm{E}-08$ \\
\hline
\end{tabular}

Total sediment solid and microbially available concentrations for Fe and Mn. 


\begin{tabular}{|c|c|c|c|c|c|c|}
\hline $\begin{array}{l}\text { Depth Interval } \\
(\mathrm{cm})\end{array}$ & $\begin{array}{c}\text { Cs-137 } \\
\text { Activity } \\
(\mathrm{Bq} / \mathrm{g}) \\
\text { Canberra }\end{array}$ & $\begin{array}{c}\text { Cs-137 } \\
\text { Activity } \\
(\mathrm{Bq} / \mathrm{g}) \\
\text { EG\&G }\end{array}$ & $\begin{array}{c}\text { Pb-210 } \\
\text { Activity } \\
(\mathrm{Bq} / \mathrm{g}) \\
\text { Canberra }\end{array}$ & $\begin{array}{c}\text { Pb-210 } \\
\text { Activity } \\
(\mathrm{Bq} / \mathrm{g}) \\
\text { EG\&G }\end{array}$ & $\begin{array}{c}\text { Excess } \\
\text { Pb-210 } \\
\text { Activity } \\
(\mathrm{Bq} / \mathrm{g})\end{array}$ & $\begin{array}{c}\text { Excess } \\
\text { Pb-210 } \\
\text { Activity } \\
(\mathrm{Bq} / \mathrm{g})\end{array}$ \\
\hline $0-1$ & 0.052051 & & 0.380049 & & 0.314179 & \\
\hline $1-2$ & 0.050724 & 0.05123 & 0.359305 & 0.351734 & 0.293435 & \\
\hline $2-3$ & & 0.051718 & & 0.282972 & & 0.217102 \\
\hline $3-4$ & 0.077886 & & 0.319614 & & 0.253744 & \\
\hline $4-5$ & 0.089764 & & 0.311505 & & 0.245635 & \\
\hline $5-6$ & 0.116348 & & 0.234934 & & 0.169064 & \\
\hline $6-7$ & 0.138459 & & 0.24229 & & 0.17642 & \\
\hline $7-8$ & 0.155984 & & 0.211352 & & 0.145482 & \\
\hline $8-9$ & & 0.144626 & & 0.157587 & & 0.091717 \\
\hline $9-10$ & & 0.048474 & & 0.135727 & & 0.069857 \\
\hline $10-12$ & & 0.031607 & & 0.120525 & & 0.054655 \\
\hline $12-14$ & 0.003139 & & 0.099331 & & 0.033461 & \\
\hline $14-16$ & -0.000092 & & 0.079679 & & 0.013809 & \\
\hline $16-18$ & & 0.000473 & & 0.055827 & & -0.01004 \\
\hline $18-20$ & -0.000233 & & 0.075985 & & 0.010115 & \\
\hline $20-22$ & & -0.00139 & & 0.039014 & & -0.02686 \\
\hline $22-24$ & & -0.00069 & & 0.06184 & & -0.00403 \\
\hline $24-26$ & & -0.00157 & & 0.028761 & & -0.03711 \\
\hline $26-28$ & & 0.001243 & & 0.07575 & & 0.00988 \\
\hline $28-30$ & & -0.00056 & & 0.067873 & & 0.002003 \\
\hline $30-32$ & 0.000165 & & 0.080057 & & 0.014187 & \\
\hline $32-34$ & & $-2.6 \mathrm{E}-05$ & & 0.071693 & & 0.005823 \\
\hline $34-36$ & 0.001580 & & 0.081313 & & 0.015443 & \\
\hline $36-38$ & & -0.00252 & & 0.055951 & & -0.00992 \\
\hline $38-40$ & & 0.000988 & & 0.066832 & & 0.000962 \\
\hline $40-42$ & & -0.00244 & & 0.05168 & & -0.01419 \\
\hline $42-44$ & & -0.00197 & & 0.067133 & & 0.001263 \\
\hline $44-46$ & -0.001439 & & 0.021529 & & -0.04434 & \\
\hline $46-48$ & 0.000890 & & 0.071377 & & 0.005507 & \\
\hline $48-50$ & -0.002746 & & 0.077145 & & 0.011275 & \\
\hline $50-52$ & -0.002651 & & 0.079577 & & 0.013707 & \\
\hline $52-54$ & & -0.00223 & & 0.064387 & & -0.00148 \\
\hline
\end{tabular}




\begin{tabular}{|ccccccc|}
\hline $\begin{array}{c}\text { Depth Interval } \\
(\mathrm{cm})\end{array}$ & $\begin{array}{c}\text { Cs-137 } \\
\text { Activity } \\
(\mathrm{Bq} / \mathrm{g}) \\
\text { Canberra }\end{array}$ & $\begin{array}{c}\text { Cs-137 } \\
\text { Activity } \\
(\mathrm{Bq} / \mathrm{g}) \\
\text { EG\&G }\end{array}$ & $\begin{array}{c}\text { Pb-210 } \\
\text { Activity } \\
(\mathrm{Bq} / \mathrm{g}) \\
\text { Canberra }\end{array}$ & $\begin{array}{c}\text { Pb-210 } \\
\text { Activity } \\
(\mathrm{Bq} / \mathrm{g}) \\
\text { EG\&G }\end{array}$ & $\begin{array}{c}\text { Excess } \\
\text { Pb-210 } \\
\text { Activity } \\
(\mathrm{Bq} / \mathrm{g})\end{array}$ & $\begin{array}{c}\text { Excess } \\
\text { Pb-210 } \\
\text { Activity } \\
(\mathrm{Bq} / \mathrm{g})\end{array}$ \\
\hline $56-58$ & -0.000493 & & 0.077298 & & 0.011428 & \\
\hline $58-63$ & -0.001555 & & 0.06587 & & $4.82 \mathrm{E}-07$ & \\
\hline $63-68$ & & -0.00251 & 0.055933 & & -0.00994 \\
\hline $67-73$ & -0.002129 & & 0.084608 & & 0.018738 & \\
\hline $73-78$ & & -0.00545 & & 0.060259 & & -0.00561 \\
\hline $78-83$ & 0.000864 & & 0.068338 & & 0.002468 & \\
\hline $83-88$ & -0.001865 & & 0.072647 & & 0.006777 & \\
\hline $88-93$ & & -0.00036 & & 0.076498 & & 0.010628 \\
\hline $93-98$ & & -0.00078 & & 0.075159 & & 0.009289 \\
\hline $98-103$ & 0.000332 & & 0.07084 & & 0.00497 & \\
\hline
\end{tabular}

$$
{ }^{210} \boldsymbol{P} b={ }^{210} \boldsymbol{P} b_{(0)} e^{-\left(\frac{\lambda_{*}}{w}\right)}
$$

Depth intervals and activities of $\mathrm{Cs}-137$ and $\mathrm{Pb}-210$. The excess activity $\mathrm{Pb}-210$ and equation above, where $\lambda$ is the decay constant of $\mathrm{Pb}-210(0.0311 / \mathrm{yr})$, and $\mathrm{w}$ is the burial velocity in $\mathrm{cm}$, were used for the CIC model. 


\section{Untreated Samples}

\begin{tabular}{|lrrrrr|}
\hline $\mathrm{C}_{\mathrm{o}}(\mathrm{M})$ & 176.63 & 149.95 & 137.00 & 83.01 & 40.17 \\
\hline $\begin{array}{l}\text { Temperature } \\
\left({ }^{\circ} \mathrm{C}\right)\end{array}$ & 18.6 & 22.4 & 24.8 & 24.3 & 21.7 \\
\hline $0-1$ & 18.74 & 50.88 & 40.17 & 28.12 & 17.40 \\
\hline $1-2$ & 32.13 & 58.91 & 49.54 & 30.79 & 18.74 \\
\hline $2-3$ & 25.44 & 70.96 & 52.21 & 44.18 & 21.42 \\
\hline $3-4$ & 25.44 & 80.33 & 61.59 & 46.86 & 24.10 \\
\hline $4-5$ & 25.44 & 84.35 & 68.28 & 48.20 & 25.44 \\
\hline
\end{tabular}

\section{Azide Treated Samples}

\begin{tabular}{|lrrrrr|}
\hline $\mathrm{C}_{\mathrm{o}}(\mathrm{M})$ & 176.63 & 140.58 & 120.00 & 115.14 & 40.17 \\
\hline $\begin{array}{l}\text { Temperature } \\
\left({ }^{\circ} \mathrm{C}\right)\end{array}$ & 18.6 & 22.4 & 24.8 & 24.3 & 21.7 \\
\hline $0-1 \mathrm{~A}$ & 57.57 & 88.36 & 74.97 & 60.25 & 38.83 \\
\hline $1-2 \mathrm{~A}$ & 57.57 & 103.09 & 83.01 & 65.60 & 42.84 \\
\hline $2-3 \mathrm{~A}$ & 54.89 & 117.82 & 101.75 & 69.62 & 56.23 \\
\hline $3-4 \mathrm{~A}$ & 56.23 & 123.17 & 108.45 & 72.30 & 66.94 \\
\hline $4-5 \mathrm{~A}$ & 61.59 & 131.21 & 111.12 & 74.97 & 80.33 \\
\hline
\end{tabular}

Table of influent dissolved oxygen concentrations $\left(C_{0}\right)$ and the effluent dissolved oxygen concentration, based on temperature, for the plug flow-through experiments. 


\section{References}

Adams, D.D., Matisoff, G., and Snodgrass, W.J.: 1982, Flux of reduced chemical constituents $\left(\mathrm{Fe}^{2+}, \mathrm{Mn}^{2+}, \mathrm{NH}_{4}{ }^{+}\right.$, and $\left.\mathrm{CH}_{4}\right)$ and sediment oxygen demand in Lake Erie, Hydrobiologia 92, 405-414

Berner, R.A.: 1974, Kinetic models for the early diagenesis of nitrogen, sulfur, phosphorus, and silicon in anoxic marine sediments, The Sea (Goldberg, E.D. ed)

Bidle, K.D., Manganelli, M., and Azam, F.: 2002, Regulation of oceanic silicon and carbon preservation by temperature control on bacteria, Science 298, 1980-1984.

Boudreau, B.P.: 1996, A method-of-lines code for carbon and nutrient diagensis in aquatic sediments, Computers \& Geosciences 22, 479-496.

Bouldin, D.R.: 1968, Models for describing the diffusion of oxygen and other mobile constituents across the mud-water interface, J. Ecol. 56,77-87.

Brock, et al.: 1994, Biology of Microorganisms Prentice Hall Inc, NJ.

Burns, N.M., et al.: 2005, Trends in temperature, Secchi depth, and dissolved oxygen depletion rates in the central basin of Lake Erie, 1983-2002, J.Great Lakes Res. 31 (Suppl. 2), 35-49.

Charlton, M.N. and Lean, D.R.S.: 1987, Sedimentation, Resuspension, and Oxygen Depletion in Lake Erie (1979), J.Great Lakes Res. 13(4), 709-723.

Charlton, M.N.: 1980, Oxygen Depletion in Lake Erie: Has there been any change?, Can. J. Fish. Aquat. Sci. 37, 72-81.

Charlton, M.N.: 1987, Lake Erie oxygen revisited, J.Great Lakes Res. 13(4), 697-708.

Christensen, P.B., Nielsen, L.P., Sorensen, J. and Revsbech, N.P.: 1990, Denitrification in nitrate-rich streams: Diurnal and seasonal variation related to benthic oxygen metabolism, Limol. Oceanogr. 35(3), 640-651.

Clesceri, L.S., Greenberg, A.E., and Eaton, A.D (eds.): 1998, Standard Methods for the Examination of Water and Wastewater (20 ed.). APHA, AWWA, and WEF, Washington D.C.

Davis, J., Fay, L. and Herdendorf, E.: 1981, Lake Erie intensive study. Sediment oxygen demand, CLEAR Tech. Report \#246.TAT \#21

DePinto, J.D., Young, T.C. and McIlroy, L.M.: 1986, Great Lakes Water Quality Improvement, Environ. Sci. Technol. 20, 752-759. 
DiToro, D.M., Thomas, N.A., Herdendorf, C.E., Winfield, R.P., and Connolly, J.P.: 1987, A post audit of a Lake Erie eutrophication model, J.Great Lakes Res. 13, 801-825.

DiToro, D.M.,: 2001, Sediment Flux Modeling, Wiley \& Sons, Inc. NY.

Gillooly, J.F., et al.: 2001, Effects of size and temperature on metabolic rate, Science 293, $2248-2251$.

Glud, R.N, Gunderson, J.K., Roy, H. and Jorgensen, B.B.: 2003 Season dynamics of benthic $\mathrm{O}_{2}$ uptake in a semienclosed bay: Importance of diffusion and faunal activity, Limnol. Oceanogr. 48(3), 1265-1276.

Great Lakes National Program Office (GLNPO) of the EPA: 2007, http://www.epa.gov/glnpo/glindicators/water/oxygenb.html

Hecky, R.E., et al.: 2004 "The neashore phosphorus shunt: a consequence of ecosystem engineering by dreissenids in the Laurentian Great Lakes," Can. J. Fish. Aquat. Sci; 61: $1285-1293$

Henderson, P.: 1992 Statistical analysis of enzyme kinetic data Enzyme Assays: A Practical Approach (Richwood, D. and Hanes, B.D. eds) Oxford University Press

Kalff, J.: 2002 Limnology, Prentice Hall Inc, NJ.

Levinton, J.S.: 1982 Marine Ecology, Prentice Hall Inc, NJ.

Lucas, A.M. and Thomas, N.A.: 1970 Sediment oxygen demand in Lake Erie's central basin, Project Hypo (Eds. N.M. Burns and C. Ross) USEPA Tech. Rept. TS-05-71-20824

Makarewicz, J.C. et al.: 2000 "Chemistry of the Offshore Surface Waters of Lake Erie: Pre- and Post-Dreissena Introduction (1983-1993),” J.Great Lakes Res.; 26(1): 82-93

Matisoff, G., Fisher, J.B, and Lick, W.: 1977 Early diagenesis and chemical mass transfer in Lake Erie sediments, EPA Contract no. R805716020

Matisoff, G. and Neeson, T.: 2005 Oxygen concentration and demand in Lake Erie sediments, J.Great Lakes Res 31 (Suppl. 2), 284-295.

Ostrom, N.E.: 2007 Evaluation of Ecosystem Metabolism in the Great Lakes via oxygen isotope techniques, presented at IAGLR (Pennsylvania).

Pallud, C. and Van Cappellen, P.: 2006 "Kinetics of microbial sulfate reduction in estuarine sediments," Geochimica et Cosmochimica Acta. 70:1148-1162. 
Pallud, C. et al.: 2007, The use of flow-through sediment reactors in biogeochemical kinetics: Methodology and examples of applications, Marine Chemistry

Rabouille, C. and Gaillard, J.F.: 1991 A coupled model representing the deep-sea organic carbon mineralization and oxygen consumption in surficial sediment, J. Geophs. Res. 96, 2761-2776.

Reimers, C.E. and Smith, K.L.: 1986 Reconciling measured and predicted fluxes of oxygen across the deep sea sediment-water interface, Limnol. Oceanogr. 31(2), 305-318.

Rockwell, D.C. , G.J. Warren, P. Bertram, D.K. Salisbury, and Burns, N.: 2005 The U.S. EPA Lake Erie Indicators Monitoring Program 1983 to 2002: trends in phosphorus, silica, and chlorophyll $a$ in the central basin, J. Great Lakes Res. 31 (Suppl. 2), 23-34.

Rockwell, D.C.: 2007 http://www.epa.gov/glnpo/glindicators/water/phosphorusb.html

Roychoudhury, A.N., Viollier, E., and Van Cappellen, P.: 1998 A plug flow-through reactor for studying biogeochemical reactions in undisturbed aquatic sediments, Applied Geochemistry 13, 269-280.

Schloesser, D.W., R.G. Stickel and Bridgeman, T.: 2005 Potential oxygen demand of sediments from Lake Erie, J. Great Lakes Res. 31 (Suppl. 2), 272-283.

Snodgrass, W.J.: 1987 Analysis of models and measurements for sediment oxygen demand in Lake Erie, J. Great Lakes Res. 13(4), 738-756.

Snodgrass, W.J. and Fay, L.A.: 1987 Values of sediment oxygen demand measured in the central basin of Lake Erie, 1979, J.Great Lakes Res. 13(4), 724-730.

Stumm, W. and Morgan, J.J.: 1981 Aquatic Chemistry John Wiley \& Sons, New York.

Van Cappellen, P. and Wang, Y.: 1995 Metal cycling in surface sediments: modeling the interplay of transport and reaction, Metal Speciation and Contamination of Aquatic Sediments (Allen, H.E. ed) Ann Arbor Press Inc., MI

Van Cappellen, P. and Wang, Y.: 1996 Cycling of iron and manganese in surface sediments: a general theory for the coupled transport and reaction of carbon, oxygen, nitrogen, sulfur, iron, and manganese, American Journal of Science 296, 197-243

Wang, Y. and Van Cappellen, P.: 1996 A multicomponent reactive transport model of early diagenesis: Application to redox cycling in coastal marine sediments, Geochem. Cosmochim. Acta. 60, 2993-3014

Whiting, P.J., Bonniwell, E.C., and Matisoff, G.: 2001 Depth and areal extent of sheet and rill erosion based on radionuclides in soils and suspended sediment. Geology, 29(12), 1131-1134 